\title{
DIVERSIDAD Y DISTRIBUCIÓN DE LOS MOLUSCOS DE AGUA DULCE EN LA COMUNIDAD DE MADRID (ESPAÑA)
}

\author{
J. Soler*, D. Moreno**, R. Araujo* y M.A. Ramos*
}

\begin{abstract}
RESUMEN
El estudio de los moluscos de agua dulce llevado a cabo en la Comunidad de Madrid permite citar 33 especies, de ellas 25 son de gasterópodos y ocho son de bivalvos. De estas especies, 23 ya habían sido citadas previamente en esta área, aunque la mayoría con otros nombres, bien porque en la actualidad son sinónimos, o bien por determinaciones erróneas. Para las 33 especies, identificadas en un total de 463 muestras analizadas, junto con el estudio de los ejemplares conservados en el Museo Nacional de Ciencias Naturales, se aportan datos taxonómicos y breves descripciones, así como información sobre los habitat en los que se han encontrado. Se indica también si habían sido citados previamente en el área y el nombre asignado por los diferentes autores. De acuerdo con los datos bibliográficos manejados, un total de nueve especies se citan por primera vez en la región: Pseudamnicola (Pseudamnicola) subproducta, Pseudamnicola (Corrosella) hinzi, Lymnaea stagnalis, Stagnicola palustris, Gyraulus (Gyraulus) chinensis, Gyraulus (Torquis) laevis, Ferrissia (Pettancylus) clessiniana, Oxyloma (Oxyloma) sarsii y Pisidium subtruncatum. Entre las especies citadas por otros autores, cabe mencionar que "Islamia" coronadoi, Anisus (Disculifer) vortex y Segmentina niti$d a$, no han podido ser localizadas. Stagnicola palustris se cita por primera vez, aunque sólo se han encontrado conchas. Dos especies, Potamopyrgus antipodarum y Gyraulus chinensis, son introducidas; la primera de ellas, considerada como invasora, presenta una amplia distribución. Del mismo modo citamos Lymnaea stagnalis y Oxyloma (Oxyloma) sarsii, que sólo se han encontrado en un centro de jardinería, por si incidentalmente pudieran extenderse a hábitats naturales en la región.
\end{abstract}

Palabras clave: Taxonomía, Diversidad, Distribución, Moluscos de agua dulce, Madrid, España.

\section{SUMMARY}

\section{Diversity and distribution of freshwater molluscs of} Comunidad de Madrid (Spain)

In this study of freshwater molluscs carried out in Comunidad de Madrid we cite the presence of 33 species, of which 25 are gastropods and eight bivalves. Twentythree of these species were previously reported in this area although most of them with different names either because they are synonyms or because they were determinated erronoeusly. The 33 species were identified from a total of 463 samples together with the specimens preserved at the Museo Nacional de Ciencias Naturales. Taxonomical data and short des-

* Museo Nacional de Ciencias Naturales (CSIC). C/ José Gutiérrez Abascal, 2. 28006 Madrid. España.

** Egmasa/Consejería de Medio Ambiente (Junta de Andalucía). C/ Marruecos 33, bajo. 04009 Almería. España. 
criptions, as well as information about the habitats in which they were found is given for the 33 species. We also indicate if they were previously reported in the area and names given by authors. According to the bibliographic data used, a total of nine species are cited for the first time in the region: Pseudamnicola (Pseudamnicola) subproducta, Pseudamnicola (Corrosella) hinzi; Lymnaea stagnalis; Stagnicola palustris; Gyraulus (Gyraulus) chinensis, Gyraulus (Torquis) laevis, Ferrissia (Pettancylus) clessiniana, Oxyloma (Oxyloma) sarsii and Pisidium subtruncatum. Among the previous records, it is worth mentioning that it was not possible to locate "Islamia" coronadoi, Anisus (Disculifer) vortex and Segmentina nitida. Stagnicola palustris, is reported for the first time although only shells were found. Two species, Potamopyrgus antipodarum and Gyraulus chinensis, are alien species. The first of those two species is considered as invasive and presents a wide distribution. Although Lymnaea stagnalis and Oxyloma (Oxyloma) sarsii were only observed in a garden center, we cite them here because there is the possibility that they might accidentally spread out into natural habitats of the region.

Key words: Taxonomy, Diversity, Distribution, Freshwater molluscs, Madrid, Spain.

\section{Introducción}

Disponer del inventario de especies es requisito fundamental para planificar, gestionar y conservar de forma racional y responsable la diversidad biológica de un país o una región. Por este motivo, el Convenio sobre Diversidad Biológica, derivado de la Conferencia de Río de Janeiro (1992), presta especial atención a este tema, y en el programa de trabajo de la Iniciativa Global sobre Taxonomía (aprobado en Bratislava, 1998), considera como objetivo prioritario la elaboración de los listados de especies y hábitat por parte de cada país signatario. En España, esa responsabilidad está, en parte, delegada a las distintas Comunidades Autónomas.

Ya Margalef (1974), en su obra Ecología, señalaba que los datos de que disponemos sobre la distribución geográfica de la mayoría de las especies animales están más relacionados con la distribución geográfica de los expertos que las estudian que con la distribución real de las mismas. Treinta años después, esta afirmación sigue siendo patente cuando se observan mapas de distribución de muchos grupos de invertebrados, incluso los que pueden considerarse relativamente bien conocidos como los coleópteros escarabéidos coprófagos (Lobo \& Martín Piera, 2002), en los que las nubes de puntos se acumulan en torno a las universidades y otros centros de investigación. Sin embargo, cuando consideramos los moluscos de agua dulce de la Comunidad de Madrid, nos damos cuenta de la escasez de información en este área con larga tradición universitaria. Hasta hoy, y desde el catálogo de Graells de los moluscos de España (1846), nos encontramos en la bibliografía con citas aisladas de 23 especies (Pérez Arcas, 1863; Álvarez, 1969; Álvarez y Selga, 1967; Gregorides, 1971; García de
Jalón y González del Tanago, 1982, Nieto, 1967). Entre ellos, cabe destacar el de Álvarez y Selga (1967) que aporta datos sobre la taxonomía de nueve especies de moluscos dulceacuícolas (ocho gasterópodos y un bivalvo), en cinco localidades de muestreo en Madrid, y el de Gregorides (1971) que describe 17 especies (11 gasterópodos y 6 bivalvos) prospectados en las cuencas de los ríos Manzanares, Tajo y Jarama, si bien varios de los nombres asignados en este artículo son sinónimos de la misma especie.

El presente trabajo se inició con una serie de campañas de recolección en 1983, y aún cuando no puede considerarse exhaustivo, describe la presencia de 33 especies de gasterópodos y bivalvos de agua dulce identificadas en las 463 muestras estudiadas, pertenecientes a 304 localidades, distribuidas por todas las cuencas fluviales de la Comunidad. Un estudio preliminar (Moreno et al., 1992) citaba 20 especies en un total de 80 localidades. Los datos disponibles sobre algunas áreas consideradas de especial interés, bien por su composición faunística o por la probabilidad de que pudieran haber sufrido alteraciones graves en sus hábitat desde que empezaron los muestreos, se han comparado con los de muestreos recientes en el marco del proyecto "Evaluación del conocimiento y del estado de conservación de la diversidad animal de Madrid" financiado por la Comunidad de Madrid. Ello nos ha permitido detectar posibles extinciones de especies antes presentes en el área, el declive en las poblaciones de otras, o la introducción de especies exóticas. Todo ello es debido, principalmente, a la alteración o destrucción de los hábitat naturales en la Comunidad de Madrid como consecuencia del aumento de población, crecimiento urbanístico, incremento de la contaminación, etc. 


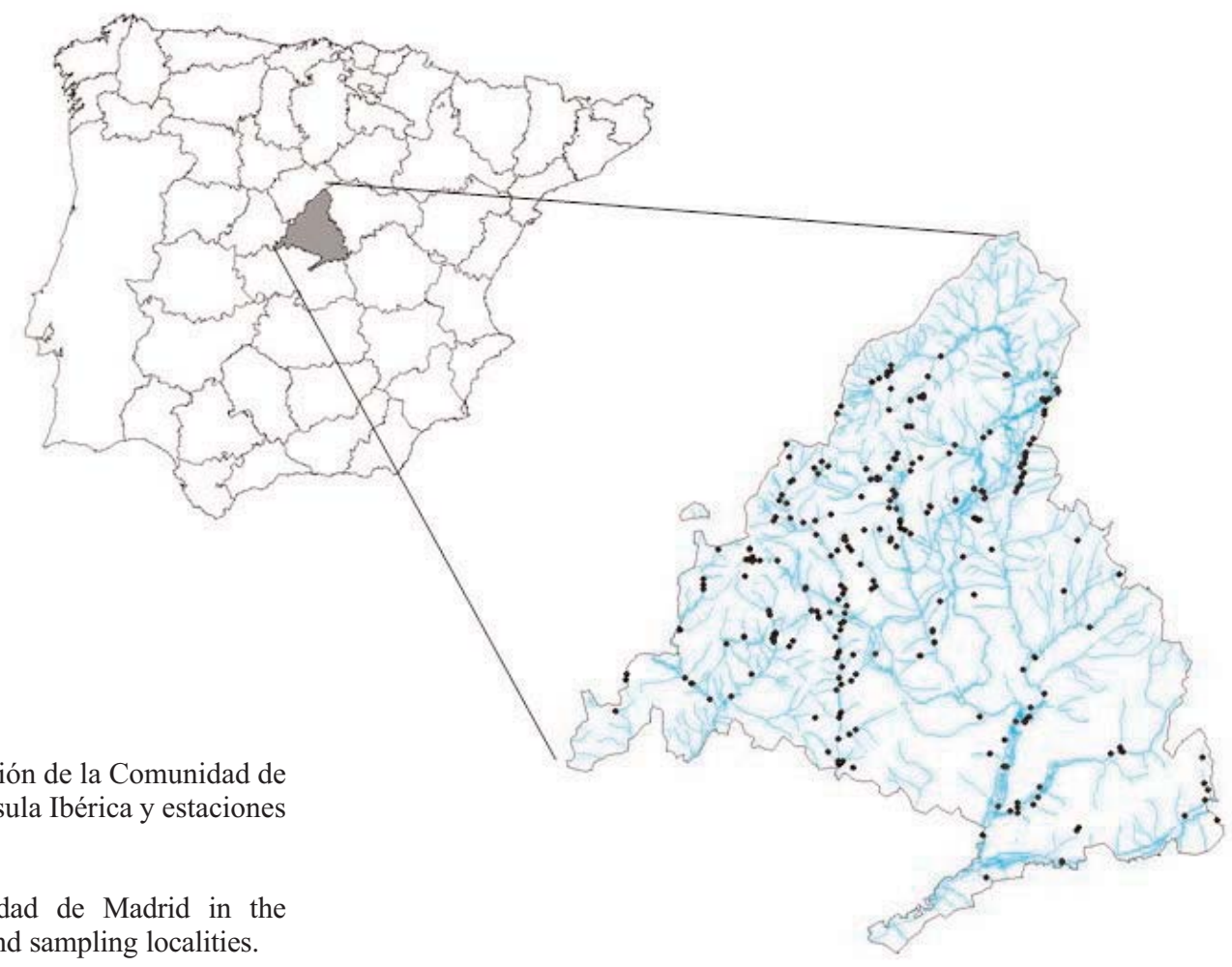

Fig. 1.- Localización de la Comunidad de Madrid en la Península Ibérica y estaciones de muestreo.

Fig. 1.- Comunidad de Madrid in the Iberian Peninsula and sampling localities.

Los moluscos de agua dulce han recibido, en general, escasa atención en nuestro país. Por este motivo hemos decidido presentar la información taxonómica lo más completa posible, incluyendo sinónimos y descripciones sucintas de las especies con el fin de facilitar su identificación, tanto con fines conservacionistas como de cualquier otro tipo. Además, se describen los hábitat de las especies y su distribución geográfica, tanto la general como la referida a la provincia de Madrid. Se citan las localidades anteriormente conocidas y los autores de las mismas, así como los nombres con los que las especies habían sido previamente citadas.

\section{Material y Métodos}

Área DE MUESTREO

El área muestreada en el presente estudio abarca la Comunidad de Madrid, situada en el centro de la Península Ibérica, con una latitud norte de $41^{\circ} 10^{\prime}$ $-39^{\circ} 53^{\prime}$ y una longitud oeste de $03^{\circ} 03^{\prime}-04^{\circ} 34^{\prime}$. La Comunidad de Madrid, con $8.024 \mathrm{~km}^{2}$, se extiende desde el Sistema Central hasta el valle del Tajo, en una extensa y constante pendiente. En la parte norte está formada por sierras de naturaleza silícea aline- adas en dirección noreste-suroeste, mientras que en la zona sur predominan los yesos y las calizas. Esto confiere una gran variabilidad de ambientes acuáticos que van desde lagunas de alta montaña (Peñalara) a anchos ríos (Tajo), pasando por tramos medios de ríos (como el Alberche, Manzanares, Jarama, Henares), así como manatiales, fuentes, y lagunas de zonas bajas (San Juan en Titulcia u Ontígola en Aranjuez) (Figuras 89-125).

Este trabajo de recolección de moluscos dulceacuícolas se remonta a 1983, cuando se realizaron las primeras campañas de muestreo. Desde entonces se han estudiado 463 muestras pertenecientes a 304 localidades distribuidas por todas las cuencas fluviales de la Comunidad: Alberche, Guadarrama, Manzanares, Lozoya, Jarama, Tajuña (todos afluentes de la margen derecha del Tajo) y Tajo (Tabla 1 y Figura 1).

\section{TÉCNICAS DE MUESTREO Y ESTUDIO}

Los moluscos dulceacuícolas incluyen gasterópodos y bivalvos de diferente tamaño y requerimientos ecológicos. Para recolectar tan diverso grupo de especies, los muestreos se realizaron en el mayor número de hábitat dulceacuícolas posible empleando diferentes métodos de captura. La recolección se 
Tabla 1.- Estaciones de muestreo.

Table 1.- Sampling localities.

\begin{tabular}{|c|c|c|c|c|c|c|}
\hline NUM & LOCALIDAD & POBLACION & FECHA & COLECTORES & UTM & FIGURAS \\
\hline 1 & Río de la Aceña & Robledondo & $09 / 04 / 1988$ & D.M. & 30TUK959949 & \\
\hline 2 & Arroyo Angostura & Pinilla del Valle & $18 / 03 / 1985$ & D.M.; N.M. & $30 T V L 300300$ & \\
\hline 3 & Arroyo Angostura & Pinilla del Valle & $12 / 08 / 1987$ & D.M. & $30 T V L 300310$ & \\
\hline 4 & Arroyo Angostura & Rascafría & $12 / 08 / 1987$ & D.M. & $30 T V L 275285$ & 109 \\
\hline 5 & Arroyo Angostura & Rascafría, Molino de Briscas & $12 / 08 / 1987$ & D.M. & $30 T V L 264278$ & 109 \\
\hline 6 & Río Aulencia & El Escorial & $25 / 02 / 1984$ & D.M. & $30 T V K 019928$ & 103 \\
\hline 7 & Río Aulencia & El Escorial & $19 / 02 / 1984$ & D.M. & 30 TVK040926 & 103 \\
\hline 8 & Río Aulencia & El Escorial & $11 / 02 / 1984$ & D.M.; N.M. & 30 TVK028926 & 103 \\
\hline 9 & Río Aulencia & El Escorial & $02 / 06 / 1984$ & D.M. & $30 T V K 028927$ & 103 \\
\hline 10 & Río Aulencia & El Escorial & $09 / 03 / 1986$ & D.M. & $30 T V K 028928$ & 103 \\
\hline 11 & Río Aulencia & El Escorial & $25 / 02 / 1984$ & D.M.; N.M. & $30 T V K 014928$ & 103 \\
\hline 12 & Turbera de Canencia & Canencia & $08 / 07 / 1984$ & D.M. & $30 T V L 364250$ & $92-93$ \\
\hline 13 & Turbera de Canencia & Canencia & $14 / 09 / 1985$ & D.M.; N.M. & $30 T V L 364251$ & $92-93$ \\
\hline 14 & Turbera de Canencia & Canencia & $15 / 05 / 1987$ & D.M. & $30 T V L 364252$ & $92-93$ \\
\hline 15 & Turbera de Canencia & Canencia & $09 / 04 / 1989$ & D.M. & 30 TVL364253 & $92-93$ \\
\hline 16 & Laguna de Casasola & Titulcia & $28 / 09 / 1988$ & M.T.A.; M.A.R.; D.M. & 30 TVK589461 & \\
\hline 17 & Río Cofio & Robledo de Chavela & $08 / 10 / 1984$ & D.M.; N.M. & 30TUK930870 & \\
\hline 18 & Río Cofio & Robledo de Chavela & $12 / 05 / 1989$ & D.M. & 30 TUK930880 & \\
\hline 19 & Río Cofio & Robledo de Chavela & $27 / 05 / 1989$ & D.M. & 30TUK930890 & \\
\hline 20 & Fuente en Colmenar de Oreja & Colmenar de Oreja & $03 / 11 / 1985$ & D.M. & 30 TVK666395 & 123 \\
\hline 21 & Arroyo Combos & Arroyomolinos & $23 / 09 / 1984$ & D.M. & $30 T V K 217584$ & \\
\hline 22 & Arroyo del Embalse de Miraflores & Miraflores & $12 / 08 / 1987$ & D.M. & $30 T V L 330190$ & \\
\hline 23 & Arroyo de la Fresnera & San Agustín de Guadalix & $17 / 06 / 1984$ & D.M.; N.M. & 30 TVL473006 & 115 \\
\hline 24 & Arroyo de la Fresnera & San Agustín de Guadalix & $23 / 06 / 1984$ & D.M.; N.M. & 30 TVL471007 & 115 \\
\hline 25 & Arroyo de la Fresnera & San Agustín de Guadalix & $05 / 10 / 1985$ & D.M. & $30 T V L 470007$ & 115 \\
\hline 26 & Arroyo de la Fresnera & San Agustín de Guadalix & $23 / 03 / 1986$ & D.M.; N.M. & 30 TVL469007 & 115 \\
\hline 27 & Arroyo de la Fresnera & San Agustín de Guadalix & $08 / 11 / 1986$ & D.M.; N.M. & 30 TVL468008 & 115 \\
\hline 28 & Arroyo de la Fresnera & San Agustín de Guadalix & $15 / 05 / 1987$ & D.M. & $30 T V L 466008$ & 115 \\
\hline 29 & Arroyo de la Fresnera & San Agustín de Guadalix & $20 / 11 / 1988$ & D.M. & $30 T V L 464009$ & 115 \\
\hline 30 & Garden Center Los Peñotes & Madrid & $19 / 07 / 1988$ & D.M. & 30 TVK464860 & \\
\hline 31 & Garden Center Los Peñotes & Madrid & $19 / 02 / 1989$ & D.M. & 30 TVK464860 & \\
\hline 32 & Río Guadarrama & El Alamo & $23 / 09 / 1984$ & D.M. & $30 T V K 196527$ & \\
\hline 33 & Arroyo de las Huertas & Venturada & $04 / 03 / 1984$ & D.M. & 30 TVL495179 & \\
\hline 34 & Río Jarama & Caraquiz & $25 / 05 / 1987$ & D.M. & $30 T V L 580167$ & \\
\hline 35 & Río Jarama & Torremocha de Jarama & $25 / 04 / 1987$ & D.M. & $30 T V L 573155$ & \\
\hline 36 & Río Jarama & Patones & $04 / 03 / 1984$ & D.M. & 30 TVL611246 & \\
\hline 37 & Río Jarama & Puente Torrelaguna & $25 / 04 / 1987$ & D.M. & 30 TVL563137 & \\
\hline 38 & Río Jarama & Talamanca del Jarama & $16 / 06 / 1985$ & D.M. & 30TVL554111 & \\
\hline 39 & Río Jarama & Talamanca del Jarama & $08 / 06 / 1986$ & D.M.; N.M. & 30TVL561118 & \\
\hline 40 & Río Jarama & Talamanca del Jarama & $22 / 03 / 1987$ & D.M.; N.M. & 30TVL563129 & \\
\hline 41 & Río Jarama & Talamanca del Jarama & $25 / 04 / 1987$ & D.M. & 30TVL563133 & \\
\hline 42 & Río Jarama & Uceda & $25 / 05 / 1987$ & D.M. & 30TVL601221 & \\
\hline 43 & Río Jarama & Valdetorres del Jarama & $16 / 06 / 1985$ & D.M. & 30TVL546060 & 114 \\
\hline 44 & Río Jarama & Valdetorres del Jarama & $08 / 06 / 1986$ & D.M. & 30 TVL550070 & 114 \\
\hline 45 & Río Jarama & Valdetorres del Jarama & $22 / 03 / 1987$ & D.M.; N.M. & 30TVL556078 & 114 \\
\hline 46 & Río Jarama & Valdetorres del Jarama & $08 / 07 / 1987$ & D.M. & 30 TVL556090 & 114 \\
\hline 47 & Río Jarama & Valdetorres del Jarama & $25 / 04 / 1987$ & D.M. & $30 T V L 562100$ & 114 \\
\hline 48 & Arroyo Junta de Energía Nuclear & Madrid-Ciudad Universitaria & $27 / 03 / 1984$ & D.M. & $30 T V K 381787$ & \\
\hline 49 & Arroyo Junta de Energía Nuclear & Madrid-Ciudad Universitaria & $28 / 03 / 1984$ & D.M. & $30 T V K 381788$ & \\
\hline 50 & Arroyo Junta de Energía Nuclear & Madrid-Ciudad Universitaria & $08 / 05 / 1984$ & D.M. & $30 T V K 381789$ & \\
\hline 51 & Arroyo Junta de Energía Nuclear & Madrid-Ciudad Universitaria & $27 / 04 / 1988$ & D.M. & $30 T V K 381790$ & \\
\hline 52 & Río Lozoya & Bajo embalse Pontón de la Ol & $04 / 03 / 1984$ & D.M. & 30TVL629259 & \\
\hline 53 & Río Lozoya & Embalse Pontón de la Oliva & $04 / 03 / 1984$ & D.M. & 30 TVL628263 & \\
\hline 54 & Río Manzanares & Colmenar VIejo & $16 / 10 / 1984$ & D.M. & 30 TVL3 17003 & \\
\hline 55 & Río Manzanares & Colmenar VIejo & / ?/1985 & D.M. & 30 TVL3 17004 & \\
\hline 56 & Río Manzanares & Colmenar VIejo & $28 / 09 / 1985$ & D.M.; N.M. & 30 TVL317005 & \\
\hline 57 & Río Manzanares & Colmenar VIejo & $23 / 11 / 1986$ & D.M.; N.M. & 30 TVL3 17006 & \\
\hline 58 & Río Manzanares & Manzanares el Real & $01 / 06 / 1984$ & D.M. & 30TVL272087 & $105-106$ \\
\hline 59 & Río Manzanares & Manzanares el Real & / /1981 & D.M. & 30 TVL272088 & $105-106$ \\
\hline 60 & Río Manzanares & Manzanares el Real & $28 / 12 / 1983$ & D.M.; N.M. & 30TVL272089 & $105-106$ \\
\hline 61 & Río Manzanares & Manzanares el Real & $05 / 02 / 1984$ & D.M. & 30TVL272090 & $105-106$ \\
\hline 62 & Arroyo Meaques & Madrid & $02 / 07 / 1989$ & D.M. & 30TVK357739 & \\
\hline 63 & Acequia en Meco & Meco y Azuqueca & $05 / 04 / 1992$ & D.M. & 30 TVK750900 & \\
\hline 64 & Arroyo Mojapan & San Agustín de Guadalix & $31 / 03 / 1985$ & D.M. & 30 TVL427046 & \\
\hline 65 & Arroyo Mojapan & San Agustín de Guadalix & $23 / 03 / 1986$ & D.M. & 30 TVL427047 & \\
\hline 66 & Arroyo Molino de Briscas & Rascafría & $12 / 08 / 1987$ & D.M. & 30 TVL262278 & \\
\hline 67 & Arroyo Navahuerta & Colmenar VIejo & $16 / 03 / 1986$ & D.M.; N.M. & 30 TVL311029 & \\
\hline 68 & Arroyo Navarrosillo & Colmenar Viejo & $07 / 05 / 1988$ & D.M.; N.M. & 30 TVK327986 & \\
\hline 69 & Laguna de Ontígola & Aranjuez & $16 / 04 / 1993$ & D.M. & $30 T V K 488302$ & 125 \\
\hline 70 & Lagunillas de los Pájaros & Peñalara & $01 / 07 / 1990$ & D.M. & $30 T V L 201230$ & \\
\hline
\end{tabular}


Tabla 1.-Cont.

\begin{tabular}{|c|c|c|c|c|c|c|}
\hline NUM & LOCALIDAD & POBLACION & FECHA & COLECTORES & UTM & FIGURAS \\
\hline 71 & Arroyo en el Parque del Oeste & Madrid & $06 / 06 / 1984$ & D.M.; N.M.; J.L.F. & 30 TVK 385765 & \\
\hline 72 & Arroyo en el Parque del Oeste & Madrid & $13 / 06 / 1984$ & D.M. & 30 TVK385766 & \\
\hline 73 & Arroyo en el Parque del Oeste & Madrid & $20 / 04 / 1988$ & D.M. & 30 TVK385767 & \\
\hline 74 & Manantial de Patones & Patones & $05 / 04 / 1992$ & D.M. & 30 TVL603240 & \\
\hline 75 & $\begin{array}{l}\text { Laguna de Peñalara } \\
\end{array}$ & Peñalara & $01 / 07 / 1990$ & D.M. & 30 TVL194216 & 89 \\
\hline 76 & Río Perales & Aldea del Fresno & $30 / 11 / 1986$ & D.M. & 30TUK985659 & \\
\hline 77 & Río Perales & Navalagamella & $01 / 03 / 1987$ & D.M. & 30 TVK059827 & 99 \\
\hline 78 & Río Perales & Navalagamella & $26 / 04 / 1987$ & D.M.; N.M. & 30TVK059828 & 99 \\
\hline 79 & \begin{tabular}{|l|l|} 
Río Perales \\
\end{tabular} & Navalagamella & $24 / 01 / 1988$ & D.M. & 30TVK059829 & 99 \\
\hline 80 & Río Perales & Quijorna & $11 / 03 / 1984$ & D.M. & 30 TVK071782 & $98,100,101$ \\
\hline 81 & Río Perales & Quijorna & $26 / 05 / 1984$ & D.M. & 30 TVK071783 & $98,100,101$ \\
\hline 82 & Río Perales & Quijorna & $31 / 10 / 1988$ & D.M. & 30TVK071784 & $98,100,101$ \\
\hline 83 & Río Perales & Quijorna & $22 / 01 / 1989$ & D.M.; N.M. & 30TVK071785 & $98,100,101$ \\
\hline 84 & \begin{tabular}{|l|l|} 
Río Perales \\
\end{tabular} & Quijorna & $13 / 11 / 1983$ & D.M. & 30TVK067771 & $98,100,101$ \\
\hline 85 & Río Perales & Quijorna & $11 / 03 / 1984$ & D.M.; N.M. & 30TVK067771 & $98,100,101$ \\
\hline 86 & Río Perales & Quijorna & $06 / 04 / 1985$ & D.M. & 30TVK067771 & $98,100,101$ \\
\hline 87 & Río Perales & Quijorna & $21 / 09 / 1985$ & D.M.; N.M. & 30TVK067771 & $98,100,101$ \\
\hline 88 & Río Perales & Quijorna & $13 / 05 / 1989$ & D.M. & 30 TVK067771 & $98,100,101$ \\
\hline 89 & Río Perales & Quijorna & $01 / 08 / 1989$ & D.M. & 30TVK067771 & $98,100,101$ \\
\hline 90 & Río Perales & Quijorna & $11 / 03 / 1984$ & D.M.; N.M. & 30 TVK068777 & $98,100,101$ \\
\hline 91 & Río Perales & Quijorna & $09 / 04 / 1984$ & D.M.; N.M. & 30 TVK 068778 & $98,100,101$ \\
\hline 92 & Río Perales & Quijorna & $05 / 05 / 1984$ & D.M. & 30TVK068779 & $98,100,101$ \\
\hline 93 & Río Perales & Quijorna & $02 / 03 / 1985$ & D.M. & 30 TVK068780 & $98,100,101$ \\
\hline 94 & Río Perales & Quijorna & $06 / 04 / 1986$ & D.M.; N.M. & 30TVK068781 & $98,100,101$ \\
\hline 95 & Embalse de las Picadas & Navas del Rey & $18 / 11 / 1988$ & D.M. & 30TUK907684 & $95-96$ \\
\hline 96 & Arroyo en la Presa del Romeral & El Escorial & $19 / 02 / 1984$ & D.M. & 30 TVK021949 & 102 \\
\hline 97 & Arroyo en la Presa del Romeral & El Escorial & $02 / 06 / 1984$ & D.M. & 30 TVK021950 & 102 \\
\hline 98 & Arroyo de la Puebla & Robledo de Chavela & $27 / 05 / 1989$ & D.M. & 30TUK884789 & \\
\hline 99 & Arroyo Recombo & Lozoyuela & $01 / 06 / 1983$ & D.M. & 30 TVL528291 & 112 \\
\hline 100 & Arroyo Recombo & Lozoyuela & $06 / 05 / 1984$ & D.M.; N.M. & 30 TVL526293 & 112 \\
\hline 101 & Arroyo Recombo & Lozoyuela & $19 / 05 / 1985$ & D.M.; N.M. & 30 TVL525293 & 112 \\
\hline 102 & Arroyo Recuenco & Manzanares el Real & $01 / 06 / 1981$ & D.M. & 30 TVL295109 & \\
\hline 103 & Arroyo Recuenco & Manzanares el Real & $20 / 02 / 1984$ & D.M. & 30 TVL295110 & \\
\hline 104 & Fuente Reña & Miraflores & $12 / 08 / 1987$ & D.M. & 30 TVL340190 & \\
\hline 105 & Arroyo Retuerta & San Agustín de Guadalix & $23 / 04 / 1989$ & D.M. & 30 TVL464069 & \\
\hline 106 & Laguna de San Juan & Titulcia & $01 / 01 / 1983$ & D.M. & 30 TVK550430 & 117,118 \\
\hline 107 & Laguna de San Juan & Titulcia & $25 / 03 / 1984$ & D.M. & 30 TVK550440 & 117,118 \\
\hline 108 & Arroyo de Santa Ana & Miraflores & $12 / 08 / 1987$ & D.M. & 30 TVL295223 & 110 \\
\hline 109 & Zanja en el Embalse de Santillana & Manzanares el Real & $22 / 07 / 1984$ & D.M. & 30 TVL275087 & 107 \\
\hline 110 & Zanja en el Embalse de Santillana & Manzanares el Real & $15 / 09 / 1984$ & D.M. & 30 TVL275088 & 107 \\
\hline 111 & Zanja en el Embalse de Santillana & Manzanares el Real & $16 / 10 / 1984$ & D.M. & 30 TVL275089 & 107 \\
\hline 112 & Arroyo Sestil del Maillo & Canencia & $13 / 05 / 1984$ & D.M. & 30 TVL338242 & 91 \\
\hline 113 & Arroyo Sestil del Maillo & Canencia & $14 / 09 / 1985$ & D.M. & $30 T V L 338243$ & 91 \\
\hline 114 & Río Tajo & La Aldehuela & $03 / 11 / 1985$ & D.M. & 30 TVK637334 & 124 \\
\hline 115 & Río Tajo & Valdajos & $28 / 10 / 1984$ & N.M. & 30 TVK637331 & \\
\hline 116 & Río Tajo & \begin{tabular}{|l} 
Valdajos \\
\end{tabular} & $/ / 1985$ & D.M. & 30TVK637332 & \\
\hline 117 & Río Tajo & Valdajos & $10 / 03 / 1985$ & D.M.; N.M. & 30 TVK637333 & \\
\hline 118 & Río Tajo & Valdajos & $03 / 11 / 1985$ & D.M. & 30 TVK637334 & \\
\hline 119 & Canal del Tajuña & Tielmes & $24 / 03 / 1984$ & D.M.; N.M. & 30 TVK 757549 & \\
\hline 120 & Río Tajuña & Tielmes & $24 / 03 / 1984$ & D.M. & 30 TVK753551 & \\
\hline 121 & Arroyo de la Tejada & Colmenar Viejo & $31 / 03 / 1985$ & D.M. & $30 T V L 378033$ & \\
\hline 122 & Arroyo de la Tejada & Colmenar Viejo & $23 / 03 / 1986$ & D.M. & 30 TVL375034 & \\
\hline 123 & Arroyo Valdeyerno & Quijorna & $11 / 03 / 1984$ & D.M. & 30TVK071781 & \\
\hline 124 & Arroyo Valdeyerno & Quijorna & $26 / 05 / 1984$ & D.M. & 30TVK071782 & \\
\hline 126 & Arroyo de la Vega & Tielmes & $24 / 03 / 1984$ & D.M. & 30 TVK 751559 & \\
\hline 127 & Arroyo de la Yunta & Colmenar de Arroyo & $11 / 03 / 1984$ & D.M. & 30TVK009777 & \\
\hline 128 & Río Jarama & Patones & $31 / 05 / 1986$ & M.T.A. & 30 TVL600239 & \\
\hline 129 & Embalse del Vellón & Guadalix de la Sierra & $29 / 10 / 1986$ & M.T.A.; M.A.R.; L.S. & 30 TVL425154 & \\
\hline 130 & Arroyo Albalá & \begin{tabular}{|l|} 
Venturada \\
\end{tabular} & $29 / 10 / 1986$ & L.S.; M.A.R.; M.T.A. & 30 TVL482168 & \\
\hline 131 & Arroyo Seco & San Lorenzo del Escorial & $14 / 11 / 1986$ & M.T.A.; M.A.R. & 30 TVK026934 & \\
\hline 132 & Río Guadarrama & Guadarrama & $14 / 11 / 1986$ & M.T.A.; M.A.R. & 30 TVK201877 & \\
\hline 133 & Río Guadalix & San Agustin de Guadalix & $20 / 10 / 1985$ & J.D. & $30 T V L 483049$ & \\
\hline 134 & Río Jarama & Valdetorres de Jarama & $25 / 04 / 1987$ & o.s. & 30 TVL556090 & 114 \\
\hline 135 & Arroyo de Brea & Brea de Tajo & $11 / 04 / 1988$ & D.M.; N.M.; M.A.R. & 30 TVK914539 & 119 \\
\hline 136 & Canales del Tajo & $\begin{array}{l}\text { Fuentiduena de Tajo } \\
\end{array}$ & $18 / 04 / 1988$ & M.A.R.; D.M.; N.M.; D.T & 30 TVK 879423 & \\
\hline 137 & Poza en el Canal de Estremera & Fuentidueña de Tajo & $18 / 04 / 1988$ & M.A.R.; D.M.; N.M.; D.T & 30 TVK918454 & \\
\hline 138 & Arroyo Sepulcro & Estremera & $18 / 04 / 1988$ & M.A.R.; D.M.; N.M.; D.T & $30 T V K 924474$ & $120-121$ \\
\hline 139 & Arroyo Sepulcro & Estremera & $18 / 04 / 1988$ & M.A.R.; D.M.; N.M.; D.T & 30TVK916488 & $120-121$ \\
\hline 140 & Canales del Tajo & Fuentiduena de Tajo & $09 / 05 / 1988$ & D.M.; M.A.R.; N.B. & 30 TVK879423 & \\
\hline 141 & Arroyo Sepulcro & Estremera & $09 / 05 / 1988$ & M.A.R.; D.M. & 30TVK 916488 & $120-121$ \\
\hline 142 & Arroyo Salado & San Pedro-Fuentidueña & $09 / 05 / 1988$ & M.A.R.; D.M. & 30 TVK 943415 & \\
\hline 143 & Laguna de la Dehesa de Bayona. & Titulcia & $28 / 09 / 1988$ & M.T.A.; M.A.R.; D.M. & 30 TVK535432 & \\
\hline
\end{tabular}


Tabla 1.-Cont

\begin{tabular}{|c|c|c|c|c|c|c|}
\hline NUM & LOCALIDAD & POBLACION & FECHA & COLECTORES & UTM & FIGURAS \\
\hline 144 & Laguna de San Juan & Titulcia & $28 / 09 / 1988$ & M.A.R.; M.T.A.; D.M. & 30 TVK550450 & 117,118 \\
\hline 145 & Laguna de San Juan & Titulcia & $28 / 09 / 1988$ & M.T.A.; D.M.; N.B.; M.A.R. & 30 TVK550450 & 117,118 \\
\hline 146 & Laguna de San Juan & Titulcia & $28 / 09 / 1988$ & M.T.A.; M.A.R.; D.M. & 30 TVK550450 & 117,118 \\
\hline 147 & Pozo del Nogal & Titulcia & $28 / 09 / 1988$ & M.T.A.; M.A.R.; D.M. & 30 TVK550450 & \\
\hline 148 & Canal de Riego. & Titulcia & $28 / 09 / 1988$ & M.T.A.; M.A.R.; D.M. & 30 TVK592480 & \\
\hline 149 & Arroyo Sepulcro & Estremera de Tajo & $26 / 09 / 1988$ & A.F.L. & 30TVK916488 & $120-121$ \\
\hline 150 & Fuente caja de las Huertas. & Colmenar de Oreja & $26 / 09 / 1988$ & A.F.L. & 30 TVK670400 & 123 \\
\hline 151 & Fuente de Soto del Real & Soto del Real & $12 / 10 / 1988$ & D.M.; N.M. & 30 TVL 357128 & \\
\hline 152 & Río Guadalix & Guadalix de la Sierra & $12 / 10 / 1988$ & N.M.; D.M. & 30 TVL425154 & \\
\hline 153 & Arroyo Valdesalices & Guadalix de la Sierra & $12 / 10 / 1988$ & N.M.; D.M. & $30 T V L 415137$ & \\
\hline 154 & Arroyo de la Fresnea & San Agustín de Guadalix & $12 / 10 / 1988$ & N.M.; D.M. & $30 T V L 464009$ & \\
\hline 155 & Fuente la Fuenfría. & Cercedilla & $18 / 03 / 1990$ & N.M.; D.M. & 30 TVL094156 & \\
\hline 156 & Rio Guadarrama & Brunete & $16 / 03 / 1989$ & R.A.; D.M. & 30TVK197695 & 104 \\
\hline 157 & Arroyo de Quijorna & Quijorna & $16 / 03 / 1989$ & R.A.; D.M. & 30 TVK099758 & \\
\hline 158 & Río Perales & Quijorna, pozas del medio & $16 / 03 / 1989$ & R.A.; D.M. & 30TVK069781 & \\
\hline 159 & Arroyo Valdeyerno & Quijorna & $16 / 03 / 1989$ & R.A.; D.M. & 30 TVK071783 & \\
\hline 160 & Rio Perales & Quijorna & $16 / 03 / 1989$ & R.A.; D.M. & 30TVK070781 & $98,100,101$ \\
\hline 161 & Arroyo de Tórtolas & San Martín de Valdeiglesias & $26 / 03 / 1989$ & R.A. & 30TUK778703 & \\
\hline 162 & Arroyo de Tórtolas & San Martín de Valdeiglesias & $25 / 03 / 1989$ & R.A. & 30TUK777692 & \\
\hline 163 & Arroyo del Parque del Oeste & Madrid & $12 / 04 / 1989$ & R.A.; D.M. & 30 TVK 386765 & \\
\hline 164 & Arroyo Junta de Energía Nuclear & Madrid-Ciudad Universitaria & $12 / 04 / 1989$ & R.A.; D.M. & $30 T V K 381787$ & \\
\hline 165 & Río Guadalix & San Agustín de Guadalix & $12 / 04 / 1989$ & R.A.; D.M. & 30 TVL482062 & \\
\hline 166 & Arroyo de la Tejada & Colmenar Viejo & $12 / 04 / 1989$ & D.M.; R.A. & 30 TVL371022 & \\
\hline 167 & Arroyo de Mojapan & San Agustín de Guadalix & $12 / 04 / 1989$ & D.M.; R.A. & 30 TVL427043 & \\
\hline 168 & Arroyo de Mojapan. & San Agustín de Guadalix & $23 / 04 / 1989$ & N.M.; D.M. & $30 T V L 427043$ & \\
\hline 169 & Arroyo de las Retuertas. & San Augustin de Guadalix. & $23 / 04 / 1989$ & N.M.; D.M. & $30 T V L 463067$ & \\
\hline 170 & Tubera de Canencia & Miraflores de la Sierra & $02 / 04 / 1989$ & N.M.; D.M. & $30 T V L 363248$ & $92-93$ \\
\hline 171 & Arroyo de la Candalosa & Quijorna & $12 / 05 / 1989$ & R.A.; D.M.; M.C. & 30 TVK 107768 & \\
\hline 172 & Río Perales & Quijorna & $12 / 05 / 1989$ & M.C.; D.M.; R.A. & 30TVK067771 & $98,100,101$ \\
\hline 173 & Arroyo de la yunta & Colmenar del Arroyo & $12 / 05 / 1989$ & R.A.; D.M.; M.C. & 30 TVK009775 & \\
\hline 174 & Arroyo del Corralizo & Colmenar del Arroyo & $12 / 05 / 1989$ & M.C.; D.M.; R.A. & 30TUK975762 & \\
\hline 175 & Navacerrada & Navacerrada & $25 / 04 / 1989$ & D.M. & 30 TVL155097 & \\
\hline 176 & Río Perales & Quijorna & $13 / 05 / 1989$ & N.M.; D.M. & 30TVK069775 & $98,100,101$ \\
\hline 177 & Arroyo de los Meaques & Madrid & $02 / 07 / 1989$ & D.M.; N.M. & 30 TVK356739 & \\
\hline 178 & Río Jarama & Patones & $08 / 08 / 1989$ & A.C. & 30 TVL605243 & \\
\hline 179 & Arroyo en Soto del Real & Soto del Real & $06 / 03 / 1995$ & C.N. & $30 T V L 337103$ & \\
\hline 180 & Río Lozoya, El Pontón de la Oliva & Patones de abajo & $04 / 05 / 2005$ & J.S. & 30 TVL626263 & \\
\hline 181 & Río Jarama & Talamanca de Jarama & $18 / 05 / 2005$ & I.A.; J.S. & 30 TVL559117 & \\
\hline 182 & Barranco en Patones de abajo & Patones de abajo & $18 / 05 / 2005$ & I.A.; J.S. & 30 TVL599244 & \\
\hline 183 & Barranco en Patones de abajo & Patones de abajo & $18 / 05 / 2005$ & I.A.; J.S. & $30 T V L 598245$ & \\
\hline 184 & Río Lozoya & Alameda del Valle & $18 / 05 / 2005$ & I.A.; J.S. & 30 TVL292298 & \\
\hline 185 & Arroyo de Santa Ana & Alameda del Valle & $18 / 05 / 2005$ & I.A.; J.S. & $30 T V L 299265$ & \\
\hline 186 & Arroyo de Santa Ana & Alameda del Valle & $18 / 05 / 2005$ & I.A.; J.S. & 30 TVL292290 & \\
\hline 187 & Río Guadalix & San Agustín de Guadalix & $23 / 05 / 2005$ & J.F.; J.S. & 30 TVL478064 & \\
\hline 188 & Río Guadalix & San Agustín de Guadalix & $23 / 05 / 2005$ & J.F.; J.S. & 30 TVL486050 & \\
\hline 189 & Río Guadarrama & Villafranca del Castillo & $25 / 05 / 2005$ & J.S. & 30TVK208822 & \\
\hline 190 & Río Aulencia & Villanueva del Pardillo & $25 / 05 / 2005$ & J.S. & 30TVK 158814 & \\
\hline 191 & Río Perales & Quijorna-Navalagamella & $25 / 05 / 2005$ & J.S. & 30TVK069767 & \\
\hline 192 & Río Perales & Navalagamella & $25 / 05 / 2005$ & J.S. & 30TVK061819 & 99 \\
\hline 193 & Puerto de Canencia & Miraflores de la Sierra & $01 / 06 / 2005$ & J.S. & 30 TVL356249 & \\
\hline 194 & Tubera de Canencia & Miraflores de la Sierra & $01 / 06 / 2005$ & J.S. & 30 TVL363248 & $92-93$ \\
\hline 195 & Río Lozoya, Gargantilla de Lozoya & Gargantilla de Lozoya & $01 / 06 / 2005$ & J.S. & 30 TVL398329 & \\
\hline 196 & Río Torote & Serracines & $02 / 06 / 2005$ & J.S. & 30TVK667967 & \\
\hline 198 & Río Torote & Daganzo & $02 / 06 / 2005$ & J.S. & 30 TVK641866 & \\
\hline 199 & Río Henares & Alcalá de Henares & $02 / 06 / 2005$ & J.S. & $30 T V K 692795$ & \\
\hline 200 & Río Perales & Quijorna & $14 / 07 / 2005$ & C.T.; A.M.; J.S. & 30TVK066774 & $98,100,101$ \\
\hline 201 & Río Perales & Quijorna & $14 / 07 / 2005$ & C.T.; A.M.; J.S. & 30TVK066774 & $98,100,101$ \\
\hline 202 & Paredes bajo Presa de Picadas & Aldea del fresno & $14 / 07 / 2005$ & C.T.; A.M.; J.S. & 30 TUK942654 & $95-96$ \\
\hline 203 & Embalse de San Juan & Pelayos de la Presa & $14 / 07 / 2005$ & C.T.; A.M.; J.S. & $30 T U K 893695$ & 94 \\
\hline 204 & Zarzalejo & Zarzalejo & $02 / 12 / 1988$ & M.G.P. & 30 TVK012895 & \\
\hline 205 & Arroyo junto a Laguna de San Juan & Chinchon & $11 / 01 / 1989$ & J.L.V. & $30 T V K 580445$ & \\
\hline 206 & Embalse de Picadas & Navas del Rey & $08 / 12 / 1988$ & D.M.; N.M. & 30 TUK907685 & $95-96$ \\
\hline 207 & Embalse de Picadas & Navas del Rey & $08 / 12 / 1988$ & D.M.; N.M. & 30TUK906685 & $95-96$ \\
\hline 208 & Arroyo de la Vega & Villaviciosa de Odon & $16 / 03 / 1989$ & R.A.; D.M. & 30 TVK221690 & \\
\hline 209 & Arroyo de las Retuertas & San Agustín de Guadalix & $12 / 04 / 1989$ & D.M.; R.A. & $30 T V L 464068$ & \\
\hline 210 & Río Jarama & Talamanca del Jarama & $08 / 06 / 1986$ & D.M. & $30 T V L 561118$ & \\
\hline 211 & Río Jarama & Valdetorres del Jarama & $08 / 06 / 1986$ & D.M. & $30 T V L 550070$ & 114 \\
\hline 212 & Río Jarama & Valdetorres del Jarama & $08 / 06 / 1986$ & D.M. & 30 TVL550070 & 114 \\
\hline 213 & Río Jarama & Valdetorres del Jarama & $16 / 06 / 1985$ & D.M. & 30 TVL546060 & 114 \\
\hline 214 & Río Jarama & Talamanca del Jarama & $16 / 06 / 1985$ & D.M. & 30 TVL554111 & \\
\hline 215 & Río Jarama & Talamanca del Jarama & $16 / 06 / 1985$ & D.M. & 30 TVL554111 & \\
\hline
\end{tabular}


Tabla 1.-Cont.

\begin{tabular}{|c|c|c|c|c|c|c|}
\hline NUM & LOCALIDAD & POBLACION & FECHA & COLECTORES & UTM & FIGURAS \\
\hline 216 & Arroyo Recombo & Lozoyuela & $06 / 05 / 1984$ & D.M. & $30 T V L 526293$ & 112 \\
\hline 217 & Arroyo Junta de Energía Nuclear & Madrid-Ciudad Universitaria & $28 / 03 / 1984$ & D.M. & $30 T V K 381788$ & \\
\hline 218 & Laguna de San Juan & Titulcia & $25 / 03 / 1984$ & D.M. & $30 T V K 550440$ & 117,118 \\
\hline 219 & Laguna de San Juan & Titulcia & $25 / 03 / 1984$ & D.M. & $30 T V K 550440$ & 117,118 \\
\hline 220 & Laguna de San Juan & Titulcia & $25 / 03 / 1984$ & D.M. & $30 T V K 550440$ & 117,118 \\
\hline 221 & Río Jarama & Talamanca del Jarama & $22 / 03 / 1987$ & D.M. & $30 T$ TL563129 & \\
\hline 222 & Río Jarama & Valdetorres de Jarama & $25 / 04 / 1987$ & O.S. & $30 T V L 550070$ & 114 \\
\hline 223 & Soto del Real & Soto del Real & 1988 & M.G.P. & $30 T V L 341117$ & \\
\hline 224 & Laguna de Ontígola & Aranjuez & $19 / 10 / 1977$ & M.T.A. & 30TVK 488302 & 125 \\
\hline 225 & Pilón Navalcarnero & Navalcarnero & $12 / 6 / 1988$ & M.G.P. & 30TVK150616 & \\
\hline 226 & Prado de Canencia & Miraflores de la Sierra & $14 / 4 / 1990$ & C.N.; E.B. & $30 T V L 363248$ & \\
\hline 227 & Lagunillas de Peñalara & Rascafría & $01 / 07 / 1990$ & N.M.; D.M. & $30 T V L 201230$ & 90 \\
\hline 228 & Laguna grande de Peñalara & Rascafría & $01 / 07 / 1990$ & N.M.; D.M. & 30TVL194216 & 89 \\
\hline 229 & Arroyo de la Tejada & Colmenar Viejo & $14 / 04 / 1985$ & D.M.; N.M. & $30 T V L 375034$ & \\
\hline 230 & Laguna de San Juan & Titulcia & 1983 & D.M. & 30 TVK550450 & 117,118 \\
\hline 231 & Embalse de Santillana & Manzanares el Real & $?$ & D.M. & 30TVL308057 & 107 \\
\hline 232 & Arroyo de la Fresnera & San Agustín de Guadalix & 1985 & D.M.; N.M. & 30TVL464009 & 115 \\
\hline 233 & Garden Center Los Peñotes & La Moraleja & / $/ 09 / 1987$ & D.M. & 30TVK464860 & \\
\hline 234 & Río Tajuña & Tielmes & $?$ & D.M. & $30 T V K 733545$ & \\
\hline 235 & Cascada de Canencia & Canencia & $15 / 08 / 1985$ & D.M. & $30 T V L 372288$ & \\
\hline 236 & Río Perales & Quijorna & $?$ & D.M. & 30TVK068770 & $98,100,101$ \\
\hline 237 & Lagunas de Peñalara & Peñalara & $?$ & J.M.R. & 30TVL193215 & 90 \\
\hline 238 & Río Guadarrama & Batres & $1 / 5 / 2005$ & N.R.; C.R. & 30TVK196524 & \\
\hline 239 & Arroyo del Sotillo & Batres & $1 / 5 / 2005$ & N.R.; C.R. & 30TVK199525 & \\
\hline 240 & Arroyo del Sotillo & Batres & $1 / 5 / 2005$ & N.R.; C.R. & 30 TVK224518 & \\
\hline 241 & Arroyo de Valdecarros & Batres & $1 / 5 / 2005$ & N.R.; C.R. & 30TVK204531 & \\
\hline 242 & Arroyo de los Vegones & Batres & $1 / 5 / 2005$ & N.R.; C.R. & 30TVK195531 & \\
\hline 243 & Arroyo de los Vegones & El Alamo & $1 / 5 / 2005$ & N.R.; C.R. & 30TVK 175548 & \\
\hline 244 & Arroyo de los Combos & Arroyomolinos & $1 / 5 / 2005$ & N.R.; C.R. & 30TVK195574 & \\
\hline 245 & Arroyo de los Combos & Arroyomolinos & $1 / 5 / 2005$ & N.R.; C.R. & 30TVK229592 & \\
\hline 246 & Arroyo de la Fuente Juncal & Navalcarnero & $1 / 5 / 2005$ & N.R.; C.R. & 30TVK197616 & \\
\hline 247 & Río Guadarrama & Navalcarnero & $1 / 5 / 2005$ & N.R.; C.R. & 30 TVK200624 & \\
\hline 248 & Arroyo del Soto & Navalcarnero & $1 / 5 / 2005$ & N.R.; C.R. & 30 TVK 200628 & \\
\hline 249 & Arroyo Sacedón & Villaviciosa de Odón & $1 / 5 / 2005$ & N.R.; C.R. & 30TVK192672 & \\
\hline 250 & Arroyo de la Vega & Villaviciosa de Odón & $1 / 5 / 2005$ & N.R.; C.R. & 30TVK201683 & \\
\hline 251 & Arroyo de la Vega & Boadilla del Monte & $1 / 5 / 2005$ & N.R.; C.R. & 30TVK229702 & \\
\hline 252 & Arroyo de la Vega & Boadilla del Monte & $1 / 5 / 2005$ & N.R.; C.R. & 30TVK268743 & \\
\hline 253 & Arroyo de Valenajo & Boadilla del Monte & $1 / 5 / 2005$ & N.R.; C.R. & 30TVK202717 & \\
\hline 254 & Arroyo de Valenajo & Boadilla del Monte & $1 / 5 / 2005$ & N.R.; C.R. & 30 TVK 225740 & \\
\hline 255 & Arroyo de la Barranca & Brunete & $1 / 5 / 2005$ & N.R.; C.R. & 30TVK192735 & \\
\hline 256 & Río Guadarrama & Brunete & $1 / 5 / 2005$ & N.R.; C.R. & 30TVK195744 & 104 \\
\hline 257 & Río Aulencia & Villanueva de la Cañada & $1 / 5 / 2005$ & N.R.; C.R. & 30TVK190774 & \\
\hline 258 & Río Aulencia & Villanueva del Pardillo & $1 / 5 / 2005$ & N.R.; C.R. & 30TVK157814 & \\
\hline 259 & Arroyo de Valbellido & Villanueva del Pardillo & $1 / 5 / 2005$ & N.R.; C.R. & 30TVK153826 & \\
\hline 260 & Arroyo de San Juan & Villanueva del Pardillo & $1 / 5 / 2005$ & N.R.; C.R. & 30TVK143828 & \\
\hline 261 & Río Guadarrama & Villanueva de la Cañada & $1 / 5 / 2005$ & N.R.; C.R. & 30TVK200789 & \\
\hline 262 & Arroyo Calabozo & Villanueva de la Cañada & $1 / 5 / 2005$ & N.R.; C.R. & 30TVK198748 & \\
\hline 263 & Arroyo de los Palacios & Villanueva de la Cañada & $1 / 5 / 2005$ & N.R.; C.R. & 30 TVK200802 & \\
\hline 264 & Arroyo de los Palacios & Villanueva del Pardillo & $1 / 5 / 2005$ & N.R.; C.R. & 30TVK179824 & \\
\hline 265 & Arroyo de El Villar & Villanueva del Pardillo & $1 / 5 / 2005$ & N.R.; C.R. & 30 TVK207806 & \\
\hline 266 & Arroyo de Carcalamero & Villanueva del Pardillo & $1 / 5 / 2005$ & N.R.; C.R. & 30TVK195850 & \\
\hline 267 & Arroyode la Fuentecilla & Villanueva del Pardillo & $1 / 5 / 2005$ & N.R.; C.R. & 30TVK212837 & \\
\hline 268 & Río Guadarrama & Las Matas & $1 / 5 / 2005$ & N.R.; C.R. & 30TVK205861 & \\
\hline 269 & Arroyo de la Torre & Las Matas & $1 / 5 / 2005$ & N.R.; C.R. & 30 TVK 208870 & \\
\hline 270 & Río Guadarrama & Torrelodones & $1 / 5 / 2005$ & N.R.; C.R. & 30TVK181934 & \\
\hline 271 & Arroyo de Peguerinos & Torrelodones & $1 / 5 / 2005$ & N.R.; C.R. & 30TVK194947 & \\
\hline 272 & Río Guadarrama & Villalba de la Sierra & $1 / 5 / 2005$ & N.R.; C.R. & 30TVK152977 & \\
\hline 273 & Arroyo de la Dehesa & Alpedrete & $1 / 5 / 2005$ & N.R.; C.R. & $30 T V L 126001$ & \\
\hline 274 & Arroyo de la Dehesa & Collado-Villalba & $1 / 5 / 2005$ & N.R.; C.R. & 30TVL150004 & \\
\hline 275 & Arroyo de Guatel Primero & Guadarrama & $1 / 5 / 2005$ & N.R.; C.R. & $30 T V L 068005$ & \\
\hline 276 & Río Guadarrama & Alpedrete & $1 / 5 / 2005$ & N.R.; C.R. & $30 T V L 100009$ & \\
\hline 277 & Arroyo de Guatel Segundo & Guadarrama & $1 / 5 / 2005$ & N.R.; C.R. & 30TVL072012 & \\
\hline 278 & Arroyo de las Pozas & Guadarrama & $1 / 5 / 2005$ & N.R.; C.R. & $30 T V L 093039$ & \\
\hline 279 & Arroyo Atalayas de las Pinilla & Guadarrama & $1 / 5 / 2005$ & N.R.; C.R. & $30 T V L 083056$ & \\
\hline 280 & Arroyo del Tejo & Guadarrama & $1 / 5 / 2005$ & N.R.; C.R. & $30 T V L 078044$ & \\
\hline 281 & Río Guadarrama & Cercedilla & $1 / 5 / 2005$ & N.R.; C.R. & 30 TVL100081 & \\
\hline 282 & Arroyo de las Fuentes & Cercedilla & $1 / 5 / 2005$ & N.R.; C.R. & $30 T V L 106085$ & \\
\hline 283 & Río de la Venta & Cercedilla & $1 / 5 / 2005$ & N.R.; C.R. & 30TVL098130 & \\
\hline 284 & Río Aulencia & Valdemorillo & $1 / 5 / 2005$ & N.R.; C.R. & 30TVK129870 & \\
\hline 285 & Arroyo de la Peralera & Valdemorillo & $1 / 5 / 2005$ & N.R.; C.R. & 30TVK 132873 & \\
\hline 286 & Río Batán & El Escorial & $1 / 5 / 2005$ & N.R.; C.R. & 30TVK076927 & \\
\hline
\end{tabular}


Tabla 1.-Cont

\begin{tabular}{|c|c|c|c|c|c|c|}
\hline NUM & LOCALIDAD & POBLACION & FECHA & COLECTORES & UTM & FIGURAS \\
\hline 287 & Arroyo de los Castaños & Escorial & $1 / 5 / 2005$ & N.R.; C.R. & 30 TVK026925 & \\
\hline 288 & Río Guadarrama & Batres & $1 / 7 / 2002$ & N.R.; C.R. & 30TVK196524 & \\
\hline 289 & Arroyo del Sotillo & Batres & $1 / 7 / 2002$ & N.R.; C.R. & 30TVK199525 & \\
\hline 290 & Arroyo del Sotillo & Batres & $1 / 7 / 2002$ & N.R.; C.R. & $30 T V K 224518$ & \\
\hline 291 & Arroyo de Valdecarros & Batres & $1 / 7 / 2002$ & N.R.; C.R. & $30 T V K 204531$ & \\
\hline 292 & Arroyo de los Vegones & Batres & $1 / 7 / 2002$ & N.R.; C.R. & 30 TVK 195531 & \\
\hline 293 & Arroyo de los Vegones & El Alamo & $1 / 7 / 2002$ & N.R.; C.R. & 30 TVK 175548 & \\
\hline 294 & Arroyo de los Combos & Arroyomolinos & $1 / 7 / 2002$ & N.R.; C.R. & 30 TVK 195574 & \\
\hline 295 & Arroyo de los Combos & Arroyomolinos & $1 / 7 / 2002$ & N.R.; C.R. & 30 TVK229592 & \\
\hline 296 & Arroyo de la Fuente Juncal & Navalcarnero & $1 / 7 / 2002$ & N.R.; C.R. & 30 TVK 197616 & \\
\hline 297 & Río Guadarrama & Navalcarnero & $1 / 7 / 2002$ & N.R.; C.R. & 30 TVK 200624 & \\
\hline 298 & Arroyo del Soto & Navalcarnero & $1 / 7 / 2002$ & N.R.; C.R. & 30 TVK 200628 & \\
\hline 299 & Arroyo Sacedón & Villaviciosa de Odón & $1 / 7 / 2002$ & N.R.; C.R. & 30 TVK 192672 & \\
\hline 300 & Arroyo de la Vega & Villaviciosa de Odón & $1 / 7 / 2002$ & N.R.; C.R. & 30 TVK 201683 & \\
\hline 301 & Arroyo de la Vega & Boadilla del Monte & $1 / 7 / 2002$ & N.R.; C.R. & 30 TVK229702 & \\
\hline 302 & Arroyo de la Vega & Boadilla del Monte & $1 / 7 / 2002$ & N.R.; C.R. & 30 TVK 268743 & \\
\hline 303 & Arroyo de Valenajo & Boadilla del Monte & $1 / 7 / 2002$ & N.R.; C.R. & $30 T V K 202717$ & \\
\hline 304 & Arroyo de Valenajo & Boadilla del Monte & $1 / 7 / 2002$ & N.R.; C.R. & 30 TVK 225740 & \\
\hline 305 & Arroyo de la Barranca & Brunete & $1 / 7 / 2002$ & N.R.; C.R. & 30 TVK192735 & \\
\hline 306 & Río Guadarrama & Brunete & $1 / 7 / 2002$ & N.R.; C.R. & 30TVK195744 & 104 \\
\hline 307 & Río Aulencia & Villanueva de la Cañada & $1 / 7 / 2002$ & N.R.; C.R. & 30 TVK 190774 & \\
\hline 308 & Río Aulencia & Villanueva del Pardillo & $1 / 7 / 2002$ & N.R.; C.R. & 30TVK157814 & \\
\hline 309 & Arroyo de Valbellido & Villanueva del Pardillo & $1 / 7 / 2002$ & N.R.; C.R. & 30 TVK 153826 & \\
\hline 310 & Arroyo de San Juan & Villanueva del Pardillo & $1 / 7 / 2002$ & N.R.; C.R. & 30 TVK 143828 & \\
\hline 311 & Río Guadarrama & Villanueva de la Cañada & $1 / 7 / 2002$ & N.R.; C.R. & 30 TVK200789 & \\
\hline 312 & Arroyo Calabozo & Brunete & $1 / 7 / 2002$ & N.R.; C.R. & 30 TVK 198748 & \\
\hline 313 & Arroyo de los Palacios & Villanueva de la Cañada & $1 / 7 / 2002$ & N.R.; C.R. & 30 TVK200802 & \\
\hline 314 & Arroyo de los Palacios & Villanueva del Pardillo & $1 / 7 / 2002$ & N.R.; C.R. & 30 TVK 179824 & \\
\hline 315 & Arroyo de El Villar & Villanueva de la Cañada & $1 / 7 / 2002$ & N.R.; C.R. & 30 TVK207806 & \\
\hline 316 & Arroyo de Carcalamero & Villanueva del Pardillo & $1 / 7 / 2002$ & N.R.; C.R. & 30 TVK 195850 & \\
\hline 317 & Arroyo de la Fuentecilla & Villanueva del Pardillo & $1 / 7 / 2002$ & N.R.; C.R. & 30 TVK212837 & \\
\hline 318 & Río Guadarrama & Las Matas & $1 / 7 / 2002$ & N.R.; C.R. & 30 TVK205861 & \\
\hline 319 & Arroyo de la Torre & Las Matas & $1 / 7 / 2002$ & N.R.; C.R. & $30 T V K 208870$ & \\
\hline 320 & Río Guadarrama & Torrelodones & $1 / 7 / 2002$ & N.R.; C.R. & 30 TVK 181934 & \\
\hline 321 & Arroyo de Peguerinos & Torrelodones & $1 / 7 / 2002$ & N.R.; C.R. & $30 T V K 194947$ & \\
\hline 322 & Río Guadarrama & Villalba de la Sierra & $1 / 7 / 2002$ & N.R.; C.R. & 30 TVK 152977 & \\
\hline 323 & Arroyo de la Dehesa & Collado-Villalba & $1 / 7 / 2002$ & N.R.; C.R. & $30 T V L 126001$ & \\
\hline 324 & Arroyo de la Dehesa & Collado-Villalba & $1 / 7 / 2002$ & N.R.; C.R. & $30 T V L 150004$ & \\
\hline 325 & Arroyo de Guatel Primero & Guadarrama & $1 / 7 / 2002$ & N.R.; C.R. & $30 T V L 068005$ & \\
\hline 326 & Río Guadarrama & Alpedrete & $1 / 7 / 2002$ & N.R.; C.R. & $30 T V L 100009$ & \\
\hline 327 & Arroyo de Guatel Segundo & Guadarrama & $1 / 7 / 2002$ & N.R.; C.R. & 30TVL072012 & \\
\hline 328 & Arroyo de las Pozas & Guadarrama & $1 / 7 / 2002$ & N.R.; C.R. & 30TVL093039 & \\
\hline 329 & Arroyo Atalayas de las Pinilla & Guadarrama & $1 / 7 / 2002$ & N.R.; C.R. & $30 T V L 083056$ & \\
\hline 330 & Arroyo del Tejo & Guadarrama & $1 / 7 / 2002$ & N.R.; C.R. & 30 TVL078044 & \\
\hline 331 & Río Guadarrama & Cercedilla & $1 / 7 / 2002$ & N.R.; C.R. & $30 T V L 100081$ & \\
\hline 332 & Arroyo de las Fuentes & Cercedilla & $1 / 7 / 2002$ & N.R.; C.R. & $30 T V L 106085$ & \\
\hline 333 & Río de la Venta & Cercedilla & $1 / 7 / 2002$ & N.R.; C.R. & 30TVL098130 & \\
\hline 334 & Río Aulencia & Valdemorillo & $1 / 7 / 2002$ & N.R.; C.R. & 30TVK129870 & \\
\hline 335 & Arroyo de la Peralera & Valdemorillo & $1 / 7 / 2002$ & N.R.; C.R. & 30 TVK 132873 & \\
\hline 336 & Río Batán & Escorial & $1 / 7 / 2002$ & N.R.; C.R. & 30 TVK076927 & \\
\hline 337 & Arroyo de los Castaños & Escorial & $1 / 7 / 2002$ & N.R.; C.R. & 30 TVK026925 & \\
\hline 338 & Charca Canto del Berrueco & Manzanares el Real & $1 / 7 / 1993$ & J.G.A. & $30 T V L 305127$ & \\
\hline 339 & Charca en la cerca del Indiano & Manzanares el Real & $1 / 7 / 1993$ & J.G.A. & 30 TVL308126 & \\
\hline 340 & Embalse de la Camorza & Manzanares el Real & $20 / 7 / 1993$ & J.G.A. & 30 TVL250106 & \\
\hline 341 & Charca en carretera M-607 & Manzanares el Real & $2 / 6 / 1993$ & J.G.A. & 30 TVL298045 & \\
\hline 342 & Presa de Cabeza del Lobo & Colmenar Viejo & $21 / 5 / 1993$ & J.G.A. & 30TVK317991 & \\
\hline 343 & Depósito "Los Palancares" & Manzanares el Real & $28 / 7 / 1993$ & J.G.A. & $30 T V L 313138$ & \\
\hline 344 & Embalse de los Peñascales & Torrelodones & $12 / 5 / 1993$ & J.G.A. & 30 TVK240920 & \\
\hline 345 & Charca enCanto del Pico & Torrelodones & $12 / 5 / 1993$ & J.G.A. & 30 TVK222946 & \\
\hline 346 & Fuente de las Cochiqueras & San Sebastián de los Reyes & $6 / 5 / 1993$ & J.G.A. & 30TVK441933 & \\
\hline 347 & Charca Valtravieso & Colmenar Viejo & $18 / 5 / 1993$ & J.G.A. & 30TVK311954 & \\
\hline 348 & Embalse de los Ciervos & Colmenar Viejo & $18 / 5 / 1993$ & J.G.A. & 30TVK299971 & \\
\hline 349 & Charca en Cantera Jarosa & Manzanares el Real & $2 / 6 / 1993$ & J.G.A. & 30 TVL259086 & \\
\hline 350 & Manantial Huertos del Pajarejo & Hoyo de Manzanares & $19 / 5 / 1993$ & J.G.A. & 30 TVK278989 & \\
\hline 351 & Charca en la Berzosa & Hoyo de Manzanares & $11 / 5 / 1993$ & J.G.A. & 30TVK206968 & \\
\hline 352 & Manantial Lanchar de Castilla & Hoyo de Manzanares & $11 / 5 / 1993$ & J.G.A. & 30 TVK209974 & \\
\hline 353 & Charca Monte del Hormigal & Collado-Villalba & $20 / 7 / 1993$ & J.G.A. & 30TVL181018 & \\
\hline 354 & Manantial de Cañacerral & Colmenar Viejo & $18 / 5 / 1993$ & J.G.A. & 30 TVK297964 & \\
\hline 355 & Charca en Canto del Pico & Torrelodones & $12 / 5 / 1993$ & J.G.A. & 30 TVK222946 & \\
\hline 356 & Charca Monte Egido 6 & Hoyo de Manzanares & $14 / 5 / 1993$ & J.G.A. & 30 TVK 247986 & \\
\hline 357 & Charca en la Berzosa & Hoyo de Manzanares & $11 / 5 / 1993$ & J.G.A. & 30 TVK211966 & \\
\hline 358 & Barranco del Cura & Torrelodones & $13 / 5 / 1993$ & J.G.A. & $30 T V K 216953$ & \\
\hline
\end{tabular}


Tabla 1.-Cont.

\begin{tabular}{|c|c|c|c|c|c|c|}
\hline NUM & LOCALIDAD & POBLACION & FECHA & COLECTORES & UTM & FIGURAS \\
\hline 359 & Manantial de Cerca de la Venta & Manzanares el Real & $28 / 5 / 1993$ & J.G.A. & 30TVL307054 & \\
\hline 360 & Charca Zaburdón & Manzanares el Real & $21 / 5 / 1993$ & J.G.A. & 30 TVL295031 & \\
\hline 361 & Charca en la cerca de Ramos & Colmenar Viejo & $21 / 5 / 1993$ & J.G.A. & 30 TVK 337980 & \\
\hline 362 & Fuente del Piojo & Fuencarral & $6 / 7 / 1993$ & J.G.A. & 30 TVK396846 & \\
\hline 363 & Presa del arroyo de El Garzo & Las Matas & $24 / 6 / 1993$ & J.G.A. & 30 TVK269876 & \\
\hline 364 & Presa del arroyo Boquillón & Las Matas & $24 / 6 / 1993$ & J.G.A. & 30 TVK 265886 & \\
\hline 365 & Charca Matachiviles & Manzanares el Real & $27 / 5 / 1993$ & J.G.A. & 30 TVL303065 & \\
\hline 366 & Embalse del Chiquillo & Navacerrada & $29 / 6 / 1993$ & J.G.A. & 30TVL149109 & \\
\hline 367 & Presa de la Barranca 2 & Navacerrada & $29 / 6 / 1993$ & J.G.A. & 30 TVL163122 & \\
\hline 368 & Embalse de Majalespino & Navacerrada & $5 / 7 / 1993$ & J.G.A. & 30TVL176112 & \\
\hline 369 & Fuente de los Pozuelos & Manzanares el Real & $20 / 5 / 1993$ & J.G.A. & 30 TVL242053 & \\
\hline 370 & Fuente de San Isidro & San Sebastián de los Reyes & $6 / 5 / 1993$ & J.G.A. & 30 TVK498948 & \\
\hline 371 & Charca de las Zahurdas & Las Matas & $23 / 6 / 1993$ & J.G.A. & 30 TVK 262870 & \\
\hline 372 & Charca Monte Egido 7 & Hoyo de Manzanares & $14 / 5 / 1993$ & J.G.A. & 30 TVK 247986 & \\
\hline 373 & Presa del río Henares 1 & Mejorada del Campo & $1 / 7 / 1999$ & J.G.A.; J.H. & 30 TVK 583735 & \\
\hline 374 & Presa del río Henares 2 & Mejorada del Campo & $1 / 7 / 1999$ & J.G.A.; J.H. & 30 TVK582737 & \\
\hline 375 & Charca en Rivas (Las Yeseras) & Mejorada del Campo & $1 / 7 / 1999$ & J.G.A.; J.H. & 30 TVK560712 & \\
\hline 376 & Laguna de San Antonio & Velilla de San Antonio & $1 / 7 / 1999$ & J.G.A.; J.H. & 30 TVK 602664 & \\
\hline 377 & Laguna del Campillo & Vaciamadrid & $1 / 7 / 1999$ & J.G.A.; J.H. & 30 TVK574636 & \\
\hline 378 & Laguna del Porcal & Vaciamadrid & $1 / 7 / 1999$ & J.G.A.; J.H. & 30TVK546610 & \\
\hline 379 & Laguna de las Madres & Vaciamadrid & $1 / 7 / 1999$ & J.G.A.; J.H. & 30 TVK566613 & \\
\hline 380 & Laguna de las Madres & Vaciamadrid & $1 / 7 / 1999$ & J.G.A.; J.H. & 30 TVK562610 & \\
\hline 381 & Charca en el Camping Lagos & Vaciamadrid & $1 / 7 / 1999$ & J.G.A.; J.H. & $30 T V K 564607$ & \\
\hline 382 & Charca Muñoz (Jet Madrid) & Vaciamadrid & $1 / 7 / 1999$ & J.G.A.; J.H. & $30 T V K 570617$ & \\
\hline 383 & Laguna Villafranca & Vaciamadrid & $1 / 7 / 1999$ & J.G.A.; J.H. & 30TVK573618 & \\
\hline 384 & Manantial de la Boyeriza & Gorquez de Abajo & $1 / 7 / 1999$ & J.G.A.; J.H. & $30 T V K 523574$ & \\
\hline 385 & Embalse de Gózquez & Gorquez de Abajo & $1 / 7 / 1999$ & J.G.A.; J.H. & 30TVK494546 & \\
\hline 386 & Charca en San Martín de la Vega & San Martín de la Vega & $1 / 7 / 1999$ & J.G.A.; J.H. & 30TVK528521 & \\
\hline 387 & Parque Tierno Galván & San Martín de la Vega & $1 / 7 / 1999$ & J.G.A.; J.H. & 30TVK522520 & \\
\hline 388 & Charca en Ciempozuelos & Titulcia & $1 / 7 / 1999$ & J.G.A.; J.H. & $30 T V K 510442$ & \\
\hline 389 & Charca en Soto de las Cuevas & Titulcia & $1 / 7 / 1999$ & J.G.A.; J.H. & $30 T V K 479385$ & \\
\hline 390 & Laguna de los Frailes & Perales del Río & $1 / 7 / 1999$ & J.G.A.; J.H. & $30 T V K 475618$ & \\
\hline 391 & Presa del río Henares 1 & Mejorada del Campo & $1 / 2 / 1999$ & J.G.A.; J.H. & $30 T V K 583735$ & \\
\hline 392 & Presa del río Henares 2 & Mejorada del Campo & $1 / 2 / 1999$ & J.G.A.; J.H. & $30 T V K 582737$ & \\
\hline 393 & Charca en Rivas (Las Yeseras) & Mejorada del Campo & $1 / 2 / 1999$ & J.G.A.; J.H. & $30 T V K 560712$ & \\
\hline 394 & Laguna de San Antonio & Velilla de San Antonio & $1 / 2 / 1999$ & J.G.A.; J.H. & 30 TVK602664 & \\
\hline 395 & Laguna del Campillo & Vaciamadrid & $1 / 2 / 1999$ & J.G.A.; J.H. & 30 TVK574636 & \\
\hline 396 & Laguna del Porcal & Vaciamadrid & $1 / 2 / 1999$ & J.G.A.; J.H. & 30 TVK546610 & \\
\hline 397 & Laguna de las Madres & Vaciamadrid & $1 / 2 / 1999$ & J.G.A.; J.H. & 30 TVK566613 & \\
\hline 398 & Laguna de las Madres & Vaciamadrid & $1 / 2 / 1999$ & J.G.A.; J.H. & 30TVK562610 & \\
\hline 399 & Charca en el Camping Lagos & Vaciamadrid & $1 / 2 / 1999$ & J.G.A.; J.H. & $30 T V K 564607$ & \\
\hline 400 & Charca Muñoz (Jet Madrid) & Vaciamadrid & $1 / 2 / 1999$ & J.G.A.; J.H. & $30 T V K 570617$ & \\
\hline 401 & Laguna Villafranca & Vaciamadrid & $1 / 2 / 1999$ & J.G.A.; J.H. & 30TVK573618 & \\
\hline 402 & Manantial de la Boyeriza & Gorquez de Abajo & $1 / 2 / 1999$ & J.G.A.; J.H. & $30 T V K 523574$ & \\
\hline 403 & Embalse de Gózquez & Gorquez de Abajo & $1 / 2 / 1999$ & J.G.A.; J.H. & 30TVK494546 & \\
\hline 404 & Charca en San Martín de la Vega & San Martín de la Vega & $1 / 2 / 1999$ & J.G.A.; J.H. & $30 T V K 528521$ & \\
\hline 405 & Parque Tierno Galván & San Martín de la Vega & $1 / 2 / 1999$ & J.G.A.; J.H. & 30TVK522520 & \\
\hline 406 & Charca en Ciempozuelos & Titulcia & $1 / 2 / 1999$ & J.G.A.; J.H. & 30 TVK510442 & \\
\hline 407 & Charca en Soto de las Cuevas & Titulcia & $1 / 2 / 1999$ & J.G.A.; J.H. & 30 TVK 479385 & \\
\hline 408 & Laguna de los Frailes & Perales del Río & $1 / 2 / 1999$ & J.G.A.; J.H. & $30 T V K 475618$ & \\
\hline 409 & Presa del río Henares 1 & Mejorada del Campo & $1 / 5 / 1999$ & J.G.A.; J.H. & 30 TVK 583735 & \\
\hline 410 & Presa del río Henares 2 & Mejorada del Campo & $1 / 5 / 1999$ & J.G.A.; J.H. & 30 TVK582737 & \\
\hline 411 & Charca en Rivas (Las Yeseras) & Mejorada del Campo & $1 / 5 / 1999$ & J.G.A.; J.H. & 30 TVK560712 & \\
\hline 412 & Laguna de San Antonio & Velilla de San Antonio & $1 / 5 / 1999$ & J.G.A.; J.H. & 30 TVK602664 & \\
\hline 413 & Laguna del Campillo & Vaciamadrid & $1 / 5 / 1999$ & J.G.A.; J.H. & 30 TVK574636 & \\
\hline 414 & Laguna del Porcal & Vaciamadrid & $1 / 5 / 1999$ & J.G.A.; J.H. & 30 TVK546610 & \\
\hline 415 & Laguna de las Madres & Vaciamadrid & $1 / 5 / 1999$ & J.G.A.; J.H. & 30TVK566613 & \\
\hline 416 & Laguna de las Madres & Vaciamadrid & $1 / 5 / 1999$ & J.G.A.; J.H. & 30TVK562610 & \\
\hline 417 & Charca en el Camping Lagos & Vaciamadrid & $1 / 5 / 1999$ & J.G.A.; J.H. & $30 T V K 564607$ & \\
\hline 418 & Charca Muñoz (Jet Madrid) & Vaciamadrid & $1 / 5 / 1999$ & J.G.A.; J.H. & 30 TVK570617 & \\
\hline 419 & Laguna Villafranca & Vaciamadrid & $1 / 5 / 1999$ & J.G.A.; J.H. & 30TVK573618 & \\
\hline 420 & Manantial de la Boyeriza & Gorquez de Abajo & $1 / 5 / 1999$ & J.G.A.; J.H. & 30 TVK523574 & \\
\hline 421 & Embalse de Gózquez & Gorquez de Abajo & $1 / 5 / 1999$ & J.G.A.; J.H. & 30TVK494546 & \\
\hline 422 & Charca en San Martín de la Vega & San Martín de la Vega & $1 / 5 / 1999$ & J.G.A.; J.H. & 30TVK528521 & \\
\hline 423 & Parque Tierno Galván & San Martín de la Vega & $1 / 5 / 1999$ & J.G.A.; J.H. & 30TVK522520 & \\
\hline 424 & Charca en Ciempozuelos & Titulcia & $1 / 5 / 1999$ & J.G.A.; J.H. & 30 TVK510442 & \\
\hline 425 & Charca en Soto de las Cuevas & Titulcia & $1 / 5 / 1999$ & J.G.A.; J.H. & 30 TVK 479385 & \\
\hline 426 & Laguna de los Frailes & Perales del Río & $1 / 5 / 1999$ & J.G.A.; J.H. & 30 TVK475618 & \\
\hline 427 & Presa del río Henares 1 & Mejorada del Campo & $1 / 10 / 1998$ & J.G.A.; J.H. & 30 TVK583735 & \\
\hline 428 & Presa del río Henares 2 & Mejorada del Campo & $1 / 10 / 1998$ & J.G.A.; J.H. & 30 TVK582737 & \\
\hline 429 & Charca en Rivas (Las Yeseras) & Mejorada del Campo & $1 / 10 / 1998$ & J.G.A.; J.H. & 30 TVK560712 & \\
\hline 430 & Laguna de San Antonio & Velilla de San Antonio & $1 / 10 / 1998$ & J.G.A.; J.H. & $30 T V K 602664$ & \\
\hline
\end{tabular}


Tabla 1.-Fin

\begin{tabular}{|c|c|c|c|c|c|c|}
\hline NUM|1 & LOCALIDAD & POBLACION & FECHA & COLECTORES & UTM & FIGURAS \\
\hline \begin{tabular}{|l|l}
431 & \\
\end{tabular} & Laguna del Campillo & Vaciamadrid & $1 / 10 / 1998$ & J.G.A.; J.H. & 30 TVK574636 & \\
\hline \begin{tabular}{|l|l}
432 & 1
\end{tabular}$-a$ & Laguna del Porcal & Vaciamadrid & $1 / 10 / 1998$ & J.G.A.; J.H. & $30 T V K 546610$ & \\
\hline \begin{tabular}{|l|l}
433 & 1 \\
\end{tabular} & Laguna de las Madres & Vaciamadrid & $1 / 10 / 1998$ & J.G.A.; J.H. & 30 TVK566613 & \\
\hline $434 \mathrm{~L}$ & Laguna de las Madres & Vaciamadrid & $1 / 10 / 1998$ & J.G.A.; J.H. & $30 T V K 562610$ & \\
\hline 435 & Charca en el Camping Lagos & Vaciamadrid & $1 / 10 / 1998$ & J.G.A.; J.H. & $30 T V K 564607$ & \\
\hline \begin{tabular}{|l|l}
436 \\
\end{tabular} & Charca Muñoz (Jet Madrid) & Vaciamadrid & $1 / 10 / 1998$ & J.G.A.; J.H. & 30 TVK570617 & \\
\hline \begin{tabular}{|l|l}
437 & 1 \\
\end{tabular} & Laguna Villafranca & Vaciamadrid & $1 / 10 / 1998$ & J.G.A.; J.H. & 30 TVK573618 & \\
\hline $438 \mid 1 \quad r a r a n$ & Manantial de la Boyeriza & Gorquez de Abajo & $1 / 10 / 1998$ & J.G.A.; J.H. & 30 TVK523574 & \\
\hline 439 & Embalse de Gózquez & Gorquez de Abajo & $1 / 10 / 1998$ & J.G.A.; J.H. & $30 T V K 494546$ & \\
\hline 440 & Charca en San Martín de la Vega & San Martín de la Vega & $1 / 10 / 1998$ & J.G.A.; J.H. & $30 T V K 528521$ & \\
\hline \begin{tabular}{|l|l}
441 & 1
\end{tabular} & Parque Tierno Galván & San Martín de la Vega & $1 / 10 / 1998$ & J.G.A.; J.H. & 30 TVK522520 & \\
\hline 442 & Charca en Ciempozuelos & Titulcia & $1 / 10 / 1998$ & J.G.A.; J.H. & $30 T V K 510442$ & \\
\hline 443 & Charca en Soto de las Cuevas & Titulcia & $1 / 10 / 1998$ & J.G.A.; J.H. & $30 T V K 479385$ & \\
\hline \begin{tabular}{|l|l}
444 & $L$
\end{tabular} & Laguna de los Frailes & Perales del Río & $1 / 10 / 1998$ & J.G.A.; J.H. & $30 T V K 475618$ & \\
\hline \begin{tabular}{|l|l}
445 & 1
\end{tabular} & Laguna de Ontígola & Aranjuez & $16 / 04 / 1993$ & D.M. & $30 T V K 488302$ & 125 \\
\hline 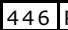 & Río Aulencia & Villanueva del Pardillo & 1987 & O.S. & $30 T V K 158814$ & \\
\hline 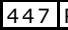 & Río Cofio & Santa María de la Alameda & 1987 & o.s. & 30 TUK959948 & \\
\hline 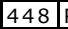 & Río Cofio & Robledo de Chavela & 1987 & o.s. & 30 TUK882790 & \\
\hline 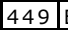 & Embalse de Miraflores & Miraflores de la Sierra & 1987 & O.S. & $30 T V L 333191$ & \\
\hline 450 & Río Guadarrama & Villanueva del Pardillo & 1987 & O.S. & $30 T V K 208822$ & \\
\hline \begin{tabular}{|l|l|l|}
451 & \\
\end{tabular} & Río Jarama & Torremocha & 1987 & O.S. & $30 T V L 602214$ & \\
\hline 452 & Río Jarama & El Espartal & 1987 & O.S. & 30TVL565139 & \\
\hline \begin{tabular}{|l|l}
453 & -1 \\
\end{tabular} & Embalse del Atazar & Atazar & 1987 & O.S. & 30 TVL606294 & 111 \\
\hline \begin{tabular}{|l|l}
454 & -1
\end{tabular} & Embalse de Santillana & Manzanares el Real & 1987 & o.s. & $30 T V L 308057$ & 107 \\
\hline \begin{tabular}{|l|l|l|}
455 & 1 \\
\end{tabular} & Río Manzanares & Colmenar Viejo & 1987 & O.S. & $30 T V L 317002$ & \\
\hline \begin{tabular}{|l|l}
456 & 1 \\
\end{tabular} & Río Perales & Valdemorillo & 1987 & O.S. & $30 T V K 059828$ & \\
\hline \begin{tabular}{|l|l|l|l|}
457 & 1 \\
\end{tabular} & Río Perales & Chapinería & 1987 & O.S. & $30 T V K 025703$ & \\
\hline 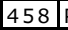 & Pilon del Pardo & El Pardo & 1850 & Graells & $30 T V K 323875$ & \\
\hline \begin{tabular}{|l|l}
459 & 1 \\
\end{tabular} & Río Jarama & Patones & $18 / 01 / 1989$ & A.C. & 30TVL605243 & \\
\hline \begin{tabular}{|l|l}
460 & 1 \\
\end{tabular} & Manantial de Patones & Patones de Abajo & $26 / 06 / 1997$ & B.A.; D.B. & 30TVL603241 & \\
\hline \begin{tabular}{|l|l}
461 & ( \\
\end{tabular} & Canal de la Parra & Patones de Abajo & $02 / 06 / 1997$ & B.A.; D.B. & 30TVL603241 & \\
\hline \begin{tabular}{|l|l|l|l|l}
462 & 1 \\
\end{tabular} & Río Henares, Finca El Encín & Alcalá de Henares & $25 / 05 / 84$ & A.F.L. & $30 T V K 754858$ & \\
\hline \begin{tabular}{|l|l|l|}
463 & \\
\end{tabular} & Arroyo en Somosierra & Somosierra & $01 / 10 / 2005$ & J.S. & $30 T V L 524529$ & \\
\hline
\end{tabular}

llevó a cabo tanto en aguas corrientes (ríos, arroyos, canales de regadío, manantiales, fuentes, abrevaderos) como en aguas estancadas (lagunas, embalses, charcas) y en zonas de elevada humedad (paredes húmedas, márgenes de ríos, arroyos o lagunas). Por otro lado, en cada localidad se intentaron prospectar todas las profundidades y sustratos (rocas, limos, arenas, vegetación acuática, detritos).

Las especies de gran tamaño, como las náyades, se recogían a mano, con la ayuda de mirafondos, cuando la profundidad lo permitía, o con pequeñas dragas de arrastre. No obstante, la mayoría de las especies, generalmente de tamaño pequeño, se recolectaban mediante coladores o mangas de luz de malla variable.

El procedimiento de recolección empleado difiere en función del tipo de sustrato. En fondos de sustratos finos (arena, cieno, materia orgánica), la muestra se toma con un colador y, una vez tamizada, se vuelca en una bandeja blanca de plástico sobre la cual los ejemplares se separaban con la ayuda de unas pinzas blandas de cobre. Si se trata de vegetación acuática o de orilla, esta se lava manualmente en una bandeja profunda con el fin de colectar los ejemplares. En las paredes húmedas se emplean cepillos y pinceles con los que se despegan los ejemplares que son posteriormente recogidos en una bandeja situada inmediatamente debajo. Las piedras y las hojas sumergidas se examinan individualmente o se lavan en bandejas, recolectando los ejemplares con las pinzas de cobre. De forma ocasional, algunos ejemplares se han localizado en muestreos realizados en el medio intersticial con el método Karaman-Chappuis (Chappuis, 1950).

Los ejemplares recolectados se conservaron vivos en botes de plástico con agua de su localidad de origen y se transportaron hasta el laboratorio en una nevera portátil con hielo. Una vez en el laboratorio, los ejemplares se preparaban para su conservación y posterior identificación. Los gasterópodos se anestesian con mentol antes de fijarlos en etanol al 70\% (Araujo et al., 1995). El uso del anestésico favorece la relajación del animal y por tanto, una fijación más eficaz de los ejemplares para su estudio, permitiendo conservar mejor la forma y tamaño originales de los órganos internos con valor taxonómico. Los ejemplares de la familia Sphaeriidae, antes de ser fijados en etanol al $70 \%$, se sometieron 
a un choque térmico de unos pocos segundos en agua a $60^{\circ} \mathrm{C}$ de forma que quedaran con las valvas abiertas. En el caso de las náyades de la familia Unionidae, se suele practicar un corte en el músculo aductor anterior que permite separar el manto de la concha antes de fijarlos en etanol al 70\%.

La identificación de los ejemplares se llevó a cabo teniendo en cuenta caracteres de la concha y anatómicos, empleando, cuando era necesario, un estereomicroscopio Olympus SZH10 con ocular 15x y aumento máximo de $105 x$. Para los estudios anatómicos se realizaron disecciones sobre placa Petri con fondo de parafina, cera y carbón activo. En el caso de especies muy pequeñas o conflictivas se utilizó microscopía electrónica de barrido (Microscopio Electrónico de Barrido Philips XL20), siguiendo el protocolo descrito en Ramos et al. (2000).

\section{MATERIAL DE ESTUDiO}

Se han estudiado principalmente muestras colectadas por los autores [J. S. (J. Soler), D. M. (D. Moreno), R. A. (R. Araujo) y M. A. R. (M. A. Ramos)] y diferentes investigadores del Museo Nacional de Ciencias Naturales de Madrid (MNCN) entre 1983 y 2005. También se ha contado con las muestras amablemente cedidas por J. García-Avilés J. G. A.), N. Roblas (N. R.) y C. Rozas (C. R.), del Centro de Investigaciones Ambientales de la Comunidad de Madrid Fernando González Bernáldez. Otros colectores que han colaborado con sus muestras han sido los siguientes (en orden alfabético): A. C. (A. Camacho), A. FL. (A. Fernandez-Lop), A. M. (A. Machordom), B. A. (B. Arconada), C. N. (C. Noreña), C. T. (C. Toledo), D. B. (D. Buckley), D. T. (D. Toribio), E. B. (E. Bello), I. A. (I. Acevedo), J. D. (J. Dorda), J. F. (J. Fernández), J. H. (J. Hidalgo), J. L. F. (J. L. Fernández), J. L.V. (J. L. Velasco), J. M. R. (J. M. Remón), L. S. (L. Saavedra), M. G. P. (M. García París), M. C. (M. Calvo), M. T. A. (M. T. Aparicio), N. B. (A. Bahamonde), N. M. (N. Martín) y O. S. (O. Soriano).

Se revisaron además los ejemplares procedentes de la provincia de Madrid conservados en la Colección de moluscos del MNCN, así como las citas bibliográficas referentes al área de estudio.

\section{Clasificación, taxonomía y distribución de los moluscos dulceacuícolas en Madrid}

Clase Gastropoda

Subclase Prosobranchia

Superorden Caenogastropoda

\author{
Orden Mesogastropoda \\ Superfamilia Rissooidea \\ Familia Hydrobiidae \\ Familia Bithyniidae \\ Subclase Pulmonata \\ Orden Basommatophora \\ Superfamilia Lymnaeoidea \\ Familia Lymnaeidae \\ Superfamilia Planorboidea \\ Familia Planorbidae \\ Familia Physidae \\ Orden Stylomatophora \\ Superfamilia Succineoidea \\ Familia Succineidae
}

Clase Bivalvia

Subclase Eulamellibranchia

Superorden Palaeoheterodonta

Orden Unionoida

Superfamilia Unionoidea

Familia Unionidae

Superorden Heterodonta

Orden Veneroidea

Superfamilia Sphaerioidea

Familia Sphaeriidae

\author{
Familia Hydrobiidae \\ Género Pseudamnicola \\ Subgénero Pseudamnicola \\ Pseudamnicola (Pseudamnicola) subproducta (Pala- \\ dilhe, 1869) n. comb. \\ Subgénero Corrosella \\ Pseudamnicola (Corrosella) hinzi Boeters, 1986 \\ Género Islamia \\ "Islamia" coronadoi (Bourguignat, 1870) \\ Islamia pallida Arconada \& Ramos, 2006 \\ Género Potamopyrgus \\ Potamopyrgus antipodarum (Gray, 1843)
}

Género Bithynia

Familia Bithyniidae

Subgénero Bithynia

Bithynia (Bithynia) tentaculata (Linnaeus, 1758)

Género Lymnaea

Familia Lymnaeidae

Lymnaea stagnalis (Linnaeus, 1758)

Género Stagnicola

Stagnicola palustris (Müller, 1774)

Género Galba

Galba truncatula (Müller, 1774)

Género Radix

Radix auricularia (Linnaeus, 1758)

Radix balthica (Linnaeus, 1758) 


\section{Familia Planorbidae}

Género Anisus

Subgénero Anisus

Anisus (Anisus) spirorbis (Linnaeus 1758)

Subgénero Disculifer Anisus (Disculifer) vortex (Linnaeus 1758)

Género Gyraulus

Subgénero Gyraulus

Gyraulus (Gyraulus) albus (Müller, 1774)

Gyraulus (Gyraulus) chinensis (Dunker, 1848)

Subgénero Torquis

Gyraulus (Torquis) laevis (Alder, 1838)

Subgénero Armiger

Gyraulus (Armiger) crista (Linnaeus, 1758)

Género Hippeutis

Hippeutis complanatus (Linnaeus, 1758)

Género Segmentina

Segmentina nitida (Müller, 1774)

Género Planorbarius

Planorbarius metidjensis (Graells, 1846)

Género Ancylus

Ancylus fluviatilis Müller, 1774

Género Ferrissia

Subgénero Pettancylus

Ferrissia (Pettancylus) clessiniana (Jickeli, 1882)

Género Physella

Familia Physidae

Subgénero Costatella

Physella (Costatella) acuta (Drapanaud, 1805)

Género Oxyloma

Familia Succineidae

Subgénero Oxyloma

Oxyloma (Oxyloma) elegans (Risso, 1826)

Oxyloma (Oxyloma) sarsii (Esmark, 1886)

Género Potomida

\section{Familia Unionidae}

Potomida littoralis (Cuvier, 1798)

Género Anodonta

Anodonta sp.

Género Unio

Unio cf. pictorum (Linnaeus, 1758)

Género Musculium

Familia Sphaeriidae

Musculium lacustre (Müller, 1774)

Género Pisidium

Pisidium casertanum (Poli, 1791)

Pisidium nitidum Jenyns, 1832

Pisidium personatum Malm, 1855

Pisidium subtruncatum Malm, 1855

\section{Relación de especies}

Pseudamnicola (Pseudamnicola) subproducta (Paladilhe, 1869) n. comb.

SINONIMIA:

Amnicola spirata Paladilhe, 1869. Nouv. Miscel. Malac.,p. 108, pl. v, fig. 10-11. (feb. 1869)

Amnicola subproducta Paladilhe, 1869. Nouv. Miscel. Malac., 140; note additionelle (feb 1869). nom. nov. pro Amnicola spirata

Pseudamnicola (Pseudamnicola) spirata (Paladilhe): Boeters, 1986. Heldia, 1(4): 125

DESCRIPCIÓN:

Concha: Presenta entre 4 y 4,75 vueltas de espira; la última muy ancha en relación al resto y muy alta, constituyendo las 3/4 partes de la altura total de la concha. Es fina y presenta una abertura ligeramente ovalada. El peristoma es completo y el ombligo pequeño y con forma de hendidura. El periostraco es de color marrón (Figura 2).

Animal: Los tentáculos cefálicos son entre 3 y 5 veces más largos que anchos. El ctenidio presenta entre 16 y 23 lamelas. En cuanto al sistema genital, las hembras se caracterizan por presentar la porción libre del oviducto pigmentada de negro, la bursa copulatrix con forma de saco y un receptáculo seminal muy alargado. Los machos presentan un pene largo; ancho y plegado en la base y pigmentado de negro en su zona distal (Figuras 34-35).

Dimensiones: Diámetro máximo 1,8 mm; altura 2,6 $\mathrm{mm}$.

HÁBITAT: En aguas con poca corriente. Vive en fuentes, arroyos y lagunas.

DisTRIBUCIÓN: Se distribuye ampliamente por la región Mediterránea. En España, hasta ahora sólo es conocida de Madrid, Islas Baleares, Comunidad Valenciana y Cataluña. En Madrid sólo se ha localizado en la Laguna de Ontígola (Figura 86).

LOCALIDADES: 445.

Pseudamnicola (Corrosella) hinzi Boeters, 1986

SINONIMIA:

Pseudamnicola (Corrosella) hinzi Boeters 1986. Heldia, 1(4), p. 125, Taf. 18a Fig. 1.

DESCRIPCIÓN:

Concha: Cónica, formada por 4-5 vueltas de espira constituyendo la última los $2 / 3$ de la altura total de la concha. Las suturas están bien marcadas. De color córneo aunque frecuentemente presenta unas incrustaciones que le confieren una coloración oscura. La 
abertura es ovalada, ligeramente aguda en la parte superior, alcanzando los $2 / 5$ de la altura total de la concha. El peristoma es continuo con el borde columelar y se inclina sobre el ombligo (Figura 3).

Animal: El cuerpo es de color oscuro a excepción del pie que es gris claro. El ctenidio está formado por entre 15 y 22 lamelas branquiales y un osfradio con forma ovalada. En los machos el pene presenta una ligera pigmentación oscura en la zona distal. En las hembras la bursa tiene forma de "J", el receptáculo es pequeño y la porción libre del oviducto está pigmentada de negro.

DiMENSIONES: Diámetro máximo 1,3-1,5 mm; altura 2,6-3,1 $\mathrm{mm}$.

HÁBITAT: Vive en ambientes acuáticos con poca corriente: fuentes, lagunas y pequeños arroyos con aguas tranquilas.

DisTRIBUCIÓN: Hasta la fecha sólo se conoce en el tercio norte de la Península Ibérica (Burgos y Zaragoza) (Boeters, 1987). En Madrid se ha encontrado en el arroyo Sepulcro, Laguna de San Juan y Fuente Caja de las Huertas (Figura 86), siendo éstas las primeras citas para la Comunidad de Madrid.

LOCALIDADES: $139 ; 141 ; 145 ; 146 ; 149 ; 150 ; 230$

“Islamia” coronadoi (Bourguignat, 1870)

\section{SINONIMIA:}

Valvata coronadoi Bourguignat, 1870. Mollusques nouveaux, litigieux on peu connus. Rev. Mag. Zool. Pure appl., (2), 22(5): 166-171.

Neohoratia (?) coronadoi (Bourguignat): Boeters, 1988. Moitessieriidae und Hydrobiidae in Spanien und Portugal. Arch. Moll., 118, (1/4), p. 181-261.

"Islamia" coronadoi (Bourguignat): Bodon, Manganelli \& F. Giusti, 2001. Malacologia, 43, p. 179.

\section{DESCRIPCIÓN:}

Concha: De tamaño relativamente grande en comparación con otras especies de hidróbidos valvatiformes (Arconada \& Ramos, 2005) y planispiral, es decir, con el desarrollo espiral dispuesto en un mismo plano. El ombligo es muy amplio, casi tan ancho como la abertura. La concha no está engrosada en la parte lateral del ombligo (Figura 4).

Animal: Se desconoce la anatomía de esta especie.

DiMENSIONES: Diámetro máximo $1,75 \mathrm{~mm}$; altura $0,85 \mathrm{~mm}$.

HÁBitaT: Según Bourguignat la especie se encontraba en arroyos y manantiales.

DisTRIBUCIÓN: Citada "en los alrededores de Madrid, o al menos, en algunos manantiales o arroyos de la provincia de Castilla la Nueva" (Bourguignat, 1870). Durante los sucesivos muestreos de los últimos años no se ha vuelto a encontrar en la Comunidad de Madrid, por lo que es presumible que se haya extinguido.

Islamia pallida Arconada \& Ramos, 2006

SinONIMIA:

Islamia pallida Arconada \& Ramos, 2006. Malacologia, 48(12): $77-132$.

\section{DESCRIPCIÓN:}

Concha: Valvatiforme, muy frágil y deprimida, constituida por 3,5 vueltas de espira; la última alcanza más de $3 / 4$ de la altura total de la concha. Protoconcha formada por 1,5 vueltas de espira. Abertura inclinada hacia delante, redondeada; peristoma completo y fino. Ombligo estrecho de aproximadamente $0,2 \mathrm{~mm}$ de diámetro (Figura 5).

Animal: Cabeza y cuerpo carentes de pigmentación. Ojos ausentes. En el sistema nervioso destaca el reducido tamaño del conectivo pleuro-esofágico y del ganglio subesofágico así como la presencia de un conectivo pleuro-supraesofágico de tamaño mediano. El esófago discurre recto por debajo de la comisura cerebral. En los machos, el pene es largo, tanto como la cabeza, no pigmentado y con un lóbulo subterminal no glandular y redondeado que se localiza cerca del extremo distal. Las hembras presentan un oviducto paleal muy pequeño, estando $1 / 3$ del mismo constreñido en la cavidad paleal. La cápsula glandular es menor que la glándula del albumen y el oviducto renal forma un lazo completo sobre esta última. En el oviducto libre se insertan dos receptáculos seminales elongados, sin conducto y muy próximos entre sí, situados en posiciones opuestas del oviducto. Carece de bursa copulatrix. Las hembras presentan un pseudopene no pigmentado que alcanza hasta la mitad de la cabeza (Arconada, 2000, Arconada y Ramos, 2006).

DiMENSIONES: Diámetro máximo 1,26 mm; altura $1,1 \mathrm{~mm}$.

HÁBITAT: Se ha encontrado en tres habitat distintos: un manantial, un canal y un río. El manantial de Patones es pequeño $(20-30 \mathrm{~cm})$ y surge entre hierba y juncos, junto a la orilla del río. En el río Jarama el hábitat es de tipo intersticial, habiéndose recolectado la especie con la técnica de KaramanChapuis a una distancia de $75 \mathrm{~cm}$ de la orilla. Por otra parte, se colectaron ejemplares juveniles sobre piedras, algas y musgos en un pequeño remanso de 
agua procedente de una fuga del Canal de la Parra (Arconada, 2000).

DISTRIBUCIÓN: Muy restringida. Sólo se conoce en la Comunidad de Madrid (Arconada y Ramos, 2006), y dentro de ésta, en las tres localidades mencionadas en las inmediaciones de Patones de Abajo (Figura 86).

LOCALIDADES: 178; 459; 460; 461.

Potamopyrgus antipodarum (Gray, 1843)

SINONIMIA:

Amnicola antipodarum Gray, 1843. Travels in New Zealand, 2: 228-265.

Paludestrina salleana Fischer, 1860. J. Conchyl., 8: 208-211.

Paludestrina cumingiana Fischer, 1860. J. Conchyl., 8: 208211.

Hydriobia fischeri Dunker, 1862. Malakozool. Blätter, 8, 150154.

Hydrobia spelaea Fraunenfeld, 1865. Vorläufige Aufzälung der Arten der Gattungen Hydrobia Htm. Und Amnicola Gld. Hldm. In der kaiserlichen und in Cuming's Sammiung. Verh. Zool.-Bot. Ges. Wien, 13: 1017-1032.

Hydrobia reevei Fraunenfeld, 1865. Vorläufige Aufzälung der Arten der Gattungen Hydrobia Htm. Und Amnicola Gld. Hldm. In der kaiserlichen und in Cuming's Sammiung. Verh. Zool.-Bot. Ges. Wien, 13: 1017-1032.

Hydrobia antipodum Martens, 1873.Critical list of the Mollusca of New Zealand contained in European collections, with references to descriptions and synonyms.

Hydrobia jenkinsi Smith, 1889. J. Conch., 6: 142-145.

Hydrobia ventrosa carinata Marshall, 1889. J. Conch., 6: 140142.

Pseudamnicola lanceolata; Cherbonnier, 1952. Bull. Mus. Hist. Nat., Paris, 24: 568-569.

Potamopyrgus jenkensi (Smith): Macan, 1977. Fresh. Biol. Assoc. Scient. Public., $13: 44$ pp.

Potamopyrgus antipodarum (Gray): Ponder, W., 1990. J. Moll. Stud. 54: 271-285.

\section{DESCRIPCIÓN:}

Concha: Cónica alargada, formada por 6-7 vueltas de espira de crecimiento regular, siendo la última más grande que el resto (constituye aproximadamente la mitad de la altura total de la concha). Las suturas son profundas. El ápice es redondeado y el ombligo estrecho. Abertura ovalada y angulosa en su parte superior. El peristoma es continuo y sencillo, con el borde columelar ligeramente inclinado sobre el ombligo. El opérculo es córneo, con núcleo excéntrico. La superficie de la concha presenta finas estrías longitudinales y es de color córneo oscuro (Figura 6). La variedad carinatus corresponde a ejemplares que presentan una carena en la zona media superior de la última vuelta, a veces visible en la penúltima vuelta.

Animal: Presentan 27 ó más lamelas branquiales. La porción libre del oviducto no está pigmenta- da. Es una especie partenogenética y ovovivípara, por lo que pueden observarse entre 30 y 45 embriones con diferente grado de desarrollo en el interior del oviducto paleal (Figuras 36-38).

DiMENSIONES: Diámetro máximo 2,5-3 $\mathrm{mm}$; altura 5-6 mm.

HÁBitAT: Vive en aguas dulces o salobres en ríos, arroyos, regatos, canales de riego, fuentes, paredes húmedas o lagunas. Suele formar poblaciones con grandes densidades de individuos sobre macrófitos, piedras o directamente sobre el sustrato. Puede encontrarse tanto en aguas limpias como aquellas con evidentes signos de contaminación (MartínezLópez et al., 1986).

DISTRIBUCIÓN: Se piensa que es una especie originaria de Nueva Zelanda introducida en Europa a mediados del siglo XIX, donde se citó por primera vez en Inglaterra en 1889 (Ponder, 1988). Desde entonces ha sufrido una notable expansión, siendo muy común en las aguas dulces del oeste de Europa. En la Península Ibérica presenta una distribución muy amplia (Vidal-Abarca \& Suárez, 1985) siendo en ocasiones una auténtica plaga. En la Comunidad de Madrid ha sido citada por Álvarez y Selga (1967) como Pseudamnicola lanceolata en el mar de Ontígola. En el contexto de este trabajo ha sido localizada en los ríos Perales, Aulencia, Guadarrama, Lozoya, Guadalix, Jarama, Torote y Tajo y en los arroyos Sacedón, del Sotillo, de los Castaños, de la Fuente Juncal, del Parque del Oeste, Albalá y de los Meaques. También se localizó sobre paredes húmedas en un barranco junto a Patones de abajo y en las proximidades de la Presa de Picadas. Así mismo, se colectó en una acequia en Meco, en un canal de riego cerca de la Laguna de San Galindo, en la Laguna de la Dehesa de Bayona, en la Laguna de San Juan y en el Pozo del Nogal (Figura 86).

LOCALIDADES: $63 ; 71 ; 72 ; 73 ; 116 ; 130 ; 136 ; 143 ; 144 ; 147$; $148 ; 163 ; 165 ; 177 ; 181 ; 183 ; 184 ; 187 ; 188 ; 191 ; 196 ; 198$; $201 ; 202 ; 239 ; 246 ; 249 ; 261 ; 284 ; 287 ; 289 ; 334$

\section{Bithynia (Bithynia) tentaculata (Linnaeus, 1758)}

\section{SINONIMIA:}

Helix tentaculata Linnaeus, 1758. Systema naturae I Vol. $10^{a}$ ed. p. $774, \mathrm{n}^{\circ} 616$.

Nerita jaculator Müller, 1774. Verm. Terr. Fluv., 2, p. 185.

Bulimus tentaculatus (Linnaeus): Poiret, 1801. Coqu. Fluv. et terr. Observées dans le département de l'Aisne et aux environs de Paris, 119 pp.

Cyclostoma impurum Draparnaud, 1801. Tab. Moll. Terr. Fluv. France, p. 41.

Paludina impura Brard, 1815. Hist. Coq. Terr. Fluv. environs París. 239 pp. 


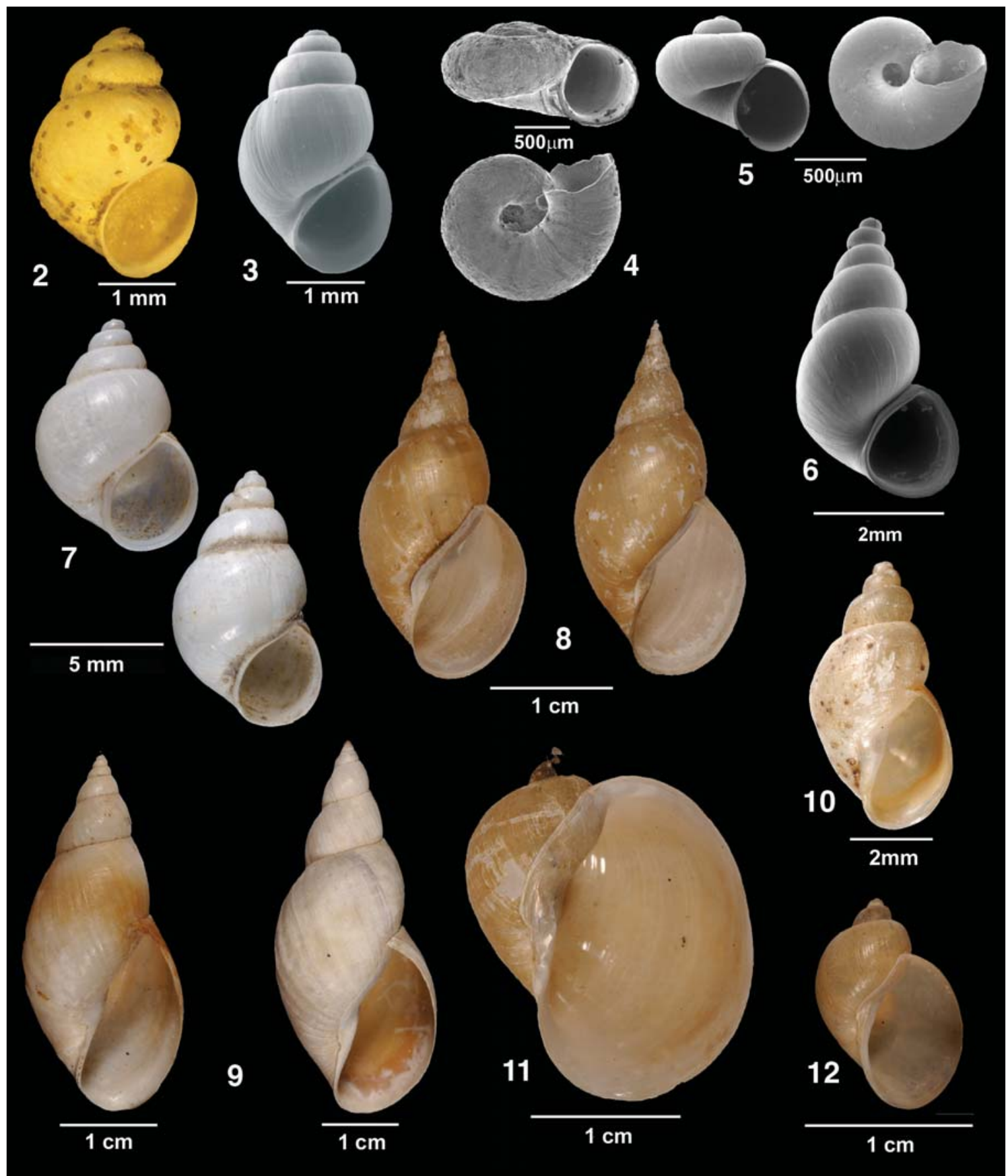

Figs. 2-12.-Conchas de 2) Pseudamnicola (Pseudamnicola) subproducta (Paladilhe, 1869). 3) Peudamnicola (Corrosella) hinzi Boeters 1986. 4) "Islamia" coronadoi (Bourguignat, 1870) holotipo. 5) Islamia pallida Arconada \& Ramos, 2006 holotipo. 6) Potamopyrgus antipodarum (Gray, 1843). 7) Bithynia (Bithynia) tentaculata (Linnaeus, 1758). 8) Lymnaea stagnalis (Linnaeus, 1758). 9) Stagnicola palustris (Müller, 1774). 10) Galba truncatula (Müller 1774). 11) Radix auricularia (Linnaeus, 1758). 12) Radix balthica (Müller 1774).

Figs. 2-12.- Shells of 2) Pseudamnicola (Pseudamnicola) subproducta (Paladilhe, 1869). 3) Peudamnicola (Corrosella) hinzi Boeters 1986. 4) "Islamia" coronadoi (Bourguignat, 1870) holotype. 5) Islamia pallida Arconada \& Ramos, 2006 holotype. 6) Potamopyrgus antipodarum (Gray, 1843). 7) Bithynia (Bithynia) tentaculata (Linnaeus, 1758). 8) Lymnaea stagnalis (Linnaeus, 1758). 9) Stagnicola palustris (Müller, 1774). 10) Galba truncatula (Müller 1774). 11) Radix auricularia (Linnaeus, 1758). 12) Radix balthica (Müller 1774). 
Paludina impura var. matritensis Graells, 1846. Cat. Mol. España. p. 17.

Paludina tentaculata (Linnaeus): Fleming, 1822. Phil. Zool., 2, p. 488.

Bythinia tentaculata (Linnaeus): MacGillivray, 1843. Hist. Moll. Aberdeen. p. 124. (grafía posterior incorrecta)

Bithynia tentaculata (Linnaeus): Moquin-Tandom, 1855. Hist. Nat. Moll. Terr. Fluv. France, 1, p. 473.

Bithynia decipiens Locard, 1894. Rev. Suisse Zool., 2: 65-143.

\section{DESCRIPCIÓN:}

Concha: Muy sólida, de forma cónica redondeada y formada por 5-6 vueltas de espira de crecimiento lento y regular; la última constituye entre $1 / 2$ y $2 / 3$ de la altura total de la concha. Las suturas son poco profundas. El ápice es bastante agudo y carece de ombligo. La abertura es oblicua, ovalada y angulosa en su parte superior. El peristoma es continuo y sencillo. El opérculo es calcáreo con núcleo central y estrías de crecimiento concéntrico. La concha es de color córneo con finas estrías longitudinales (Figura 7).

Animal: Animal de color grisáceo con manchas claras. Posee dos tentáculos filiformes en cuya base se sitúan los ojos. Las puestas suelen realizarse al principio de la primavera (Figuras 39-40).

DiMENSIONES: Diámetro máximo 5-8 mm; altura 9$16 \mathrm{~mm}$.

HÁBITAT: Vive en aguas de escasa corriente de lagunas, lagos, canales y tramos remansados de ríos. Soporta bien el escaso contenido en oxígeno, alta conductividad y altos valores de $\mathrm{pH}$ (MartínezLópez et al., 1988).

DistRIBUCión: Europa, Marruecos, Argelia y norte América. Ampliamente distribuida por la Península Ibérica (Vidal Abarca \& Suárez, 1985). En la Comunidad de Madrid ha sido citada previamente por Graells (1846, como Paludina impura var. matritensis) y Pérez Arcas (1863 como Paludina tentaculata). También ha sido citada en el Tajo a su paso por Aranjuez (Servain, 1880; Margalef, 1958), en la Laguna de Ontígola (Álvarez \& Selga, 1967), en el río Jarama a su paso por Titulcia (Gregorides, 1971) y en el río Manzanares (Servain, 1880 y Locard, 1894 como Bythinia matritensis). Las colecciones del Museo Nacional de Ciencias Naturales de Madrid albergan ejemplares de esta especie colectados en Aranjuez, San Fernando de Henares, Chapinería, San Isidro (probablemente se refiera a la pradera que lleva su nombre, situada en las proximidades del río Manzanares a su paso por la ciudad de Madrid) y Colegio Unión Carabanchel. Nosotros la hemos encontrado en los ríos Jarama y Tajo y en la Laguna de San Juan (Figura 86).

LOCALIDADES: $41 ; 114 ; 116 ; 117 ; 144 ; 145 ; 146 ; 181 ; 230$.

\section{Lymnaea stagnalis (Linnaeus, 1758)}

SINONIMIA:

Helix stagnalis Linnaeus, 1758. Syst. Nat. $10^{\mathrm{a}}$ ed., vol. 1. p. $774, \mathrm{n}^{\circ} 612$.

Buccinum stagnale (Linnaeus): Müller, 1774. Verm. Terr. Fluv., vol. 2, p. 132.

Limneus stagnalis (Linnaeus): Draparnaud, 1801. Tab. Moll. Terr. Fluv. France, p.51. (Grafia de género posterior incorrecta).

Limnaea major Jefreys, 1830. Trans. Linn. Soc. London, 16, p. 375. (Grafía de género posterior incorrecta).

Stagnicola vulgaris Hartmann, 1840. Erd- und Süssw. Gast. Vol. 1(2), p. 44, pl.8.

Limnaea stagnalis (Linnaeus): Dupuy, 1850. Hist. Nat. Moll. France, fasc 4, p.467. (Grafía de género posterior incorrecta). Limnaea borealis Bourguignat, 1862. Revue et Magas. de Zoologie, 2, p.96. (Grafía de género posterior incorrecta).

Limnaea elophila Bourguignat, 1862. Revue et Magas. de Zoologie, 2, p.97. (Grafía de género posterior incorrecta).

Limnaea colpodia Bourguignat, 1862. Revue et Magas. de Zoologie, 2, p.99. (Grafía de género posterior incorrecta).

Limnaea arenaria Colbeau, 1865. Ann. Soc. Malacol. Belgique, p.69. (Grafía de género posterior incorrecta).

Limnaea stagnalis var. variegata Hazay, 1881. Malak. Blät, p.46. (Grafía de género posterior incorrecta).

Limnaea westerlundi Locard, 1893. Conchyologie française, p.18. (Grafía de género posterior incorrecta).

Limnaea locardi Coutagne in Locard 1893. Conchyologie française, p.18. (Grafía de género posterior incorrecta).

Limnaea variegata Locard, 1893. Conchyologie française, p.19. (Grafía de género posterior incorrecta).

Limnaea turgida Locard, 1893. Conchyologie française, p.19. (Grafía de género posterior incorrecta).

Limnaea coutagnei Locard, 1893. Conchyologie française, p.19. (Grafía de género posterior incorrecta).

Limnaea (Limnaea) stagnalis (Linnaeus): Germain, 1931. Mollusques terrestres et fluviatiles. Faune de France (douxiéme partie). Libraire de la Faculte des Sciences. París; 483485, Fig. 474, 475. (Grafía de género posterior incorrecta).

\section{DESCRIPCIÓN:}

Concha: Muy grande, dextrógira y alargada; formada por 6-8 vueltas de espira, constituyendo la última los $2 / 3$ de la altura de la concha. Las suturas entre las vueltas son profundas. El ápice de la concha es puntiagudo. La abertura es ovalada, ligeramente puntiaguda en la parte superior y con una altura similar a la mitad de la concha. El ombligo está recubierto por la columela. La concha presenta unas estrías longitudinales y transversales muy finas que le confieren un aspecto reticulado (Figura 8).

Animal: De color grisáceo y con el manto negro con manchas irregulares blancas (Figuras 41-42). Prepucio mucho más grande que la vaina del pene, de aspecto globoso. Conducto deferente muy largo. Próstata con muchos pliegues. Vagina alargada y estrecha. El conducto de la espermateca se ensancha gradualmente en forma de embudo en la unión con la vagina.

DiMENSIONES: Diámetro máximo 16-35 mm; altura 35-80 mm. 
HÁBITAT: Vive en aguas estancadas o con corriente débil, soportando una salinidad de hasta el 7\% (Girod et al., 1980).

DisTRIBUCIÓN: Norte de América, Europa, gran parte de Asia (Hubendick, 1951), Argelia, Marruecos y Egipto (Brown, 1980) e introducida en Tasmania y Nueva Zelanda (Zhadin, 1965). Es muy rara en la Península Ibérica (Vidal Abarca \& Suárez, 1985). En la Comunidad de Madrid tan solo se localizó en un centro de jardinería al aire libre de la Moraleja (Alcobendas), por lo que debe tratarse de una introducción accidental (Figura 86).

LOCALIDADES: 30; 31; 233.

\section{Stagnicola palustris (Müller, 1774)}

\section{SINONIMIA:}

Buccinum palustre Müller, 1774. Vermium Terrestrium et Fluviatilium seu animalium infusorium, helminthicorum, et testaceorum non marinorum succincta historia. Heinick and Faber, Havnia and Lipsia. xxxvi $+1-214+\mathrm{x}$ [unpaginated indices].

Helix crassa Razoumowski, 1789. Hist. Mont Jorat, 1, p.276 (non Da Costa).

Limnaea turricula Held, 1836. Aufzählung der in Bayern lebenden Mollusken. Isis 29, 4 : 271-282. (Grafía de género posterior incorrecta).

Limnaea variabilis Millet, 1854, Mem.Soc. Linn. Maine-etLoire, 1, p.51. (Grafía de género posterior incorrecta).

Limnaea renoufi Servain, 1881. Histoire malacologique du lac Balaton en Hongrie, p.74. (Grafía de género posterior incorrecta).

Limnaea contorta Bourguignat in Servain, 1881. Histoire malacologique du lac Balaton en Hongrie, p.61. (Grafía de género posterior incorrecta).

Limnaea palustris (Müller): Draparnaud, 1801. Tableau des Mollusques terrestres et fluviatiles de France, p.50. (Grafía de género posterior incorrecta).

Limnaea (Stagnicola) palustris (Müller): Germain, 1931. Mollusques terrestres et fluviatiles. Faune de France (douxiéme partie). Libraire de la Faculte des Sciences. París, 497499, Figs. 505-514. (Grafía de género posterior incorrecta).

Stagnicola palustris (Müller): Glöer \& Meier-Brook, 1998. Süsswassermollusken, Deuscher Jugendbund für Naturbeobachtung, Hamburg, 50.

\section{DESCRIPCIÓN:}

Concha: Sólida, dextrógira, fusiforme, con el ápice agudo, con 6-7 vueltas de espira de crecimiento lento siendo la última grande y poco engrosada. La abertura es oval, aguda, estrecha y constituye $1 / 2-1 / 3$ de la altura total de la concha. Las suturas están bastante marcadas. De color córneo, rojizo, con estrías longitudinales y transversales que le confieren un patrón reticulado (Figura 9).

Animal: De color gris oscuro (Figura 43). La vaina del pene es generalmente más corta que el prepucio. Presenta dos músculos retractores del pene, uno insertado en el extremo de éste y el otro, doble, en la parte distal del prepucio. La pared de la próstata tiene, a menudo, más de un pliegue. Espermateca piriforme.

DiMENSIONES: Diámetro máximo 9-18 mm; altura 17-35 mm.

HÁBITAT: En ambientes leníticos, preferentemente en aguas estancadas como pantanos, lagunas, charcas, etc. donde prefiere ambientes con abundante vegetación. Tolera bien la disminución del oxígeno disuelto del agua y es muy resistente a la desecación (Girod et al., 1980).

DiSTRIBUCIÓN: Europa, Asia incluyendo Arabia Saudí y posiblemente Norte América (Hubendick, 1951 en Vidal Abarca \& Suárez, 1985). También en Argelia, Marruecos y Egipto (Brown, 1980). En la Península Ibérica se ha citado en Cataluña, Valencia, Burgos, Douro Litoral (Vidal Abarca \& Suárez, 1985), Ciudad Real (Ramos \& Aparicio, 1985) y Huelva (Pérez-Quintero et al., 2004) aunque según nuestras propias observaciones también se halla en la Laguna de Somolinos (Guadalajara). En la Comunidad de Madrid tan sólo se encontraron unas conchas en la Laguna de San Juan (Figura 86).

LOCALIDADES: 107.

\section{Galba truncatula (Müller, 1774)}

SINONIMIA:

Buccinum truncatulum Müller, 1774. Verm. Terr. Fluv. Vol.2, p. 130.

Helix truncatula (Müller): Gmelin, 1790. Caroli a Linné, Sistema Naturae ed. 13, vol. 1, p. 3659.

Bulimus obscurus Poiret, 1801. (non Müller). Coqu. Fluv. et terr. Obs. Dép. Aisne Paris, p.35 Limneus minutus Draparnaud, 1801. Tab. Moll. Terr. Fluv. France, p. 51.

Limneus truncatulus (Müller): Jeffreys, 1830. Tr. Linn. Soc. London, 16 (2), p. 377. (Grafía de género posterior incorrecta). Limnaea gingivata Goupil, 1835. Hist. Moll. Terr. Fluv., p.65. (Grafía posterior incorrecta).

Limnophysa truncatula (Müller): Beck, 1838. Index. Moll. Mus. Ch. Fred., (2), p. 112. (Grafía de género posterior incorrecta).

Limnaea truncatula (Müller): Wood, 1848. Crag. Moll. (Pal. Soc. I) Mar., p. 8. (Grafía posterior incorrecta).

Limnaea pumila Locard, 1893. Conchiol. Franç., p 32. (Grafía de género posterior incorrecta).

Limnaea moquini Locard, 1893. Conchiol. Franç., p 32. (Grafía de género posterior incorrecta).

Limnaea (Fossaria) truncatala (Müller): Westerlund, 1898. Ann. Mus. Zool. Acad. Imp. Sciec. St. Petersbourg. 155 pp. (Grafía de género posterior incorrecta).

Limnaea (Galba) truncatula; Germain 1931. Moll. Terrestres Fluv. Faune de France (douxiéme partie): 501-503, Fig. 515. (Grafía de género posterior incorrecta).

Galba truncatula (Müller): Glöer \& Meier-Brook, 1998. Süsswassermollusken, Deuscher Jugendbund für Naturbeobachtung, Hamburg, 53. 


\section{DESCRIPCIÓN:}

Concha: De pequeñas dimensiones, dextrógira, ovoide, más alta que ancha y constituida por 4-6 vueltas de espira. Las primeras vueltas son de crecimiento regular, mientras que la última es más hinchada y constituye $\operatorname{los} 2 / 3$ de la altura total de la concha. Las suturas son muy profundas y el ápice no es agudo. El ombligo está parcial o totalmente cubierto por el eje columelar. La abertura es oblicua, ovalada y constituye $1 / 3$ de la altura de la concha. La concha es de color castaño amarillento con finas estrías (Figura 10).

Animal: De color gris oscuro con el manto negro y manchas circulares claras (Figura 44). En cuanto al aparato genital, posee un prepucio mucho más largo que la vaina del pene. La vagina se encuentra a la derecha de la glándula nidamental. El conducto de la espermateca, que mantiene una anchura prácticamente idéntica en todo su recorrido, describe un arco en la superficie de la espermateca, alejándose de esta por el borde la próstata hasta su zona media donde se introduce entre la próstata y la glándula nidamental. En la unión con la vagina, situada a la derecha de la glándula nidamental, el conducto de la espermateca se ensancha gradualmente a modo de embudo.

DiMENSIONES: Diámetro máximo 4-6 mm; altura 6$10 \mathrm{~mm}$.

HÁBITAT: En aguas poco profundas entre el limo o en zonas de corriente cuando existe vegetación sumergida. También habita charcas con vegetación, fuentes y pilones. Tolera la presencia de materia orgánica y una salinidad del $0,5 \%$ (Girod et al., 1980). Es una especie que puede resistir mucho tiempo emergida en zonas donde exista humedad (Adam, 1960; Rolán, 2001).

DISTRIBUCIÓN: Distribución holártica (Hubendick, 1951) incluyendo el suroeste de Arabia y parte de África (Brown, 1980). Ampliamente distribuida por la Península Ibérica (Vidal Abarca \& Suárez, 1985). En la Comunidad de Madrid ha sido citada con anterioridad por Pérez Arcas (1863, como Limnaea minu$\mathrm{ta}$, diciendo de ella que es una de las especies más comunes de los alrededores de Madrid), Westerlund (1898, como Limnaea (Fossaria) truncatala en los aluviones del río Jarama) y Álvarez (1969). En base a nuestros muestreos, y coincidiendo con las observaciones de Pérez Arcas (1863), la especie es muy común en la Comunidad de Madrid, distribuyéndose por todas sus cuencas fluviales (Figura 86).

LOCALIDADES: $2 ; 8 ; 23 ; 36 ; 37 ; 40 ; 47 ; 52 ; 69 ; 72 ; 73 ; 74 ; 91$ $100 ; 119 ; 128 ; 135 ; 137 ; 138 ; 139 ; 140 ; 141 ; 148 ; 149 ; 156$; $161 ; 162 ; 163 ; 171 ; 173 ; 176 ; 183 ; 184 ; 194 ; 199 ; 201 ; 230$; $272 ; 303 ; 311 ; 362 ; 402 ; 420 ; 446$.

\section{Radix auricularia (Linnaeus, 1758)}

SINONIMIA:

Helix auricularia Linnaeus, 1758. Systema naturae per regna tria naturae..., 10 $0^{\mathrm{a}}$ Edición p.774, $\mathrm{n}^{\circ} 617$.

Buccinum auricula Müller, 1774. Verm. Terre. Fluv. Vol. 2, p. 126.

Limneus auricularius (Linnaeus): Draparnaud, 1801, Tabl. Moll. Terr. Fluv., p. 48. (Grafía de género posterior incorrecta).

Lymneus acronicus Studer, 1820. Anz. Allg. Schweiz. Ges., 3 (12), p. 93. (Grafía de género posterior incorrecta).

Limnaea canalis Graells in Dupuy, 1851. Hist. Nat. Moll. France, fasc 5, p.482. (Grafía de género posterior incorrecta). Limnaea auricularia var. canalis Moquin-Tandon,1855. Hist. Nat Moll Terr Fluv. France, 1, p.463. (Grafía de género posterior incorrecta).

Limnaea ampulla Küster, 1862, Conch. Cab. P.12. (Grafía de género posterior incorrecta).

Limnaea multizonata Bourguignat in Servain, 1881. Hist. Malac. lac Balaton Hongrie, p.58. (Grafía de género posterior incorrecta).

Limnaea stricta Locard, 1893. Conchyol. Franç., p.26. (Grafía de género posterior incorrecta).

Limnaea (Radix) auricularia (Linnaeus): Germain, 1931. Moll. Terr. Fluv. Faune de France (douxiéme partie): 487-488, Figs. 477. (Grafía de género posterior incorrecta).

Radix auricularia (Linnaeus): Glöer \& Meier-Brook, 1998. Süssw. Moll.,Hamburg, 54.

\section{DESCRIPCIÓN:}

Concha: Dextrógira y globosa. Presenta cuatro vueltas de espira, siendo las tres primeras poco convexas y pequeñas y la última muy grande, redondeada, ventruda, ocupando la mayor parte de la concha y muy frecuentemente sobrepasando las primeras vueltas, que a su vez forman una pequeña punta. Sutura muy profunda a lo largo de la última vuelta. La abertura es muy grande y en forma de oreja, igual a $5 / 6$ de la altura de la concha. Borde columelar replegado por encima del ombligo. Color amarillo córneo (Figura 11).

Animal: El cuerpo es amarillento; el manto presenta manchas claras sobre un fondo oscuro que frecuentemente es visible por transparencia a través de la concha (Figuras 45-46). El borde del manto siempre presenta una franja de pigmentación en el margen, formada por puntos con el borde liso. En el aparato genital se diferencia un conducto deferente fino que sale del borde derecho de la próstata y un canal de la espermateca largo, bien delimitado y con la misma anchura en todo su recorrido (Falniowski, 1980).

DiMENSIONES: Diámetro máximo 20-30 mm; altura 25-30 mm.

HÁBITAT: Vive en aguas estancadas o con poca corriente y con abundante vegetación acuática.

Distribución: Europa, Asia, Norte de África y Norteamérica (Hubendick, 1951). Tiene una amplia 




Figs. 13-20.- Conchas de 13) Anisus (Anisus) spirorbis (Linnaeus, 1758). 14) Anisus (Disculifer) vortex (Linnaeus, 1758). 15) Gyraulus (Gyraulus) albus (Müller, 1774). 16) Gyraulus (Gyraulus) chinensis (Dunker, 1848). 17) Gyraulus (Torquis) laevis (Alder, 1838). 18) Gyraulus (Armiger) crista (Linnaeus, 1758). 19) Hippeutis complanatus (Linnaeus, 1758). 20) Planorbarius metidjensis (Forbes, 1838).

Figs. 13-20.- Shells of 13) Anisus (Anisus) spirorbis (Linnaeus, 1758). 14) Anisus (Disculifer) vortex (Linnaeus, 1758). 15) Gyraulus (Gyraulus) albus (Müller, 1774). 16) Gyraulus (Gyraulus) chinensis (Dunker, 1848). 17) Gyraulus (Torquis) laevis (Alder, 1838). 18) Gyraulus (Armiger) crista (Linnaeus, 1758). 19) Hippeutis complanatus (Linnaeus, 1758). 20) Planorbarius metidjensis (Forbes, 1838). 
distribución en la Península Ibérica (Vidal Abarca \& Suárez, 1985). Citada previamente para Madrid por Graells (1846, como Limnaea canalis) Nieto, (1967, en el río Manzanares a su paso por el puente de la carretera que une Colmenar Viejo y Manzanares el Real), por Álvarez (1969) y Gregorides (1971, en el río Samburiel a su paso por Cerceda y en el río Manzanares a su paso por Hoyo de Manzanares y por el Pardo). En las colecciones del Museo Nacional de Ciencias Naturales de Madrid existe una muestra recolectada en Alcalá de Henares. Nosotros la hemos encontrado en los ríos Perales, Lozoya, Manzanares, Guadalix y Jarama y en los arroyos Fresnera y Valdesaelices (Figura 86).

LOCALIDADES: $23 ; 24 ; 28 ; 39 ; 47 ; 52 ; 53 ; 57 ; 59 ; 85 ; 91 ; 93 ; 94$; $153 ; 154 ; 158 ; 165 ; 172 ; 176 ; 180 ; 181 ; 211 ; 212 ; 232$.

\section{Radix balthica (Linnaeus, 1758)}

SINONIMIA:

Helix balthica Linnaeus, 1758. Syst. Nat. $10^{\mathrm{a}}$ ed. p. $775, \mathrm{n}^{\circ} 618$.

Buccinum peregrum Müller, 1774. Verm. Terr. Fluv.

Helix limosa Linnaeus, 1758. Syst. Nat. $10^{\mathrm{a}}$ ed. p. 774 , no 615

Buccinum medium Studer in Coxe, 1789. Trav. Switz., vol 3, p. 433.

Helix putris Pennant, 1777. Brit. Conchiol., $4^{\circ}$ edit, p.121 (non Linnaeus).

Limneus pereger (Müller): Draparnaud, 1801. Tabl. Moll. Terr. Fluv. France, p.48. (Grafía de género posterior incorrecta).

Limneus ovatus Draparnaud, 1805. Hist. Nat. Moll. France, p. 50. (Grafía de género posterior incorrecta).

Limnaea intermedia Férusac in Lamarck, 1822. Hist. Nat. Anim. sans vert. Paris. p162. (Grafía de género posterior incorrecta).

Limnaea peregra (Müller): Dupuy, 1850. Hist. Nat. Moll

France, fasc. 4, p.472. (Grafía de género posterior incorrecta).

Limnaea blauneri Dupuy, 1850. Hist. Nat. Moll France, fasc 4, p.473. (Grafía de género posterior incorrecta).

Limnaea plagiostoma Bourguignat in Servain, 1881. Hist. Malac. lac Balaton, Hongrie, p.55. (Grafía de género posterior incorrecta).

Limnaea meridionalis Locard, 1893. Conchyol. Franç., p.36. (Grafía de género posterior incorrecta).

Limnaea prolata Locard, 1893. Conchyol. Franç., p.37. (Grafía de género posterior incorrecta).

Limnaea (Radix) peregra (Müller): Germain, 1931. Mollusques terrestres et fluviatiles. Faune de France (douxiéme partie): 494-497. (Grafía de género posterior incorrecta).

Radix peregra (Müller): Glöer \& Meier-Brook, 1998. Süssw. Moll., Hamburg, p. 55.

Radix balthica (Linnaeus): Bargues, Vigo, Horak, Dvorak, Patzner, Pointier, Jackiewicz, Meier-Brook \& Mas-Coma, 2001. Infection, Genetics and Evolution 1: 85-107.

Radix balthica (Linnaeus): Falkner et al., 2002. Mollusques continentaux de France. Liste de Référence annotée et Bibliographie. Publ. Mus. natl. Hist. nat. Paris, p. 95

\section{DESCRIPCIÓN:}

Concha: Dextrógira, aunque hay algunos individuos levógiros no observados en Madrid. Forma ovoide con 4 a 5 vueltas de espira abombadas. Las primeras, que están muy poco desarrolladas, forman un ápice agudo y la última, que es muy grande (igual a $4 / 5$ de la altura total de la concha), crece rápidamente dando un aspecto ventrudo a la concha. La abertura es ovalada, más alta que ancha, con una altura próxima a 2/3 de la concha. La columela es gruesa y retorcida y frecuentemente recubre al ombligo. El peristoma es de color claro, fino y algo ensanchado en la parte inferior. Concha de color castaño claro (Figura 12).

Animal: La pigmentación del manto consiste en unas manchas claras sobre un fondo pardo claro, a veces algo amarillento (Figuras 47-48). El borde del manto no suele presentar la franja de puntos que aparece en $R$. auricularia, no obstante, cuando está presente, no es continua y el borde de los puntos es dentado. El aparato genital presenta un conducto deferente que sale de la zona ventral de la próstata más grueso que en $R$. auricularia, y una espermateca que, o bien carece de canal o, bien, en caso de estar presente, no está bien delimitado y se va estrechando gradualmente hacia la vagina.

DimENSIONES: Diámetro máximo 8-20 mm; altura 12-30 mm.

HÁBITAT: Se localiza en casi todos los medios límnicos aunque es más frecuente en aguas estancadas o de poca corriente. En cuanto al sustrato no presenta preferencias, habiéndose encontrado sobre cantos rodados, rocas, limos y macrófitos.

Distribución: Europa, Irak, Islas Canarias y Noroeste de África (Hubendick, 1951; Brown, 1980). Muy común en la Península Ibérica (Vidal Abarca \& Suárez, 1985). Citada previamente por Pérez Arcas (1863) como Limnaea intermedia. Álvarez y Selga (1967) la citan en una fuente-abrevadero a la entrada de Meco, en la fuente de la plaza de Bustarviejo, en la Fuente de los Chopos a la salida del mismo pueblo y en la Laguna de Ontígola. Gregorides (1971) la cita en el río Samburiel a su paso por Cerceda, en el río Manzanares a su paso por Hoyo de Manzanares y en el río Jarama a su paso por Titulcia. También fue hallada en la Laguna de Ontígola por Álvarez y Agulló (1981). Otras citas para Madrid corresponden a Nieto (1967, en el río Manzanares a su paso por el puente de la carretera que une Colmenar Viejo y Manzanares el Real) y Alvarez (1969). En base a nuestros propios muestreos, es una de las especies más frecuentes en la Comunidad de Madrid, encontrándose en todas sus cuencas fluviales (Figura 86).

LOCALIDADES: $1 ; 11 ; 25 ; 26 ; 29 ; 36 ; 48 ; 49 ; 60 ; 61 ; 71 ; 72 ; 83$; $107 ; 114 ; 119 ; 128 ; 130 ; 133 ; 135 ; 136 ; 138 ; 139 ; 140 ; 143$; 
$144 ; 148 ; 158 ; 161 ; 164 ; 182 ; 183 ; 184 ; 187 ; 188 ; 222 ; 224$. $230 ; 277 ; 284 ; 331 ; 334 ; 445 ; 453$.

\section{Anisus (Anisus) spirorbis (Linnaeus, 1758)}

SINONIMIA:

Helix spirorbis Linnaeus, 1758. Sist. Natur. $10^{\mathrm{a}}$ ed. I Vol., p. $770, \mathrm{n}^{\circ} 588$.

Planorbis spirorbis (Linnaeus): Müller, 1774. Verm. Terr. Fluv. Vol. 2, p. 161

Planorbis rotundatus Poiret, 1801. Coq. Aisne p. 93.

Planorbis (Paraspira) spirorbis (Linnaeus): Bofill y Haas, 1920. Estudi sobre la malacologia de les valls pirenaiques. V. Conca del Llobregat. Treb. Mus. Cienc. Nat. Barcelona, III, p. 381-831.

Planorbis (Spiralina) spirorbis (Linnaeus): Germain, 1931. Moll. Terr. Fluv. Faune de France (douxiéme partie) : 532, Fig. 542.

Anisus (Anisus) spirorbis (Linnaeus): Zhadin, 1965. Moll. U.S.S.R. Acad. Sci. U.S.S.R. No. 46: 284-287.

\section{DESCRIPCIÓN:}

Concha: De forma discoidal y constituida por entre 4,5 y 5,5 vueltas de espira de crecimiento lento, siendo la última más ancha que la precedente. Ambas caras están umbilicadas y presentan suturas evidentes. Superficie con estrías transversales. La abertura es redondeada y en algunos ejemplares presenta un fuerte labio blanco. El color es córneo claro brillante (Figura 13).

Animal: De color grisáceo. Presenta tentáculos relativamente largos. En el sistema genital masculino el prepucio presenta un estrechamiento en el tercio posterior. La vaina del pene se une al prepucio mediante una prolongación tubular de aproximadamente $1 / 2$ de la longitud de la vaina.

DiMENSIONES: Diámetro máximo 6-7 mm; altura 1,3-1,5 mm.

HÁBITAT: Vive en aguas tranquilas tanto de ambientes lóticos como leníticos.

Distribución: Europa y Siberia (Zhadin, 1965). En la Península Ibérica ha sido citada en Gerona, Barcelona, Castellón, Valencia, Zaragoza, Ciudad Real, Granada, Sevilla, Pontevedra, Bieira Litoral, Douro Litoral, Extremadura y Minho (Vidal Abarca \& Suárez, 1985). En la Comunidad de Madrid ha sido citada previamente por Álvarez (1969). En las colecciones del Museo Nacional de Ciencias Naturales se conserva una muestra recolectada en 1892 en el río Manzanares. La única localidad donde se ha hallado la especie en el contexto de este trabajo ha sido en el río Henares, en las proximidades de Alcalá de Henares (Figura 86).

LOCALIDADES: 462.

\section{Anisus (Disculifer) vortex (Linnaeus, 1758)}

SINONIMIA:

Helix vortex Linnaeus, 1758. Syst. Nat. $10^{\mathrm{a}}$ ed. I Vol. p. $770, \mathrm{n}^{\mathrm{o}} 583$.

Helix planorbis Da Costa, 1778. Hist. Nat. Test. Bri., p. 254.

Planorbis tenellus Studer, 1789. Trav. Switz., vol. 3, p. 392.

Planorbis vortex (Linnaeus): Müller, 1774. Verm. Terr. Fluv., vol.2, p. 158

Anisus (Spiralina) vortex (Linnaeus): Zhadin, 1965. Moll. U.S.S.R. Acad. Sci. U.S.S.R., 46: 284-287.

Anisus (Disculifer) vortex (Linnaeus): Falkner, Bank \& Proschwitz, 2001. Heldia, 4 (1/2): p. 29.

DESCRIPCIÓN:

Concha: Discoidal pero más aplanada que la especie anterior, constituida por 5-7 vueltas de espira de crecimiento lento, siendo la última casi dos veces más ancha que la anterior y presentando una quilla aguda situada por encima de la línea media. El lado inferior es cóncavo mientras que el superior es aplanado. Abertura ovalada y oblicua. Color córneo aunque frecuentemente cubierta por incrustaciones oscuras (Figura 14).

Animal: No hemos podido comprobar la anatomía de esta especie ya que sólo se dispone de la concha de un ejemplar.

Dimensiones: Diámetro máximo 6-9 mm; altura 0,8-1,1 mm.

HÁBITAT: Aguas tranquilas con abundante vegetación. Se alimenta principalmente de algas (Girod et al., 1980).

DisTRIBUCIÓN: Europa y Asia occidental (Girod et al., 1980). En la Península Ibérica ha sido citada por Graells (1846) para Cataluña aunque según Haas (1929) se trata de una cita que ha quedado sin comprobar, y por Locard (1899) para Douro Litoral en Portugal. Citada en Madrid por Pérez Arcas (1863, como Planorbis vortex). En las colecciones del Museo Nacional de Ciencias Naturales de Madrid se conserva la concha de un único ejemplar recolectado en el río Manzanares en 1892. Por nuestra parte, no hemos localizado la especie en ninguno de los lugares muestreados, por lo que es probable que la especie se haya extinguido en la región.

\section{Gyraulus (Gyraulus) albus (Müller, 1774)}

\section{SINONIMIA:}

Planorbis albus Müller, 1774. Verm. Terr. Fluv., vol.2, p. 164. Planorbis hispidus Draparnaud, 1805. Hist. Nat. Moll. France, p. 43.

Planorbis crosseanus Bourguignat, 1862. Malac. lac QuatreCantons, p.42.

Gyraulus albus (Müller): Meier-Brook, 1983. Malacologia, 23 $(1-2): 1-113$

Gyraulus (Gyraulus) albus (Müller): Falkner, Bank \& Proschwitz, 2001. Heldia, 4 (1/2): p. 29. 


\section{DESCRIPCIÓN:}

Concha: De color córneo claro (Figura 15). Forma discoidal y constituida por 4,25 vueltas de espira de crecimiento rápido. La cara superior está profundamente umbilicada, mientras que la inferior es más aplanada. Presenta estrías transversales y longitudinales formando una escultura reticular bien desarrollada. El periostraco puede presentar pequeñas protuberancias en forma de "pelillos". La abertura es elíptica y está girada de forma oblicua hacia arriba.

Animal: De color gris claro (Figuras 49-50). La pigmentación del manto es muy débil a excepción de una línea gris oscuro en el lado derecho, paralela al músculo columelar. En individuos que han sido narcotizados antes de ser fijados, los bordes del riñón son rectos. El complejo peneal es muy similar al de G. laevis. El número de divertículos de la próstata es ligeramente superior al de $G$. laevis (entre 13 y 20) y están dispuestos regularmente.

DimENSIONES: Diámetro máximo 4-7 mm; altura $1,2-1,8 \mathrm{~mm}$.

HÁBITAT: Vive en aguas dulces estancadas o con poca velocidad de corriente, entre las plantas acuáticas. Puede soportar una salinidad del 3\%, así como periodos de sequedad, enterrándose en los sedimentos del cauce (Girod et al., 1980).

DiSTRIBUCIÓN: Europa occidental hasta Asia central (Meier-Brook, 1983). En la Península Ibérica se distribuye ampliamente (Vidal Abarca \& Suárez, 1985; Martínez-López et al., 1988; Larraz \& Equisoain, 1993). Citada previamente para Madrid por Álvarez (1969) y Prat (1978; 1979, en el Embalse de Santillana). Nosotros la hemos encontrado en los ríos Perales, Aulencia, Guadalix, Lozoya y Jarama y en los arroyos Angostura, Candalosa, Fresnera y Albalá (Figura 86).

LOCALIDADES: $2 ; 27 ; 37 ; 42 ; 52 ; 53 ; 82 ; 83 ; 85 ; 90 ; 91 ; 130$; $133 ; 158 ; 160 ; 165 ; 171 ; 172 ; 334$.

\section{Gyraulus (Gyraulus) chinensis (Dunker, 1848)}

SINONIMIA:

Planorbis chinensis Dunker, 1848. Proc. Zool. Soc. London, 16 (182), p.41

Gyraulus chinensis (Dunker): Meier-Brook, 1983.

Malacologia, 23 (1-2):1-113.

Gyraulus (Gyraulus) chinensis (Dunker): Falkner, Bank \& Proschwitz, 2001. Heldia, 4 (1/2): p. 29.

DESCRIPCIÓN:

Concha: Discoidal formada por 3,5-4 vueltas de espira de crecimiento rápido. El borde de la última vuelta es redondeado o moderadamente angulado. En algunos ejemplares el periostraco forma un ribete periférico. Líneas de crecimiento pronunciadas. Concha poco brillante de color claro a marrón córneo (Figura 16).

Animal: De color gris claro (Figura 56). El manto presenta una pigmentación muy contrastada que es visible por transparencia. La bursa copulatrix es globosa y en ocasiones alargada. La próstata presenta entre 8 y 20 divertículos.

Dimensiones: Diámetro máximo 3,5-4 mm; altura 1,2-1,3 $\mathrm{mm}$.

HÁBITAT: Es típico de arrozales y zonas próximas, aunque en la Comunidad de Madrid se ha encontrado en el río Manzanares donde no existe este tipo cultivos.

DISTRIBUCIÓN: Es una especie originaria de Asia, introducida en Italia y en La Camarga francesa a través del cultivo de los cultivos de arrroz (MeierBrook, 1983). También se ha encontrado en Holanda y en Guinea Bissau (Brown et al, 1998). En la Península Ibérica ha sido citada en la Cuenca del Segura (Gómez \& Vidal-Abarca, 1988; VidalAbarca et al. 1991) en la Comunidad Valenciana (Martinez-Ortí \& Robles, 2003) y en Portugal (Simoes, 1996). En la Comunidad de Madrid sólo se ha localizado en el río Manzanares en las proximidades de Colmenar Viejo, siendo la primera cita para la provincia (Figura 87).

LOCALIDADES: 56.

\section{Gyraulus (Torquis) laevis (Alder, 1838)}

\section{SINONIMIA:}

Planorbis laevis Alder, 1838. Trans. Nat. Hist. Soc. Northumberland, 1838, p.337. (Falta confirmación MAAZ) Planorbis thermalis Westerlund, 1885. Fau. Palaerct. Reg. Binneconch., 5, p.83.

Gyraulus laevis (Alder): Meier-Brook, 1983. Malacologia, 23 $(1-2): 1-113$

Gyraulus (Torquis) laevis (Alder): Falkner, Bank \& Proschwitz, 2001. Heldia, 4 (1/2): p. 29.

\section{DESCRIPCIÓN:}

Concha: Forma discoidal y contorno siempre redondeado. Constituida por 3,5 vueltas de espira separadas por profundas suturas. Presenta estrías transversales irregulares pero no estrías espirales, por lo que nunca presenta escultura reticular. La abertura es redondeada, ligeramente diagonal y no difiere apenas de la última vuelta. El color es córneo-marrón (Figura 17).

Animal: De color grisáceo, con el manto escasamente pigmentado (Figuras 54-55). El contorno del 




Figs. 21-25.- Conchas de: 21) Ancylus fluviatilis Müller, 1774. 22) Ferrissia (Pettancylus) clessiniana (Jickeli, 1882). 23) Physella (Costatella) acuta (Drapanaud, 1805). 24) Oxyloma (Oxyloma) elegans (Risso, 1826). 25) Oxyloma sarsii (Esmark, 1886).

Figs. 21-25.- Shells of: 21) Ancylus fluviatilis Müller, 1774. 22) Ferrissia (Pettancylus) clessiniana (Jickeli, 1882). 23) Physella (Costatella) acuta (Drapanaud, 1805). 24) Oxyloma (Oxyloma) elegans (Risso, 1826). 25) Oxyloma sarsii (Esmark, 1886).

riñón, visible por transparencia, es ondulado. El complejo peneal de las especies del género Gyraulus está formado por un prepucio y una vaina que alberga el pene, en cuyo extremo presenta un estilete córneo. La próstata de esta especie presenta entre siete y nueve divertículos de forma y disposición irregulares.

DIMENSIONES: Diámetro máximo 4-5 mm; altura 1$1,5 \mathrm{~mm}$.
HÁBITAT: En aguas limpias, estancadas o con ligera corriente. Capaz de resistir periodos de sequedad (Rolán, 2001).

DisTRIBUCIÓN: Distribuida por Europa occidental (Meier-Brook, 1983). En la Península Ibérica ha sido citada en las provincias de levante (desde Cataluña hasta Murcia), Zaragoza, Huelva, Soria, Granada, Baixo Alentejo, Estremadura y Beira 
Litoral (Vidal-Abarca \& Suárez, 1985). En la Comunidad de Madrid fue localizada por Graells a mediados del siglo XIX en un pilón de El Pardo (inédito). En base a nuestros muestreos, la especie se distribuye por los tramos medios de los ríos Perales, Aulencia, Manzanares y Guadalix. También se ha localizado en el Arroyo Fresnera, en la laguna del Campillo y en canales de riego en las proximidades de Fuentidueña de Tajo (Figura 87).

LOCALIDADES: $26 ; 57 ; 82 ; 83 ; 133 ; 136 ; 140 ; 158 ; 160 ; 284$; $334 ; 431 ; 458$.

\section{Gyraulus (Armiger) crista (Linnaeus, 1758)}

\section{SINONIMIA:}

Nautilus crista Linnaeus, 1758. Syst. Nat. $10^{\mathrm{a}}$ ed. I Vol. p. 779. Turbo nautileus Linnaeus,1767. Syst. Nat. $10^{\mathrm{a}}$ ed. 12, p.1241.

Planorbis imbricatus Müller, 1774. Verm. Terr. Fluv., vol.2, p. 165.

Planorbis cristatus Draparnaud, 1805. Hist. Nat. Moll. France, p. 44.

Planorbis nautileus Dupuy, 1850. Hist. Nat. Moll France, fasc $4: 331-458$.

Planorbis paladilhi Moitessier, 1867. Rev. Mag. Zool., 2, 19, p.424.

Armiger crista (Linnaeus): Ehrmann, 1933. Tier. Mitt.,1, p.172. Gyraulus (Armiger) crista (Linnaeus): Soos, 1935. Allat. Közlemények, 32, p.28.

\section{DESCRIPCIÓN:}

Concha: De color gris blanquecino a córneo oscuro (Figura 18). Forma discoidal y constituida por 3 vueltas de espira de crecimiento rápido, siendo la última muy ancha con una carena ligeramente marcada en su zona media. La cara superior es profundamente umbilicada y la inferior plana. Finamente estriada o con costillas muy visibles. La abertura se inclina hacia arriba por encima de la penúltima vuelta.

Animal: Débilmente pigmentado, con la masa cefalopedal de color gris claro y el manto con pigmentación clara y difusa (Figuras 51-53). Los bordes del riñón son ondulados. Los divertículos de la próstata son de longitud reducida, de forma que la glándula queda casi reducida al conducto de la próstata.

DiMENSIONES: Diámetro máximo 2-2,8 mm; altura 0,75-0,9 $\mathrm{mm}$.

HÁBITAT: Vive en ríos, arroyos y lagunas entre la vegetación acuática o bajo las piedras. Resiste periodos de sequía introduciéndose en el limo o bajo hojas muertas (Girod et al, 1980)

DisTRIBUCIÓN: Paleártica, desde la península Ibérica e Inglaterra hasta el estrecho de Bering; también en
Norteamérica (Meier-Brook, 1983). En la Península Ibérica ha sido citada en Alicante, Barcelona, Gerona, Granada, Sevilla, Valencia, Zaragoza, Aveiro, Beira, Douro Litoral, Estremadura (Vidal Abarca \& Suárez, 1985) y Navarra (Larraz \& Equisoain, 1993). En la Comunidad de Madrid ha sido citada por Graells (1846, como Planorbis nautileus) y por Álvarez (1969, como Armiger crista en el Soto de Migas Calientes, en las inmediaciones del Real Jardín Botánico). En base a nuestras prospecciones, la especie se distribuye por los ríos Perales, Aulencia, Guadalix, Jarama y Henares y por los arroyos Angostura y Sotillo. También ha sido localizada en las lagunas de San Juan, Casasola, y del Campillo (Figura 87).

LOCALIDADES: $2 ; 16 ; 34 ; 42 ; 47 ; 82 ; 83 ; 133 ; 145 ; 146 ; 158$; $160 ; 172 ; 230 ; 239 ; 284 ; 289 ; 334 ; 377 ; 395 ; 395 ; 428 ; 428$; $431 ; 431$.

\section{Hippeutis complanatus (Linnaeus, 1758)}

SINONIMIA:

Helix complanata Linnaeus, 1758. Syst. Nat. $10^{\text {a }}$ ed. I Vol. p. $779, \mathrm{n}^{\circ} 579$.

Helix fontana Lightfoot, 1786. Phil. Trans. London, 76 (1), p. 165.

Helix lenticularis Alten, 1812. Conch. Augsburg, p. 35.

Planorbis lenticularis Hartmann, 1821. Neue Alpina I, p. 256.

Planorbis nitidus Gray in Turton, 1840. Man. Land Freshw. shells Brit. Is., London, p. 268. (non Müller).

Planorbis fontanus Dupuy ,1850. Hist. Nat. Moll France, fasc $4: 331-458$.

Planorbis fragilis Mousson in Moquin-Tandom, 1855. Hist. Nat. Moll. Terr. Fluv. France, p. 427.

Planorbis euphaeus Bourguignat, 1864. Malac. Algérie, en Hist. Nat. Anim.Afrique.,II: 380 pp.

Planorbis complanatus (Linnaeus): Draparnaud, 1805. Hist. Nat. Moll. France, p. XX

Hippeutis complanatus (Linnaeus): Hubendick, 1955. Trans. Zool. Soc. Lond. 28: 453-542.

Segmentina (Hippeutis) complanatus (Linnaeus): Macan, 1977. Freshw. Biol. Assoc. Sci. Publ., 13: 44 pp.

DESCRIPCIÓN:

Concha: Pequeña, fina y aplanada de forma lenticular con unas 3 a 4 vueltas de espira de crecimiento rápido. La última presenta una carena en su parte media y envuelve parte de la penúltima vuelta. El ápice está ligeramente hundido y el ombligo es estrecho. La abertura es más o menos triangular y el peristoma es simple y discontinuo. La pared de la concha es brillante, transparente y de color córneo claro (Figura 19).

Animal: Color grisáceo transparente. Los tentáculos son finos y alargados y de color oscuro. El pie es de color amarillento. La pseudobranquia es pequeña, estrecha, engrosada en el ápice y ligera- 
mente lobulada. Se ha observado la puesta adherida al ombligo (Figuras 57-58).

DiMENSIONES: Diámetro máximo 4-5 $\mathrm{mm}$; altura $0,8-1,5 \mathrm{~mm}$.

HÁBITAT: Vive en aguas estancadas con vegetación y fondos fangosos. Soporta los periodos de sequía enterrándose en el fango (Girod et al, 1980)

DisTRIBUCIÓN: Distribuido por Europa, Asia occidental (Girod et al, 1980) y el noroeste de África (Brown, 1980). En la Península Ibérica citado en Gerona, Sevilla, Valencia, Algarve, Baixo Alentejo, Beira Litoral, Douro Litoral, Estremadura y Minho (Vidal Abarca \& Suárez, 1985). En la Comunidad de Madrid ha sido citada previamente por Álvarez (1969) en el Soto de Migas Calientes, en las inmediaciones del Real Jardín Botánico. Nosotros la hemos encontrado en los ríos Aulencia y Guadarrama y en las lagunas de San Juan y Casasola (Figura 87).

LOCALIDADES: $16 ; 145 ; 230 ; 322 ; 334$.

Segmentina nitida (Müller, 1774)

SINONIMIA:

Planorbis nitidus Müller, 1774. Verm. Terr. Fluv., vol.2, p. 163. Panorbis complanatus Poiret, 1801. Coq., p.93.

Planorbis clausulatus Férussac, 1820. J. Phys., 90, p.301.

Nautilus lacustris Lightfoot, 1786. Phil. Trans. So.c, 75, p.163. Segmentina lineata, Fleming, 1828. Hist. Brit. Anim, p.279.

Segmentina lacustris (Müller): Swainson, 1840. Treat. Malac. p. 333.

Segmentina servaini, Bourguignat in Servain, 1881. Hist. Mal. lac Balaton, Hongrie, p. 86.

Segmentina microcephala Bourguignat in Servain, 1881. Hist. Mal. lac Balaton, Hongrie p. 88 .

Segmentina montgazoniana Bourguignat in Servain, 1881. Hist. Mal. lac Balaton, Hongrie, p.89.

Segmentina nitida (Müller): Zhadin, 1965. Moll. U.S.S.R. Acad. Sci. U.S.S.R., 46: 284-287.

Segmentina (Hippeutis) nitida (Müller): Macan, 1977. Freshw. Biol. Assoc. Sci. Publ., 13: 44 pp.

DESCRIPCIÓN:

Concha: Pequeña, aplanada y formada por 3-4 vueltas de espira de crecimiento rápido. La última está más dilatada, presenta una carena en su parte superior y envuelve a la precedente. La concha es muy convexa en la parte inferior y aplanada en la parte superior. La abertura es triangular ovalada.

Animal: Color oscuro. Tentáculos finos, filiformes y dilatados en la base. Pseudobranquia pequeña y lisa. En el último giro de la concha pueden observarse por transparencia tres lamelas internas claras que se disponen: una sobre el borde superior, otra sobre el inferior y otra sobre el borde parietal.
DimENSIONES: Diámetro máximo $5 \mathrm{~mm}$; altura 1,5 $\mathrm{mm}$.

HÁBitAT: En aguas estancadas o de corriente débil con vegetación acuática.

DistribuCión: Europa, Norte de Asia y parte de Asia Central (Zhadin, 1965). En la Península Ibérica ha sido citada en Barcelona, Gerona, Lérida, Sevilla, Valencia y Zaragoza (Vidal Abarca \& Suárez, 1985). En la Comunidad de Madrid citada por Graells (1846) y Pérez Arcas (1863) (ambos como Planorbis nitidus). En este trabajo no se ha encontrado ningún ejemplar.

\section{Planorbarius metidjensis (Forbes, 1838)}

\section{SINONIMIA:}

Planorbis metidjensis Forbes, 1838. Ann. Nat. Hist., 2, p. 254. Planorbis dufourii Graells, 1846. Cat. Mol. España, p. 11, lam. 1, figs. 11-15.

Planorbis aclopus Bourguignat, 1856. Rev. Mag. Zool., 11. p 135.

Planorbis agraulus Bourguignat 1864. Malac. Algerie, en Hist. Nat. Moll Nort de l'Afrique; II, pl. IX.

Planorbis benoiti Bourguignat 1864. Malac. Algerie, en Hist. Nat. Moll Nort de l'Afrique; II, pl. IX.

Planorbis (Planorbis) dufourei (Graells): Bofill \& Haas, 1920. Treb. Mus. Cienc. Nat. Barcelona, III, p. 576.

Coretus dufourei (Graells): Haas, 1929. Treb. Mus. Zool Barcelona., p. 378.

Coretus corneus metidjensis (Forbes): Álvarez \& Selga, 1967. Bol. R. Soc. Española Hist. Nat. (Biol), 65:171-197.

Planorbarius metidjensis (Forbes): Álvarez, 1969. Malacologia, 9(1): 53-57.

DESCRIPCIÓN:

Concha: Con tres a cuatro vueltas de espira redondeadas y enrolladas en un solo plano, de forma que la parte superior es cóncava mientras que la inferior es casi plana. Presenta unas estrías transversales y espirales que le confieren un aspecto ajedrezado, sobre todo en las primeras vueltas. Las suturas son profundas. La apertura es grande, redondeada y un poco oblicua. El color es amarillo pálido (Figura 20).

Animal: de color oscuro rojizo, con los tentáculos finos y largos típicos de la familia planorbidae. El poro reproductor femenino está cerca del pneumostoma y el masculino detrás del tentáculo izquierdo. El complejo del pene, de gran importancia para la sistemática de las especies del género Planorbarius, está formado casi exclusivamente por un prepucio muy desarrollado, piriforme, en cuyo extremo posterior más dilatado presenta una pequeña protuberancia, el saco del pene. Este alberga un pene de pequeñas dimensiones que carece de apéndices. Las puestas están formadas por una masa gelatinosa 
transparente de tono algo rojizo, con 30-60 cápsulas en su interior, cada una de ellas con un huevo. Se han hallado en primavera (abril) adhieridas a la vegetación acuática, piedras o las mismas conchas de otros individuos de la especie (Figuras 59-61).

DiMENSIONES: Diámetro máximo 13-18 mm; altura $6 \mathrm{~mm}$.

HÁBITAT: Habita lugares donde la velocidad de la corriente es escasa o nula y aunque suele hallarse en ambientes de aguas permanentes, también puede localizarse en arroyos estacionales.

DisTRIBUCIÓN: Península Ibérica y Norte de África. Relativamente común en la Península Ibérica a excepción de las regiones más septentrionales donde es sustituida por $P$. corneus. Citada en la Comunidad de Madrid por Pérez Arcas (1863, como Planorbis metidjensis), Álvarez y Selga (1967, en la Fuente de las Huertas y el río Guadalix) y por Álvarez (1969 como Planorbarius metidjensis). También citada en la región (zonas palustres cerca del río Manzanares) por Graells (1846), si bien este autor la describe como especie nueva, Planorbis dufouri. Hidalgo (en Álvarez y Selga, 1967) establece la sinonimia al rotular el tubo que contiene los ejemplares tipo de $P$. dufouri, y que se encuentra en la colección del MNCN, como Planorbis metidjensis. Martorell y Bofill (1888) la citan como Planorbis dufouri y Vélaz \& Ugarte (1933) como Coretus dufourei (en el río Manzanares). Nieto (1967) cita la presencia de Planorbis corneus (sinónimo de Planorbarius corneus que es una especie propia del centro de Europa) en el arroyo Tejada, lo que podría ser una identificación errónea de Planorbarius metidjensis. En nuestras prospecciones la especie se ha localizado en los ríos Perales, Aulencia, Jarama, Lozoya y Guadarrama, en los arroyos Recuenco, de la Yunta, Candalosa, Retuertas, Valdeyerno, Fresnera, de los Castaños, de la Dehesa y de San Juan. También en las turberas de Canencia, y en fuentes de Soto del Real, Navalcarnero, Navacerrada y Zarzalejo (Figura 87).

LOCALIDADES: $8 ; 9 ; 10 ; 12 ; 13 ; 29 ; 52 ; 78 ; 102 ; 128 ; 151 ; 159$; $169 ; 171 ; 173 ; 175 ; 192 ; 194 ; 204 ; 223 ; 225 ; 226 ; 229 ; 260$; $274 ; 281 ; 287 ; 331$.

\section{Ancylus fluviatilis Müller, 1774}

\section{SINONIMIA:}

Ancylus fluviatilis Müller, 1774. Vermium Terrestrium et Fluviatilium seu animalium infusorium, helminthicorum, et testaceorum non marinorum succincta historia. Heinick and Faber, Havnia and Lipsia. xxxvi $+1-214+\mathrm{x}$ [unpaginated indices].
Ancylus capuloides Porro 1838. Malacologia terrestre e fluviale della provincia Comarca, Milano, 39 pp.

Ancylus obtusus Morelet 1845. Description des Mollusques terrestres et fluviatiles du Portugal. L.B.Bailliere, París, 115 pp.

Ancylus strictus Morelet 1845. Description des Mollusques terrestres et fluviatiles du Portugal. L.B.Bailliere, París, 115 pp.

Ancylus vitraceus Morelet 1845. Description des Mollusques terrestres et fluviatiles du Portugal. L.B.Bailliere, París, $115 \mathrm{pp}$.

Ancylus gibbosus Baudon 1852. Catalogue des Mollusques de département de l'Oise, Mem. Soc. Acad. Oise, II, p. 93-108.

Ancylus costulatus Bourguignat 1853. Notice sur le genre Ancylus, survie d'un Catalogue synonymique des espèces de ce genre, Journ. de Conchyliol., IV, p. 55-66 et p. 168-199.

Ancylus simplex Bourguignat, 1853. Notice sur le genre Ancylus, survie d'un Catalogue synonymique des espèces de ce genre, Journ. de Conchyliol., IV, p. 55-66 et p. 168-199.

Ancylus benoitianus Bourguignat 1862. Les speciléges malacologiques. Etude synonymique sur le genre Ancylus. Rev. et Mag. Zool., 15: 139-263.

Ancylus janinensis Bourguignat 1862. Les speciléges malacologiques. Etude synonymique sur le genre Ancylus. Rev. et Mag. Zool., 15: 139-263.

\section{DESCRIPCIÓN:}

Concha: Pateliforme, cónica, con el ápice prolongado hacia atrás y ligeramente desviado hacia la derecha. No obstante, la forma varía en función de las condiciones ambientales en las que habita, encontrándose formas más aplanadas y circulares en zonas con mayor velocidad de corriente y formas más elevadas y estrechas en aguas más tranquilas. La abertura es ligeramente elíptica, subcircular con un peristoma membranoso. La superficie puede ser lisa o presentar estrías radiales y concéntricas. El color de la concha varía entre el córneo amarillento y el marrón terroso (Figura 21).

Animal: Color grisáceo, casi transparente. La cavidad pulmonar está reducida y presenta una pseudobranquia. El pie es ovalado, casi circular y un poco más pequeño que la abertura de la concha. La mandíbula es semicircular, formada por placas ligeramente alargadas. Los tentáculos son cortos y de forma triangular y en su base se encuentran los ojos. Es frecuente observar las puestas en primavera y verano (julio) sobre o bajo las piedras de los arroyos (Figuras 62-64).

DiMENSIONES: Diámetro máximo 5-11 mm; altura 2,5-5,0 $\mathrm{mm}$.

HÁBITAT: Vive en todo tipo de aguas corrientes adherida a piedras, rocas u otros sustratos sólidos, aunque principalmente en tramos de ríos medios y altos. Soporta cierta contaminación orgánica.

DistribuCiÓn: Europa occidental, Inglaterra, Islas Canarias, norte de África, parte de la Península Arábiga y Turkestán (Vidal Abarca \& Suárez, 1985). De amplia distribución en la 


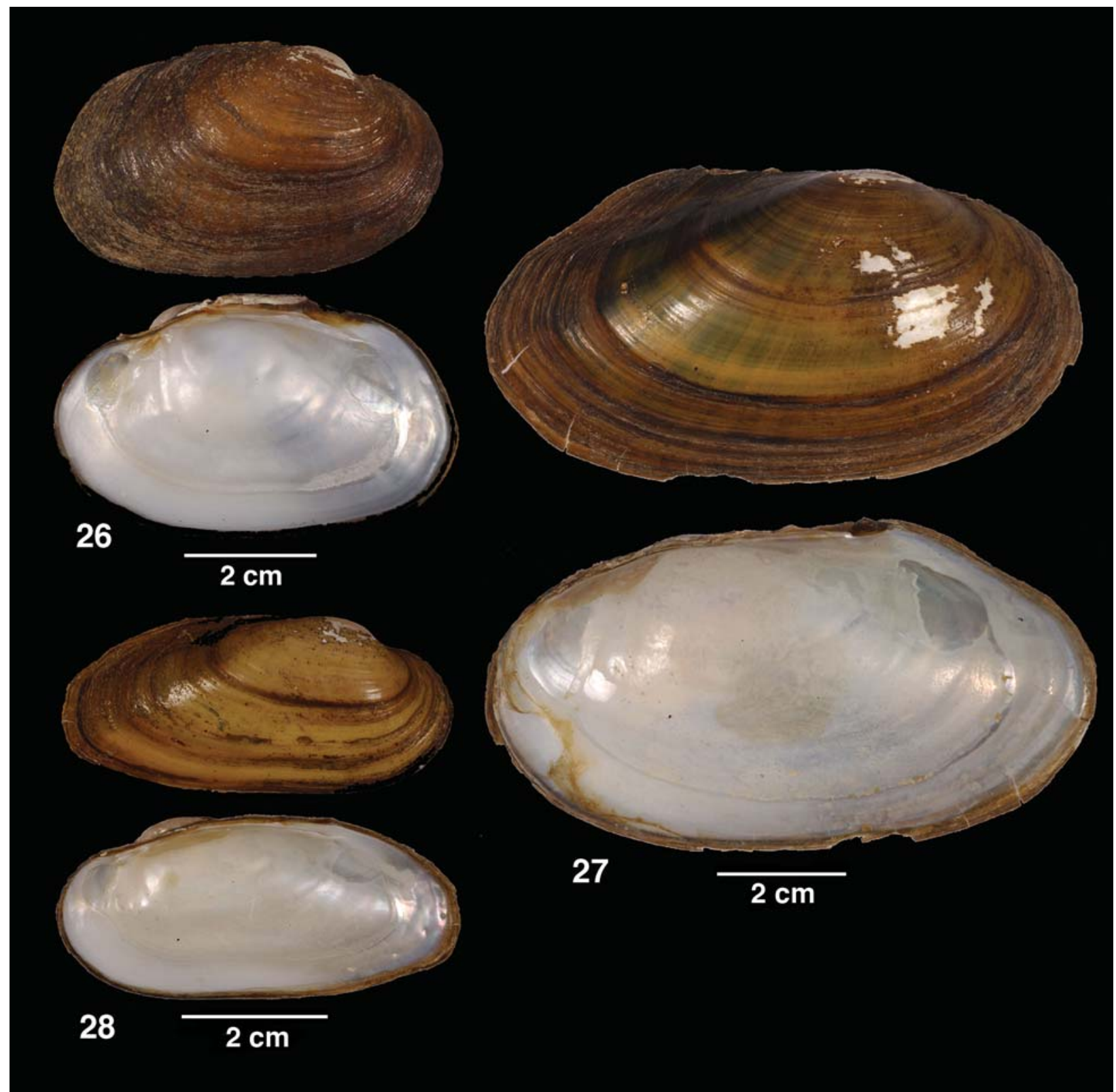

Figs. 26-28.- Valva derecha de: 26) Potomida littoralis (Cuvier, 1798). 27) Anodonta sp. 28) Unio cf. pictorum (Linnaeus, 1758).

Figs. 26-28.- Right valve of: 26) Potomida littoralis (Cuvier, 1798). 27) Anodonta sp. 28) Unio cf. pictorum (Linnaeus, 1758).

Península Ibérica. En la Comunidad de Madrid ha sido citada previamente por Westerlund (1898), Vélaz \& Ugarte (1933, en el río Manzanares), Álvarez \& Selga (1967, en Meco, Navas del Rey, Miraflores de la Sierra, San lorenzo del Escorial y en la laguna de la finca "La Granjilla"), Nieto (1967, en el río Manzanares a su paso por el puente de la carretera que une Colmenar Viejo y Torrelodones), y por Gregorides (1971, en el río Manzanares a su paso por el Prado de las Zorras, la Pedriza y Hoyo de Manzanares). García de Jalón y González del Tanago (1982) la citan en los ríos Lozoya y Jarama. Según nuestras observaciones es una de las especies más frecuentes, 
habiéndose encontrado en todas las cuencas fluviales (Figura 87).

LOCALIDADES: $1 ; 7 ; 9 ; 29 ; 34 ; 35 ; 37 ; 41 ; 47 ; 52 ; 55 ; 56 ; 57 ; 67$; $68 ; 74 ; 78 ; 83 ; 85 ; 90 ; 93 ; 94 ; 95 ; 97 ; 100 ; 101 ; 112 ; 124 ; 127$; $128 ; 130 ; 131 ; 133 ; 134 ; 139 ; 141 ; 144 ; 145 ; 146 ; 149 ; 153$; $158 ; 159 ; 160 ; 162 ; 165 ; 166 ; 167 ; 168 ; 169 ; 172 ; 173 ; 174$; $176 ; 181 ; 184 ; 185 ; 186 ; 187 ; 188 ; 191 ; 192 ; 195 ; 196 ; 198$; $199 ; 201 ; 202 ; 209 ; 216 ; 229 ; 260 ; 269 ; 271 ; 272 ; 275 ; 276$; $277 ; 279 ; 281 ; 282 ; 283 ; 284 ; 287 ; 306 ; 308 ; 319 ; 320 ; 322$ $327 ; 331 ; 333 ; 334 ; 373 ; 377 ; 388 ; 398 ; 401 ; 407 ; 415 ; 416$; $434 ; 446 ; 447 ; 448 ; 449 ; 450 ; 451 ; 452 ; 453 ; 455 ; 456 ; 457$.

\section{Ferrissia (Pettancylus) clessiniana (Jickeli, 1882)}

SINONIMIA:

Ancylus clessiniana Jickeli, 1882. Jb. dt. Malakozool. Ges. 8: 366-370.

Ferrissia clessiniana (Jickeli): Walter, 1912. A revision of the Ancylidae of South Africa. Nautilus Philad., 25: 139-144.

Watsonula wautieri Mirolli, 1960. Mem. Ist. Ital. Idrobiol. 12: 121-162.

Ferrissia wautieri (Mirolli): Girod, Bianchi \& Mariani, 1980. Guide per il reconoscimento delle specie animali delle acque interne italiane, 7: 66-67.

Ferrissia (Pettancylus) clessiniana (Jickeli): Falkner \& Proschwitz, 1998. J. Conchol., 36(3): 39-40.

\section{DESCRIPCIÓN:}

Concha: Pateliforme y muy frágil. La abertura es elíptica y tiene un peristoma continuo y membranoso. El ápice es romo y está ligeramente desviado hacia la derecha. La concha presenta finas estrías de crecimiento concéntricas (Figura 22). Es frecuente encontrar conchas con un septo en la abertura, lo cual se ha relacionado con periodos de sequía (Brown, 1980).

Animal: El color grisáceo del animal es debido a la hemolinfa y la gándula digestiva ya que los tejidos son totalmente transparentes. Los tentáculos son pequeños, con la extremidad redondeada (Figuras 65-66). El órgano copulador presenta un flagelo aunque son frecuentes los individuos sin pene (Brown, 1980).

DiMENSIONES: Diámetro máximo $4 \mathrm{~mm}$; altura $2 \mathrm{~mm}$.

HÁBITAT: Vive en aguas con poca velocidad de corriente como tablas, charcas, lagunas o tramos remansados de ríos. Es herbívora y suele encontrarse sobre la vegetación acuática.

DistRIBUCIÓN: Descrita por primera vez en Alejandría (Egipto). Se distribuye por la región mediterránea. Al norte de esta región, la distribución de la especie parece ser relativamente reciente. En las últimas décadas se ha expandido rápidamente por nuevas áreas de Europa occidental, central y oriental, en un proceso que todavía continúa y que es proba- ble que esté siendo facilitado por la acción del hombre (Falkner \& Proschwitz, 1998). En la Península Ibérica se ha citado en Alicante, Barcelona, Gerona, Tarragona y Valencia (Vidal Abarca \& Suárez, 1985). En la Comunidad de Madrid la hemos encontrado en los ríos Perales y Henares, el arroyo de la Fresnera, una zanja cercana al Embalse de Santillana, la fuente de Valsordo en Cebreros y varias charcas y lagunas del sureste (Figura 87).

LOCALIDADES: $27 ; 82 ; 83 ; 110 ; 125 ; 160 ; 383 ; 386 ; 413 ; 428$; $431 ; 433 ; 434 ; 437 ; 440 ; 441 ; 442 ; 443$.

\section{Physella (Costatella) acuta (Drapanaud, 1805)}

\section{SINONIMIA:}

Physa acuta Draparnaud, 1805. Histoire naturelle des Mollusques terrestres et fluviatiles de la France, Paris. 164 pp. Physa fluviatilis De Ferussac, 1807. Mem. Soc. Med. D'Emulat., p.55.

Physa rivalis Brown, 1827, Illustrations of the conchology of Great Britain and Ireland, fig.58-59, (non Turton, non Maton et Rackett).

Physa acuta var. castanea Moquin-Tandon, 1843. Mem. Acad. Sc. Toulouse, $2^{\circ}$ serie, 6, p.179.

Physa mamoi Benoît, 1879. Bull. Soc. Mal. Ital.1, p.159.

Physa martorelli Servain, 1880. Étude sur les mollusques recueillis en Espagne et en Portugal. St. Germain. 171 pp.

Physa acroxa Fagot, 1884. Contribution a la faune malacológique de la Catalogne. Ann. Malac., 2: 169-194.

Physa dilucida Letourneux in Servain, 1881. Histoire malacologique du lac Balaton en Hongrie, p.139.

Physa saint-simonis Fagot, 1883. Bull.Soc. Hist Nat. Toulouse, p.224.

Physa castanea Locard, 1893. Conchyologie française, p.50.

Physa gallica Bourguignat in Locard, 1893. Conchyologie française, p.50.

Physa salieti De Saint-Simon in Locard, 1893, Conchyologie française, p.50.

Physa massoti Penchinat in Locard, 1893. Conchyologie française, p.52.

Physa castroi Locard, 1899. Conhyologie portugaise. Les coquilles terrestres. Arch. Musée Hist. Nat Lyon, 7: 1-303.

Physella (Costatella) acuta (Draparnaud): Vidal Abarca \& Suárez, 1985. Lista faunística y bibliográfica de los moluscos (Gastrópoda \& Bivalvia) de las aguas continentales de la península Ibérica e Islas Baleares. Listas de la flora y fauna de las aguas continentales de la Península Ibérica. Publicación n². Asociación Española de Limnología.

\section{DESCRIPCIÓN:}

Concha: Levógira, oval alargada y con el ápice agudo. Está formada por 5-6 vueltas de espira poco convexas, de crecimiento regular, siendo la última de mayor tamaño que las restantes, constituyendo casi $2 / 3$ de la altura total de la concha. La abertura es larga, ovalada, aguda en la parte superior y ligeramente oblicua. Las suturas están poco marcadas. El peristoma es agudo y en algunos individuos presenta una callosidad interna poco desarrollada en el 
margen palatal. El ombligo está cubierto por el eje columelar. La concha es frágil, brillante, con finas estrías longitudinales y de color córneo amarillento (Figura 23).

Animal: El manto presenta siete digitaciones en el lado derecho que se repliegan sobre la columela y cuatro ó cinco en el lado izquierdo. El sistema genital presenta un largo prepucio con una glándula accesoria relativamente pequeña en su zona distal. La vaina del pene es más corta que el prepucio. La puesta consiste en una masa gelatinosa transparente y alargada, con 20-60 cápsulas, cada una de ellas con un huevo. Es muy frecuente observar puestas de esta especie sobre el sustrato (vegetación, piedras, plásticos, etc.), desde el final del invierno (febrero) y primavera hasta el verano (Figuras 67-69).

DiMENSIONES: Diámetro máximo 4-10 mm; altura 9-17 $\mathrm{mm}$.

HÁBITAT: Vive sobre piedras con algas y entre la vegetación acuática de lagos, lagunas, charcas, ríos, arroyos y acequias. Soporta la contaminación orgánica y una salinidad de hasta el 8\% (Girod et al., 1980).

DisTRIBUCIÓN: Descrita en Francia por Drapanaud (1805), muchos investigadores europeos asumieron que era nativa de Europa (Germain, 1931). No obstante, la ausencia de restos de conchas en los sedimentos europeos anteriores al siglo XIX parece sugerir que se trata de una introducción proveniente del Norte de América (Lozek, 1964; Anderson, 2003). Fuera de Europa se encuentra en todos los continentes excepto en la Antártida y Groenlandia (Te, 1978; Brown, 1980; Collier \& Winterbourn, 1986; Raut et al., 1995). De amplia distribución en la Península Ibérica (Vidal Abarca \& Suárez, 1985). En la Comunidad de Madrid ha sido citada previamente por Álvarez y Selga (1967, como Physa acuta en la fuente-abrevadero de Meco, en el Mar de Ontígola y en la laguna de la finca "La Granjilla" en las proximidades de San Lorenzo del Escorial), Nieto (1967), y por Gregorides (1971, en el río Manzanares a su paso por El Pardo, en el arroyo Butarque, en el río Jarama a su paso por el Puente Largo sitado en las inmediaciones de Aranjuez y en el mismo río a su paso por Titulcia). García de Jalón y González del Tanago (1982) la citan en los ríos Lozoya y Jarama. Según nuestras propias observaciones es la especie más frecuente en la región, encontrándose en todas las cuencas fluviales. En numerosas localidades que presentaban una fuerte contaminación de las aguas, esta ha sido la única especie encontrada (Figura 87).
LOCALIDADES: $7 ; 16 ; 23 ; 24 ; 26 ; 27 ; 29 ; 34 ; 37 ; 39 ; 40 ; 41 ; 47$; $52 ; 63 ; 69 ; 82 ; 83 ; 85 ; 91 ; 93 ; 94 ; 107 ; 110 ; 119 ; 124 ; 125 ; 129$; $132 ; 134 ; 136 ; 137 ; 140 ; 143 ; 144 ; 145 ; 146 ; 148 ; 152 ; 153$; $154 ; 156 ; 158 ; 159 ; 160 ; 161 ; 162 ; 166 ; 169 ; 172 ; 174 ; 176$; $181 ; 184 ; 188 ; 189 ; 192 ; 196 ; 198 ; 199 ; 201 ; 203 ; 205 ; 207$; $208 ; 216 ; 217 ; 224 ; 232 ; 238 ; 239 ; 246 ; 247 ; 249 ; 252 ; 261$; $262 ; 265 ; 268 ; 269 ; 270 ; 272 ; 276 ; 277 ; 281 ; 286 ; 289 ; 302$; $306 ; 307 ; 311 ; 318 ; 319 ; 320 ; 322 ; 327 ; 331 ; 334 ; 336 ; 362$; $373 ; 378 ; 379 ; 381 ; 382 ; 386 ; 387 ; 388 ; 389 ; 391 ; 392 ; 396$; $398 ; 399 ; 400 ; 401 ; 407 ; 410 ; 413 ; 416 ; 417 ; 425 ; 426 ; 427$; 428 ; 431; 433; 434; 435; 436; 436; 437; 441; 442; 443; 444; $444 ; 448$.

\section{Oxyloma (Oxyloma) elegans (Risso, 1826)}

SINONIMIA:

Succinea elegans Risso, 1826. Histoire naturelle des principales productions de l'Europe méridionale, et particulièrement de celles des environs de Nice et des Alpes-Maritimes, París et Strasbourg, vol 5, p. 59.

Succinea pfeifferi Rossmässler, 1835. Iconographie der Land und Süswasser Mollusken... Dresde et Leipzig, I, p. 92, pl. I, fig. 46.

Succinea italica Jan in Villa, 1841. Dispositio Systematica Conchyliarum terrestrium et fluviatilium quae adservantur in collectione fratrum, p. 8.

Succinea hordeacea Bourguignat, 1877. Histoire des Clausilies de France vivantes et fossiles. Ann. Sc. Nat. París, V, p. 11.

Succinea sublongiscata Bourguignat, 1877. Histoire des Clausilies de France vivantes et fossiles. Ann. Sc. Nat. París, V, p. 21.

Succinea pyrenaica Bourguignat, 1877. Histoire des Clausilies de France vivantes et fossiles. Ann. Sc. Nat. París, V, p. 12.

Succinea strepholena Bourguignat in Servain, 1880. Etude sur les Mollusques recueillis en Espagne et en Portugal, p. 9.

Oxyloma elegans (Risso): Kerney, Cameron \& Jungbluth, 1983. Die Landschnecken Nord-und Mitteleuropas. Parey. Hamburg, p.82.

\section{DESCRIPCIÓN:}

Concha: Muy frágil, ovalada, alargada superiormente y formada por 3-3,5 vueltas de espira, constituyendo la última $3 / 4$ de la altura total de la concha. Con suturas oblicuas bien marcadas. La abertura, que constituye más de la mitad de la altura de la concha, es ovalada, redondeada en la parte inferior y angulosa en su parte superior. El peristoma es recto y no reflejado. La concha carece de ombligo y es de color pardo brillante (Figura 24). Dado que la forma de la concha es muy similar a la de Succinea putris, es necesario revisar la anatomía para la correcta identificación de las especies (Ondina et al, 1996).

Animal: El cuerpo presenta generalmente pigmentación oscura, aunque pueden darse individuos pálidos. Presenta dos pares de tentáculos, estando los inferiores muy poco desarrollados. En cuanto a la genitalia, en el género Oxyloma el pene presenta en su parte superior un epifalo enrollado y un apéndice peneal incluidos en un saco peneal (Grossu, 
1987). Por su parte, el género Succinea presenta un epifalo libre y carente de apéndice peneal. Para diferenciar las especies del género Oxyloma es necesario analizar las proporciones de la genitalia. $O$. (O.) elegans presenta un pene y una vagina relativamente cortos y un conducto de la espermateca relativamente largo.

Dimensiones: Diámetro máximo 4,5-6 mm; altura $11 \mathrm{~mm}$.

HÁBITAT: Vive en zonas húmedas, cerca del agua, márgenes de ríos y lagos.

DISTRIBUCIÓN: Europa, llegando a ser rara o ausente en las zonas altas de Escandinavia (Kerney et al., 1983), norte de África, Asia occidenta y septentrional (Adam, 1960). En la Península Ibérica ha sido citada en Valencia (Martínez-Ortí \& Robles, 2003), Galicia (Ondina et al., 1996), Cataluña (Bech, 1990) y en Castilla la Mancha (Talavan \& Talavan, 2004). En la Comunidad de Madrid fue citada por Gregorides (1971) como Succinea pfeifferi en el arroyo Butarque. Nosotros la hemos encontrado en los ríos Aulencia, Guadarrama, Jarama y Torote y en los arroyos de Brea, Valenajo, Sotillo, Mojapán y Sepulcro. También se encontró en las Lagunas de Casasola, de la Dehesa de Bayona y de San Juan (Figura 87).

LOCALIDADES: $16 ; 64 ; 135 ; 143 ; 146 ; 149 ; 156 ; 181 ; 198 ; 230$; $284 ; 289 ; 303 ; 311$.

\section{Oxyloma sarsii (Esmark, 1886)}

\section{SinONIMIA:}

Succinea pfeifferi var. Sarsii Esmark, 1886. En: Esmark \& Hoyer. 1886. Die Land-und Süsswassermollusken der arctischen Norwegens, Mala. Bl., p 108, Taf V., Fig.2.

Succinea elegans Quick, H.E., 1933. The anatomy of British Succineae. Proc. Malac. Soc. London, 20: 295-318 (non Risso 1826)

\section{DESCRIPCIÓN:}

Concha: Muy similar a la de $O$. (O.) elegans, aunque de mayor tamaño y relativamente más estrecha. El borde inferior de la abertura es ligeramente recto, lo que le confiere una forma triangular. De color ámbar oscuro. Esta especie no se puede diferenciar de manera concluyente de algunas formas de $O$. (O.) elegans basándose únicamente en los caracteres externos (Figura 25).

Animal: Se diferencia de $O$. (O.) elegans por las diferentes proporciones de la genitalia. O. sarsii presenta un pene y una vagina más largos y un conducto de la espermateca más corto.
Dimensiones: Diámetro máximo 9-10 mm; altura 19-22 $\mathrm{mm}$.

HÁBITAT: Idéntico al de la especie precedente, con la cual se encuentra a veces asociada (Bech, 1990).

DisTRIBUCIÓN: Mal conocida debido a la confusión con $O$. (O.) elegans. No obstante, se ha comprobado su presencia en Inglaterra, Bélgica, Holanda, Alemania, Dinamarca y el este de Escandinavia (Kerney et al., 1983). En la Península Ibérica ha sido citada por varios autores en Cataluña, aunque según Bech (1990), éstas deberían ser comprobadas. En la Comunidad de Madrid sólo se localizó en una pequeña balsa en el centro de jardinería Los Peñotes, en Alcobendas, por lo que puede tratarse de una introducción accidental (Figura 87).

LOCALIDADES: 30 .

\section{Potomida littoralis (Cuvier, 1798)}

SINONIMIA:

Unio littoralis Cuvier, 1798. Tableau élèmentaire de l'Histoire Naturelle des animaux, p.425.

Unio subtetragonus Michaud, 1831. Complément de l'Histoire naturelle des mollusques terrestres et fluviatiles de la France, Verdun. 128 pp.

Unio incurvus Lea, 1831. Transactions Amer. Phil. Soc., vol.IV.

Unio pianensis Farines in Boubée, 1833. Bulletin d'Histoire naturelle de la France...París. 40 pp.

Potomida littoralis (Cuvier): Swainson, 1840. A treatise on malacology, 282, 289.

Unio umbonatus Rossmässler, 1844. Iconog. Land-Süsw-Moll., 2, p.26.

Unio rhomboideus Moquin-Tandom, 1855. Hitoire naturelle des mollusques terrestres et fluviatiles de France. París. Pag 568.

Unio subreniformis Bourguignat, 1863. Moll. nouv. Lit. peu connus, p. 138

Unio gandiensis Drouet, 1888. J. de Conch. , 36, p.103.

Unio rhysopygus Drouet, 1893. J. de Conch., 41, p.168.

Unio circinatus Drouet, 1893. J. de Conch.,41, p.167.

Unio littoralis taginus Kobelt, 1903. Iconog. Land-Süsw-Moll, 2, p.28.

Unio batavus catalonicus Haas in Bofill \& Haas, 1920. Treb. Mus. Cienc. Nat. Barcelona, 3, p.291, 363.

Unio incurvus Lea, 1831. Trans. Amer. Philos. Soc. Philadelphia, 4, p.97.

Unio litoralis var. umbonatus Rossmässler, 1844. Iconog. Land-Süsw-Moll, 4, p.36.

Unio hispalensis Kobelt, 1888. Die Bivalven NiederAndalusiens. Nachr. Bl. Deutsch. Mal. Ges, XX. Pag.

Unio calderoni Kobelt, 1888. Die Bivalven NiederAndalusiens. Nachr. Bl. Deutsch. Mal. Ges, XX. Pag.

Unio calderoni var. salvadori Kobelt, 1892. Nachr. Bl. Dtsch. Malak. Ges. Frankfurt, 24, p. 201.

Rhombunio littoralis (Cuvier): Haas, 1917. Estudios sobre las náyades del Ebro. Bol. Soc. Arag. Cien. Nat., vol. 16. pag

Psilunio littoralis (Cuvier): Haas, 1929. Fauna malacológica terrestre y de agua dulce de Cataluña. Barcelona. pag 


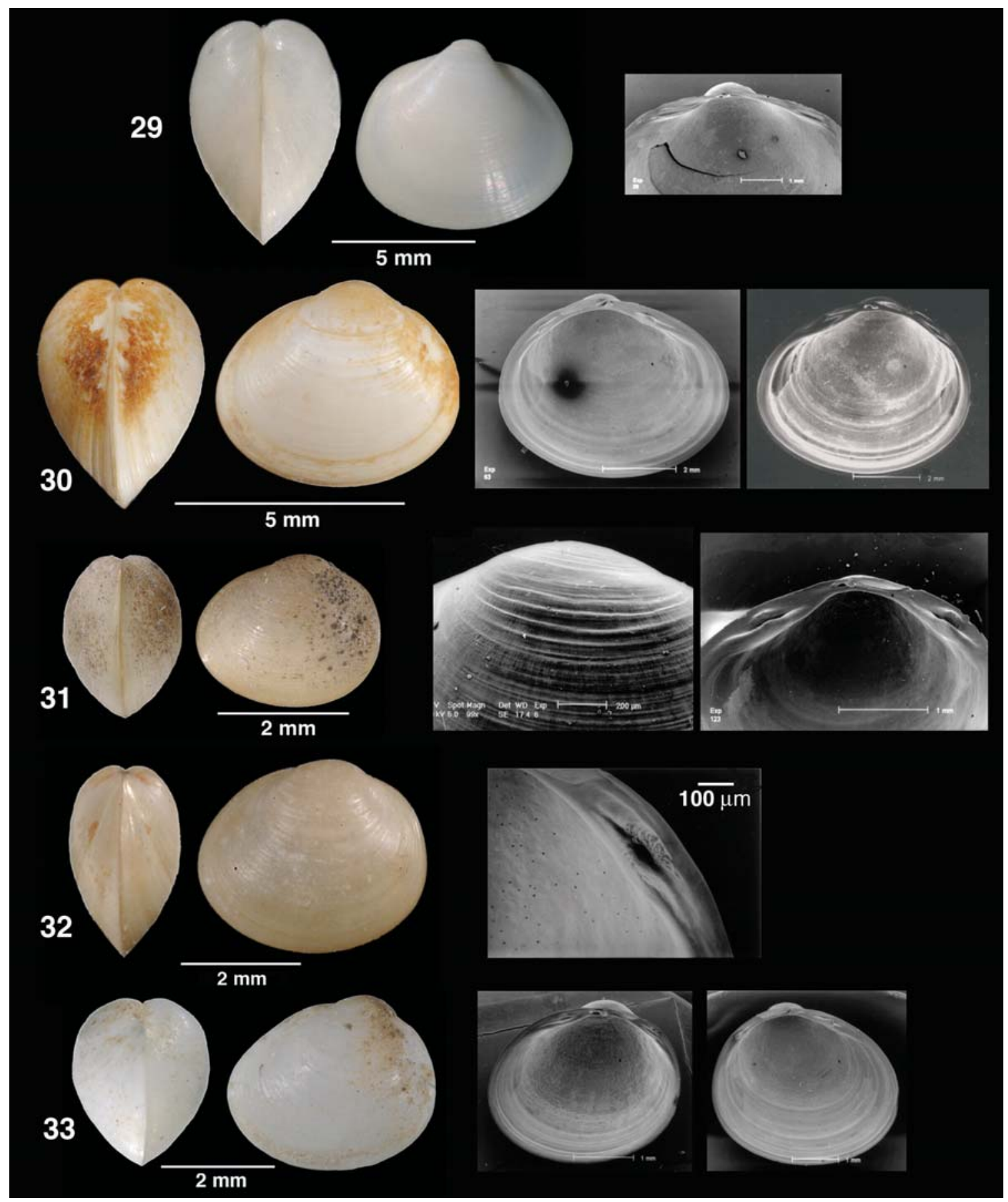

Figs. 29-33.- 29) Visión frontal, valva derecha y charnela derecha de Musculium lacustre (Müller, 1774). 30) Visión frontal, valva izquierda, charnela izquierda y charnela derecha de Pisidium casertanum (Poli, 1791). 31) Visión frontal, valva izquierda, umbo, con las costillas nepiónicas y charnela derecha de Pisidium nitidum Jenyns, 1832. 32) Visión frontal, valva izquierda y dientes laterales posteriores y callo de la valva derecha de Pisidium personatum Malm, 1855. 33) Visión frontal, valva izquierda, charnela derecha y charnela izquierda de Pisidium subtruncatum Malm 1855.

Figs. 29-33.-29) Frontal view, right valve and right hinge of Musculium lacustre (Müller, 1774). 30) Frontal view, left valve, left hinge and right hinge of Pisidium casertanum (Poli, 1791). 31) Frontal view, left valve, umbo, with nepionic ridges and right hinge of Pisidium nitidum Jenyns, 1832. 32) Frontal view, left valve and cardinal teeth and callus of the right valve of Pisidium personatum Malm, 1855. 33) Frontal view, left valve, right hinge and left hinge of Pisidium subtruncatum Malm 1855. 


\section{DESCRIPCIÓN:}

Concha: Robusta y ligeramente cuadrangular. Grosor de nácar variable dependiendo del hábitat. En los ríos de Madrid es generalmente aplanada y con el nacar poco grueso. Ligamento externo. Umbo generalmente con escultura en forma de ondas. Charnela de la valva izquierda con dos dientes laterales y dos cardinales fuertes y aserrados. En la derecha un diente lateral y uno cardinal de forma piramidal también aserrado. Se distingue de las especies del género Unio por ser menos alargada y más alta, de forma que para una misma longitud, esta especie siempre es más alta. Color pardo oscuro, a veces verduzco; en ocasiones con lineas amarillentas radiales que parten del umbo (Figura 26).

Animal: Debajo de la concha están los dos lóbulos del manto. Bajo este y a cada lado hay dos branquias laminares con función respiratoria $y$ reproductora (fertilización e incubación de los huevos). Es el único uniónido ibérico en el que las cuatro branquias actuan como marsupio. Entre las branquias presentan un pie musculoso y el paquete visceral. Dos músculos aductores muy potentes, uno anterior y otro posterior, mantienen juntas las valvas (Figuras 70-71).

DiMENSIONES: Longitud: 80-90 mm; altura: 55-60 $\mathrm{mm}$; anchura: 30-35 $\mathrm{mm}$.

HÁBITAT: Vive en lugares típicos de grandes bivalvos de agua dulce, en fondos de grava y cieno. También entre las raíces de los árboles de ribera. En otras áreas de la Península Ibérica puede ser abundante en determinados canales y acequias de fondos naturales.

Distribución: Península Ibérica, Francia, Grecia y Asia Menor. Fósil en Inglaterra. En la Península Ibérica mal conocida, pero distribuída tanto por las cuencas atlánticas como mediterráneas. En prospecciones recientes de ríos ibéricos se ha comprobado que está despareciendo de muchas de las localidades que antes ocupaba. En la Comunidad de Madrid ha sido citada por Pérez Arcas (1863, como Unio littoralis), Drouet (1893-94, como Unio littoralis en el río Jarama a su paso por San Fernando de Henares, el río Henares a su paso por Alcalá de Henares y en un caz en Mejorada del Campo). Estas citas están incluidas en las obras de Haas (1917), Pardo (1932, como Rhombunio littoralis) y Azpeitia (1933). La especie también fue citada por Nieto (1967 como Unio umbonatus en las inmediaciones de un lugar conocido como Soto el Mayor, en la carretera que une Aranjuez con Villarejo de Salvanés) y por Gregorides (1971, como Unio rhysopygus en el río Tajo a su paso por Aranjuez y como Unio umbonatus en el puente de
Arganda sobre el río Jarama). Según Soriano et al. (2001), la especie fue encontrada en el río Jarama a su paso por Mejorada del Campo (antes de 1933), San Martín de la Vega (antes de 1933), Arganda (en 1897 y en 1961) y San Fernando de Henares (en 1943) y en el río Tajo a su paso por Aranjuez ( $\sin$ fecha de captura disponible). Nosotros la hemos encontrado en los ríos Tajo, Jarama y Perales (Figura 88). También en el río Tajuña en Guadalajara.

LOCALIDADES: 45; 115; 117; 172; 211.

\section{Anodonta sp.}

DESCRIPCIÓN:

Concha: Forma muy variable, grande, a veces globosa, generalmente mayor de $10 \mathrm{~cm}$ en los adultos, y de concha muy fina. Es muy difícil la diferenciación entre las distintas especies del género. Charnela sin dientes, lo que sirve para distinguirla del resto de las náyades ibéricas. Escultura del umbo generalmente poco marcada. Color muy variable, desde amarillo verdoso hasta pardo muy oscuro. Las formas juveniles generalmente aplanadas lateralmente y con el borde dorsal formando un ángulo muy marcado con el borde posterior (Figura 27).

Animal: Anatomía muy similar a la de la especie anterior. Solamente las branquias externas se utilizan para incubar los huevos. En experiencias en acuario en 1988 se comprobó que emitía gloquidios en el mes de noviembre (Figuras 72-80), y que se fijaban a Gambusia affinis (especie de pez introducida).

DiMENSIONES: Longitud: 95-150 mm; altura: 50-55 mm; espesor: 35-40 mm.

HÁBITAT: En aguas poco corrientes y ambientes lénticos, también en lóticos. Abundante en algunos embalses, canales y acequias de fondos naturales. Tolera bien los fondos de cieno.

DisTRIBUCión: La especie se ha citado como $A$. cygnea en el Tajo (ver Vidal Abarca y Suárez, 1985), en la Comunidad de Madrid y se ha encontrado en el Embalse de Picadas (Figura 88) y en el de San Juan (Figura 94), aunque con total seguridad vive en otros embalses y ríos de la provincia.

LOCALIDADES: 95; 206.

\section{Unio cf. pictorum (Linnaeus, 1758)}

SINONIMIA:

Mya pictorum Linnaeus, 1758. Systema naturae I Vol. (10 ${ }^{\mathrm{a}}$ edición). London. 823 p. 
Unio delphinus Spengler, 1793. Skrivter af Naturhistorisk Selskabet, Copenhague, vol III.

Limnaea pictorum (Linnaeus): Poli, 1791. Test. Sicil. I. Introduc. P.31.

Unio gibbus Spengler, 1793. Skrivter af Naturhistorisk Selskabet, Copenhague, vol III.

Unio hispanus Rossmässler, 1844, Iconog. Land-Süsw-Moll, 2 , p.26.

Unio dactylus Morelet, 1845. Description des mollusques terrestres et fluviatiles du Portugal. París.

Unio mucidus Morelet, 1845. Description des mollusques terrestres et fluviatiles du Portugal. París.

Unio lusitanus Drouret, 1879. J. de Conch., 27, p.327.

Unio nevesi Silva e Castro, 1885. Unionidae nouveaux $d u$ Portugal. Bull. Soc. Mal. France, vol. II.

Unio simoesi Silva e Castro, 1885. Unionidae nouveaux $d u$ Portugal. Bull. Soc. Mal. France, vol. II.

Unio sevillensis Kobelt, 1887. Unios y anodontes nuevos de la fauna española. Anal. Soc. Esp. Hist. Nat., vol. 16.

Unio hispanus var. sphenoides Westerlund, 1892. An. Soc. Esp. Hist. Nat.,21, p.390.

Unio cameratus Drouet, 1893. Unionidae de l'Espagne. Mem. Acad Sci. Arts. Bell-Letr. Dijon, 4.

Unio limosellus Drouet, 1893. Unionidae de 1'Espagne. Mem. Acad Sci. Arts. Bell-Letr. Dijon, 4.

Unio decurtatus Drouet, 1893. Unionidae de l'Espagne. Mem. Acad Sci. Arts. Bell-Letr. Dijon, 4.

Unio callipygus Drouet, 1893. Unionidae de l'Espagne. Mem. Acad Sci. Arts. Bell-Letr. Dijon, 4.

Unio gravatus Drouet, 1893. Unionidae de l'Espagne. Mem. Acad Sci. Arts. Bell-Letr. Dijon, 4.

Unio turdetanus Drouet, 1893. Unionidae de l'Espagne. Mem. Acad Sci. Arts. Bell-Letr. Dijon, 4.

Unio taganus Locard, 1899. Conchyliologie portugaise... Arch. Musée Hist. Nat. Lyon, vol. 7.

Unio abrantesianus Locard, 1899. Conchyliologie portugaise... Arch. Musée Hist. Nat. Lyon, vol. 7.

Unio scalabisianus Locard, 1899. Conchyliologie portugaise... Arch. Musée Hist. Nat. Lyon, vol. 7.

Unio allenianus Locard, 1899. Conchyliologie portugaise... Arch. Musée Hist. Nat. Lyon, vol. 7.

Unio cyrtus Locard, 1899. Conchyliologie portugaise... Arch. Musée Hist. Nat. Lyon, vol. 7.

Unio novus Locard, 1899. Conchyliologie portugaise... Arch. Musée Hist. Nat. Lyon, vol. 7.

Unio neothaumus Locard, 1899. Conchyliologie portugaise... Arch. Musée Hist. Nat. Lyon, vol. 7.

Unio pictorum (Linnaeus): Haas, 1969. Superfamilia Unionacea. Das Tiereich, 88.

DESCRIPCIÓN:

Concha: Color pardo oscuro. Forma alargada con el extremo posterior generalmente (pero no siempre) apuntado. Charnela con los dientes cardinales laminares, lo que la distingue de Potomida, aunque también pueden ser aserrados. Escultura del umbo no siempre presente (Figura 28).

Animal: Como el resto de las náyades. Los huevos solamente se incuban en las branquias externas (Figuras 81-82).

DiMENSIONES: Longitud $70-85 \mathrm{~mm}$; altura $35-40$ $\mathrm{mm}$; anchura: 25-30 $\mathrm{mm}$.
HÁBITAT: Vive en lugares típicos de grandes bivalvos de agua dulce. En ríos y arroyos de aguas limpias y fondos de arenas, a veces en gravas o cieno. En ocasiones, entre las raíces de los árboles de ribera.

DisTRIBUCión: Paleártica con excepción del Mediterráneo. En la Península Ibérica está mal conocida, aunque sí se sabe que sólo vive en los ríos atlánticos. Todavía se desconoce la adscripción específica de este taxon, aunque parece próximo a la especie europea Unio pictorum (L, 1758). En recientes prospecciones de ríos ibéricos comprobamos que está despareciendo de muchas de las localidades que antes ocupaba. En la Comunidad de Madrid ha sido citada por Drouet (1893-94) (como Unio limosellus en el río Manzanares a su paso por Madrid, en el Henares a su paso por Alcalá de Henares y en el Jarama a su paso por San Fernando de Henares). Estas citas fueron recogidas en los trabajos de Calderón (1894), Haas (1917), Pardo (1932) y Azpeitia (1933). También citada en por Vélaz \& Ugarte (1933 en el río Manzanares) y Nieto (1967, como Unio limosellus en el río Manzanares a su paso por los puentes de las carreteras que unen Comenar Viejo y Torrelodones, Colmenar Viejo y Manzanares el Real, El Pardo y Cerceda). En este trabajo (Nieto, 1967), también se cita la presencia de Unio microdactylus y Unio jourdheuili, ambas sinonimias de Unio mancus, lo cual suponemos como una cita errónea dado que esa especie se distribuye unicamente por las cuencas del Mediterráneo (Haas, 1969). También citada en Madrid por Gregorides (1971, como Unio hispanus en el puente de Arganda sobre el río Jarama y como Unio limosellus en el río Manzanares a su paso por Hoyo de Manzanares). Según Soriano et al. (2001), la especie se ha encontrado en los ríos Guadarrama, Manzanares (a la altura de Puerta de Hierro y en Hoyo de Manzanares), Tajo (a su paso por Aranjuez), Jarama (a la altura de San Martín de la Vega, Arganda y San Fernando de Henares), Lozoya (a su paso por Lozoya), Sanburiel (a la altura de Cerceda) y en el río Henares (a su paso por Mejorada del Campo). Nosotros la hemos encontrado en los ríos Lozoya, Perales, Aulencia y Cofio (Figura 88). También en el río Tajuña en Guadalajara. En el Jarama se observaron grupos de valvas de ajemplares comidas por ratas de agua (Figura 82) aunque no la hemos encontrado viva en los últimos muestreos. Probablemente extinguida en el Jarama y en vías de desaparición en otros ríos.

LOCALIDADES: $17 ; 43 ; 45 ; 46 ; 82 ; 83 ; 84 ; 85 ; 87 ; 89 ; 90 ; 176$; 190; 200; 211. 


\section{Musculium lacustre (Müller, 1774)}

SINONIMIA:

Tellina lacustris Müller, 1774. Vermium Terrestrium et Fluviatilium seu animalium infusorium, helminthicorum, et testaceorum non marinorum succincta historia. Heinick and Faber, Havnia and Lipsia. xxxvi +1-214 + x [unpaginated indices].

Cyclas caliculata Draparnaud, 1805. Histoire naturelle des Mollusques terrestres et fluviatiles de la France, Paris. P. 130. pl. X figs. 13-14.

Cyclas lacustris Ferrusac, 1807. Exposé succint d'un systeme conchyliologique appliquée. Mem. Soc. Méd. D’Emulat. París, 4, p. 128. (non Draparnaud)

Cyclas stagnicola (Leach) Lamarck, 1818. Histoire naturelle des animaux sans vertebres...París, vol. 5, p. 559.

Calyculina lacustris (Müller): Clessin, 1877. Die Mollusken fauna Europa's, 1, Nürnberg. P. 492. fig. 318.

Sphaerium jeannoti Normand, 1854. Coupd'œeil sur les mollusques de la famille des Cyclades, observés jusqu'à ce jour dans le bassin sous-pyrénéen, Toulouse, p. 2.

Sphaerium subrotundatum (Dupuy) Locard, 1893. Conchyliologie française. Lyon et París, p. 136.

Sphaerium uncinatum Locard, 1882. Prodrome de la malacologie française. Mollusques terrestres, des eaux douces et des eaux sumâtres. Lyon et París. P. 256.

Sphaerium eucodium Bourguignat in Locard, 1893. Conchyliologie française. Lyon et París, p. 136-137.

Sphaerium lacustre (Müller): Bourguignat, 1854. Malacol. de L'Algérie, en Hist. Nat. des Animaux Moll. Terr. et Fluviat. recueillis jusqu'a ce jour dans nos possessions du Nort de L' Afrique, Tomo I, p. 36, pl IV figs. 11-18.

Sphaerium hispanicum Bourguignat, 1870. Rev. et Mag. Zool., $2^{\circ}$ ser., XXII, 170.

Sphaerium castroi Locard, 1899. Conchiliologie Portugaise, 205.

Musculium lacustre (Müller): Bofill y Haas, 1920. Estudi sobre la Malacologia de les Valls Pirenaiques; Conca del Llobregat, 598.

Sphaerium (Musculium) lacustre (Müller): Germain, 1931. Mollusques terrestres et fluviatiles. Faune de France, Lechevalier, Paris 21/22: 693.

Sphaerium caliculatum (Draparnaud): Azpeitia, 1933. Conchas Bivalvas de agua dulce de España y Portugal, 667.

DESCRIPCIÓN:

Concha: Pequeña, delgada y frágil, de color gris o pardo claro transparente, a menudo con depósitos que enmascaran la escultura de estriación fina y regular. Forma ligeramente romboidal, con el margen superior recto que se une al margen anterior por un ángulo casi recto y al posterior por un ángulo obtuso, de forma que la región posterior de la concha es más cuadrada. Umbos prominentes y cónicos, con un estriado concéntrico muy marcado, con prodisoconcha muy evidente y prominente, lo que hace de ella una especie difícil de confundir. Charnela muy estrecha, más larga en la parte posterior que en la anterior; dientes cardinales muy pequeños y laterales largos, estrechos y lisos. Ligamento corto y estrecho no visible externamente (Figura 29).

Animal: Presenta dos auténticos sifones con paredes musculares, lo que sirve para distinguirla de las especies del género Pisidium. Branquias con dos lamelas; las posteriores son más pequeñas que las anteriores pero no tanto como en las especies del género Pisidium.

DiMENSIONES: Longitud 8-15 mm; altura 6-11 mm; anchura: $3,5-7 \mathrm{~mm}$.

HÁBITAT: Esta especie suele habitar en charcas, lagos y remansos de ríos de escasa corriente, sobre el cieno del fondo, especialmente en el retenido por la vegetación sumergida.

DistriBUCIÓN: Cosmopolita: en toda Europa salvo el sur de Italia, sur de los Balcanes, norte de Escocia y Laponia. En el norte de Asia desde Ladoga a Armenia y Kamtchatka. En toda América y Australia. Introducida en Japón y Hawai (Araujo, 1995). En la Península Ibérica es poco común habiéndose citado en las Cuencas del Ebro, Segura, Guadiana, Guadalquivir, Cuencas Internas de Cataluña y Mondego (Araujo, 1995). La especie ha sido citada previamente en la Comunidad de Madrid por Pérez Arcas (1863, como Cyclas calyculata), Bourguignat (1870) y Westerlund (1890, como Sphaerium hispanicum). Nosotros la hemos encontrado en el río Perales (Figura 88).

LOCALIDADES: 85; 172; 236.

\section{Pisidium casertanum (Poli, 1791)}

SINONIMIA:

Cardium casertanum Poli, 1791. Testacea utriusque Siciliae eorumque Historia et Anatome 1, p.61, pl. XVI fig. 1 (non Cyclas casertanum Risso).

Figs. 34-48. - Gasterópodos de agua dulce de la Comunidad de Madrid. 34-35) Macho de Pseudamnicola (Pseudamnicola) subproducta, laguna de Ontígola (IV-1993). 36-37) Ejemplares vivos de Potamopyrgus antipodarum, en los que se observa por transparencia de la concha los huevos incubados, Parque del Oeste, Madrid (IV-1988). 38) Hembra y juveniles recién eclosionados de Potamopyrgus antipodarum, canales del río Tajo (V-1988). 39) Ejemplar de Bithynia tentaculata mostrando el opérculo calcáreo, rio Tajo, Valdajos (XII-1986). 40) Puestas de Bithynia tentaculata en distintas fases de desarrollo (en acuario), río Tajo, Valdajos (III-1985). 41-42) Ejemplar adulto de Lymnaea stagnalis con el aparato genital evaginado, centro de jardinería al aire libre de la Moraleja, Alcobendas, Madrid (II-1989). 43) Ejemplar vivo de Stagnicola palustris, laguna de Somolinos, Guadalajara (VII1988). 44) Animal de Galba truncatula, fuente de la Calera, Miralrío, Guadalajara (III-1987). 45-46) Adulto y juvenil, con manto moteado, de Radix auricularia, charcas del río Jarama, Talamanca (III-1987). 47-48) Ejemplar reptando y adultos en cópula de Radix balthica, arroyo de la Aceña Peguerinos, Ávila (VII-1984). 

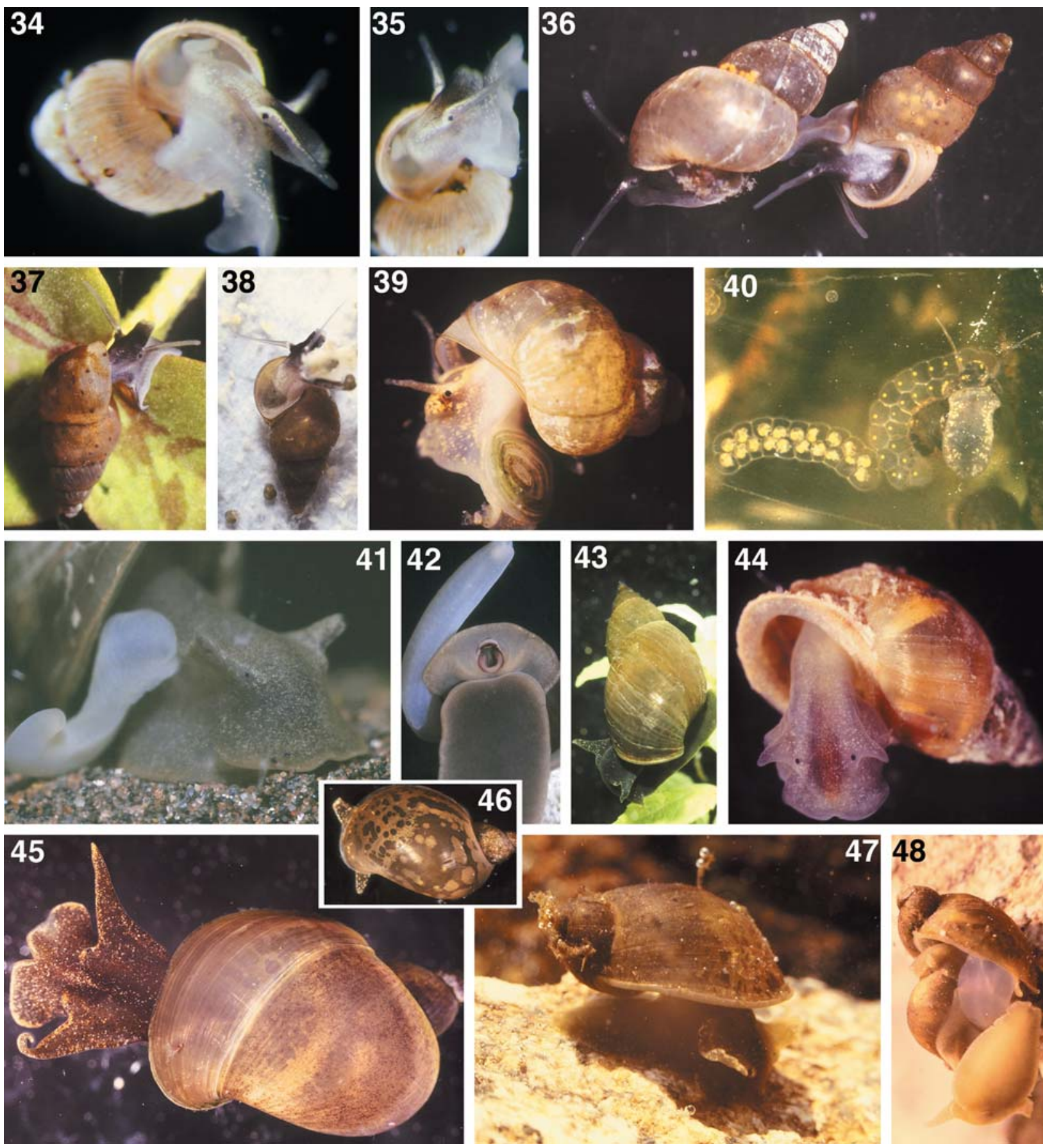

Figs. 34-48. - Freshwater gastropods of Comunidad de Madrid. 34-35) Male of Pseudamnicola (Pseudamnicola) subproducta, Lake Ontígola (IV-1993). 36-37). Live specimens of Potamopyrgus antipodarum showing incubated eggs, Parque del Oeste, Madrid (IV-1988). 38) Potamopyrgus antipodarum female and recently hatched juveniles, Tajo river channels (V-1988). 39) Bithynia tentaculata specimen showing calcareous operculum, Tajo river, Valdajos (XII-1986). 40) Several developmented stages of Bithynia tentaculata layings (in aquarium), Tajo river, Valdajos (III-1985). 41-42) Adult Lymnaea stagnalis with evaginated genital system, garden center in La Moraleja, Alcobendas, Madrid (II-1989). 43) Live Stagnicola palustris specimen, Laguna de Somolinos, Guadalajara (VII-1988). 44) Galba truncatula, Calera Fountain, Miralrío, Guadalajara (III-1987). 45-46) Adult and juvenile Radix auricularia, showing the dotted mantle, Jarama river pools, Talamanca (III-1987). 47-48) Adult specimens of Radix balthica crawling and during copulation, Aceña stream, Peguerinos, Ávila (VII-1984). 
Cardium lenticularis Normand, 1844. Notice sur plusieur espèces de Cyclades découvertes dans les environs de Valenciennes, p. 8.

Pisidium cinereum Alder, 1838. Trans. Nat. Hist. Soc. Northumberland, II, p. 341.

Pisidium fontinale (Pfeifer): Brown, 1840. Illustrations of the recent conchology of Great Britain and Ireland...2 $2^{\circ}$ ed. London, p. 94.

Pisidium lenticulare Dupuy, 1850. Histoire naturelle des Mollusques terrestres et d'eau douce qui vivent en France, fasc 4, p. 680.

Pisidium casertanum (Poli): Baudon, 1857. Essai monographique sur les Pisidies françaises. Mem. Soc. Acad. Oise, 3, p. 30 , pl.II fig. c.

Cardium mouchousii Companyo, 1963. Hist. Natur. PyrénéesOrient., III, p. 519.

Pisidium ibericum Clessin, 1873. Malak. Blätt., XX, 29

Pisidium hispanicum Clessin, 1879. Die Familie der Cycladeen, 37

Pisidium herminii Welwitsch in Clessin, 1879, Die Familie der Cycladeen, 61

Pisidium cazertanum (Poli): Chia, 1886. Catálogo de los moluscos testáceos terrestres y fluviátiles de la comarca de Gerona, 41

\section{DESCRIPCIÓN:}

Concha: Las especies ibéricas del género Pisidium son todas pequeñas (rara vez pasan de los $10 \mathrm{~mm})$ y muy difíciles de distinguir. Pisidium casertanum presenta una forma muy variable, generalmente con poco brillo y una estriación fina e irregular, de silueta ovalada o triangular y con los umbos poco prominentes. La charnela es también muy variable, pero generalmente ancha. En la valva izquierda, el diente cardinal inferior está generalmente arqueado mientras que el superior normalmente es más corto, recto y débil. En la valva derecha, el diente cardinal suele ser curvo y ahorquillado en su región posterior. La fosa del ligamento es larga y ancha, a menudo con el borde inferior sinuoso. Los dientes laterales también son muy variables, destacando el anterior inferior de la valva derecha por ser generalmente muy robusto (Figura 30).

Animal: Como en todas las especies de Pisidium, los sifones son dos simples aberturas sin paredes musculares. Las branquias anteriores son de mayor tamaño que las posteriores. La anterior presenta una lamela externa completa y una interna bastante más baja que la externa. La branquia posterior, más baja que la anterior, presenta sólo lamela externa. Incuban los huevos fertilizados entre las lamelas de la branquia anterior (Figura 83).

DiMENSIONES: Longitud 3-8 mm; altura 3-6 mm; anchura 2,5-5 mm.

HÁBITAT: Todo tipo de ambientes acuáticos con sedimentos finos: desde manantiales, ríos, acequias y riachuelos, hasta embalses, lagos, estanques y fuentes. Vive tanto en fuentes termales como en lagos de alta montaña.

DISTRIBUCIÓN: Es una especie cosmopolita y se ha encontrado en toda Europa y Siberia, Madagascar, gran parte de África, Canarias, Madeira y Azores, India, Japón, Australia, Tasmania, Nueva Zelanda, Norte de América y Central, Cuba y Puerto Rico, Brasil, Patagonia y Groenlandia (Araujo, 1995). De amplia distribución en la Península Ibérica es la más frecuente de las especies de este género. En la Comunidad de Madrid ha sido citada previamente por Azpeitia (1933 en la Casa de Campo, el río Lozoya y en Puerta de Hierro, Madrid), Nieto (1967, en las inmediaciones del puente de la carretera que une Colmenar Viejo y Manzanares el Real) y por Gregorides (1971, en el río Manzanares a su

Figs. 49-69. - Gasterópodos de agua dulce de la Comunidad de Madrid. 49-50) Ejemplar de Gyraulus albus y detalle de la cabeza, río Perales, Quijorna (I-1989). 51-52) Ejemplares vivos de Gyraulus crista, laguna de San Juan, Titulcia (X-1988). 53) Ejemplares de Gyraulus crista con concha de borde aserrado, laguna de Somolinos, Guadalajara (VIII-1988). 54) Animal de Gyraulus laevis, canales de Fuentidueña de Tajo (IV-1988). 55) Detalle de la cabeza de Gyraulus laevis con nematodos, río Jarama, Uceda (IV-1987). 56) Animal de Gyraulus chinensis, río Manzanares, Colmenar Viejo (XII-1986). 57-58. Ejemplares vivos de Hippeutis complanatus, uno de ellos con la puesta en el ombligo, laguna de San Juan, Titulcia (X-1988). 59-61) Ejemplar vivo, detalle del animal mostrando la pseudobranquia y puesta de Planorbarius metidjensis, río Perales, Navalagamella (IV-1987). 62) Ejemplares vivos de Ancylus fluviatilis, río Manzanares, Colmenar Viejo (XII-1986). 63) Puestas de Ancylus fluviatilis sobre las piedras del arroyo de Valle de En medio, Peguerinos, Ávila (VII-1990). 64) Ejemplares de Ancylus fluviatilis con costillas radiales marcadas, río Perales, Aldea del Fresno (XI-1986). 65) Ejemplar vivo de Ferrissia clessiniana con septo en la concha, sobre la vegetación, fuente de Valsordo, Ávila (II-1989). 66) Detalle del animal de Ferrissia clessiniana, sin septo en la concha, río Perales, Quijorna (I-1989). 67-69) Animal de Physella acuta mostrando digitaciones del manto, puesta y detalle de una cápsula con embrión en desarrollo con ojos ya formados, río Alberche, puente Valsordo, Ávila (II-1989).

Figs. 49-69.- Frashwater gastropods of Comunidad de Madrid. 49-50) Gyraulus albus specimen and detail of the head, Perales river, Quijorna (I-1989). 51-52) Live specimens of Gyraulus crista, San Juan Lake, Titulcia (X-1988). 53) Gyraulus crista with sawed shell margin, Somolinos Lake, Guadalajara (VIII-1988). 54) Gyraulus laevis specimen, Fuentidueña de Tajo chanels (IV- 

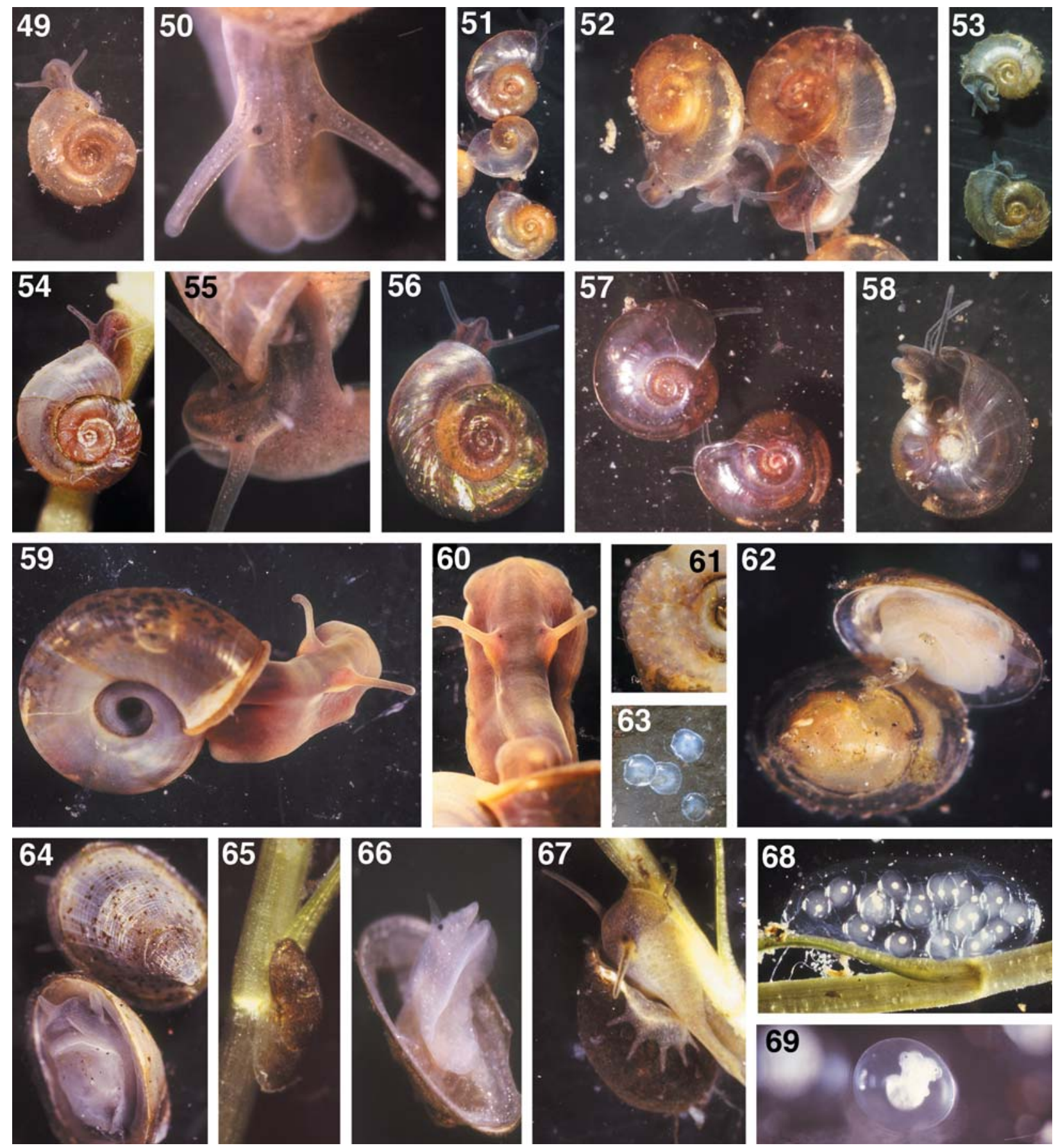

1988). 55) Head of Gyraulus laevis with nematodes, Jarama river, Uceda (IV-1987). 56) Gyraulus chinensis, Manzanares river, Colmenar Viejo (XII-1986). 57-58) Hippeutis complanatus specimens, one of them with a laying on the umbilicus, San Juan Lake, Titulcia (X-1988). 59-61) Live apecimens, detail of the body showing the pseudobranch and egg laying of Planorbarius metidjensis, Perales river, Navalagamella (IV-1987). 62) Ancylus fluviatilis live specimens, Manzanares river, Colmenar Viejo (XII1986). 63) Eggs of Ancylus fluviatilis on stones of the Valle de En Medio stream, Peguerinos, Ávila (VII-1990). 64) Ancylus fluviatilis with marked radial ribs, Perales river, Aldea del Fresno (XI-1986). 65) Live specimen of Ferrissia clessiniana with septum in the shell, Valsordo Fountain, Ávila (II-1989). 66) Detail of a specimen of Ferrissia clessiniana without septum in the shell, Perales river, Quijorna (I-1989). 67-69) Physella acuta specimens showing mantle digitations, egg laying and detail of one capsule with a developing embryo showing the formed eyes, Alberche river, Valsordo bridge, Ávila (II-1989). 

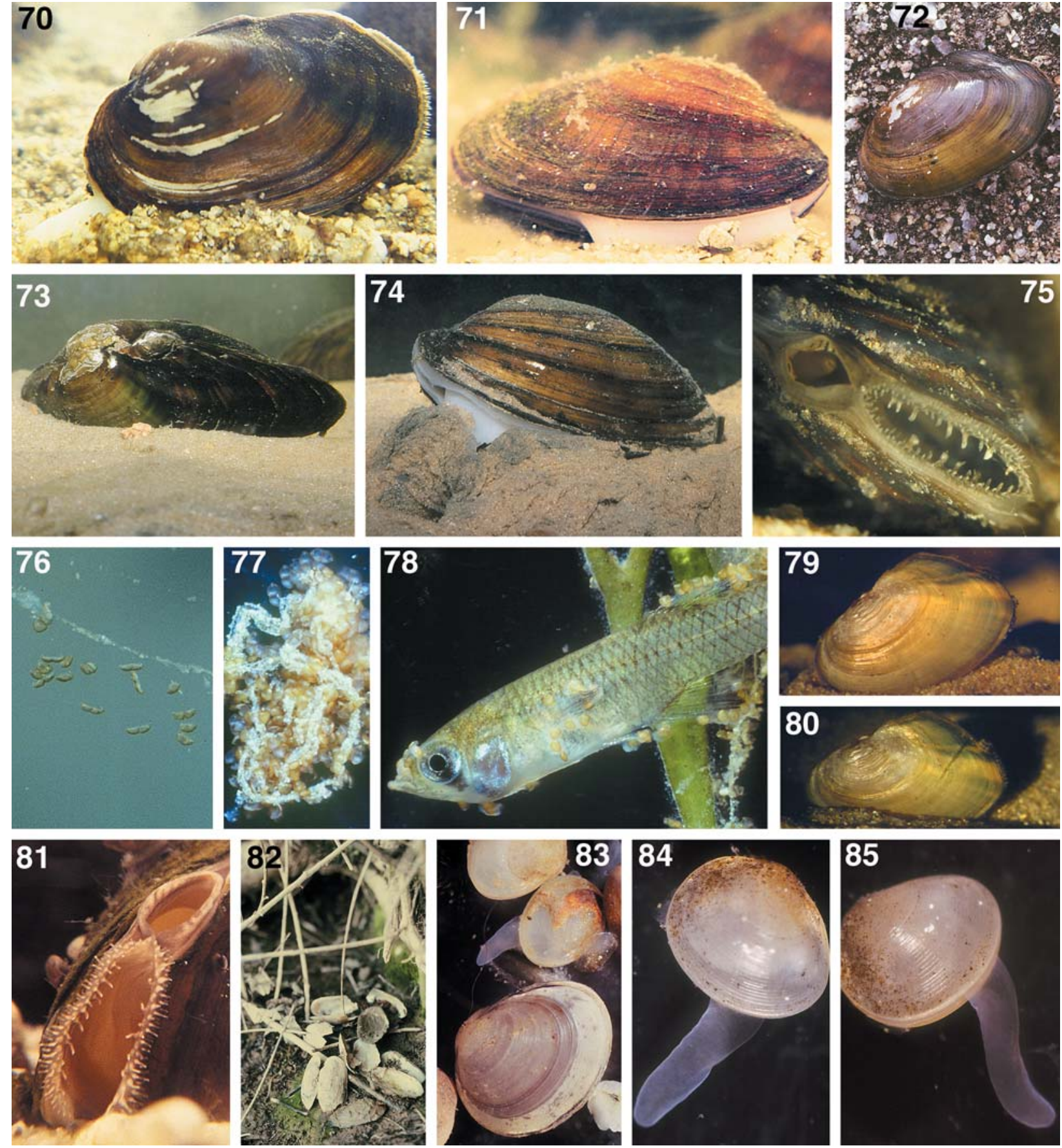

Figs. 70-85.- Bivalvos de la Comunidad de Madrid. 70) Ejemplar vivo de Potomida littoralis, río Tajo, Valdajos (III-1985). 71) Pie de Potomida littoralis, río Jarama Valdetorres (VII-1987). 72) Concha de Anodonta sp. en la orilla del embalse de San Juan, cuenca del Alberche (II-1989). 73-75) Ejemplar vivo, pie y sifones de Anodonta sp., embalse de Picadas, cuenca del Alberche (XI1988). 76-78) Gloquidios de Anodonta sp. liberados colgando de un filamento, filamento caído con masa de gloquidios, y pez (Gambusia holbrooki) infectado por gloquidios, embalse de Picadas (XI-1988). 79-80) Juveniles de Anodonta sp. enterrándose en el sedimento, embalse de Picadas (XI-1988). 81) Sifones de Unio cf. pictorum, río Jarama, Valdetorres (III-1987). 82) Grupo de conchas vacías de Unio cf. pictorum comidas por rata de agua en la orilla del río Jarama, Valdetorres (III-1987). 83) Ejemplares vivos de Pisidium casertanum, fuente Valsordo, Ávila (II-1989). 84-85) Pisidium nitidum mostrando pie extendido y sifón, fuente Valsordo, Ávila (I-1989). 
paso por Cerceda y en el puente de Arganda sobre el río Jarama). En base a nuestras prospecciones, la especie se distribuye por los ríos Guadarrama, Manzanares y Perales, por los arroyos Guatel, Fresnera, de la Yunta, Corralizo, en la Fuente de la Fuenfría, las Lagunas de Peñalara y las Turberas de Canencia (Figura 88).

LOCALIDADES: $24 ; 61 ; 155 ; 156 ; 158 ; 170 ; 173 ; 174 ; 227 ; 228$; $234 ; 235 ; 237 ; 277 ; 281 ; 327 ; 331$.

\section{Pisidium nitidum Jenyns, 1832}

SINONIMIA:

Pisidium nitidum Jenyns, 1832. Trans. Camb. Phil. Soc., 4, p. 304, pl. XX fig. 7-8.

\section{DESCRIPCIÓN:}

Concha: De silueta bastante variable, se distingue por ser muy brillante y con escultura patente, generalmente regular. Suele presentar tres o cuatro costillas nepiónicas justo debajo del umbo. La fosa del ligamento es siempre corta y ancha, lo que puede ser de gran utilidad en la determinación, ya que los dientes de la charnela y la silueta pueden ser muy similares a los de otras especies presentes en la Comunidad de Madrid, principalmente P. casertanum y P. personatum (Figura 31).

Animal: Igual que la especie anterior (Figuras 84-85).

DiMENSIONES: Longitud 2-4,3 $\mathrm{mm}$; altura 2-3,5 $\mathrm{mm}$; anchura 1,5-2,7 $\mathrm{mm}$.

HÁBITAT: Ríos, arroyos, lagunas, canales, acequias y fuentes, en el sedimento.

DistribuCión: Holártica, desde Islandia, Feroe y Escandinavia hasta España, Córcega, Sicilia y Bulgaria. En América, desde Vancouver y El Labrador hasta México (Araujo, 1995). Se puede localizar en todas las cuencas hidrográficas de la Península Ibérica aunque no parece ser muy abundante en ninguna de ellas a excepción de la del río Júcar, donde aparece con frecuncia en fuentes (Araujo, 1995). La especie fue citada para la Comunidad de Madrid por Álvarez y Selga (1967) en Navas del Rey y la fuente de Las Huertas en las proximidades de Chapinería. En base a nuestras propias prospecciones la especie vive en los ríos Perales y Guadalix, en los arroyos Valdeyerno, de las Retuertas, de los Meaques y de la Fresnera, en la Laguna de San Juan y en sus canales (Figura 88).

LOCALIDADES: $27 ; 83 ; 144 ; 148 ; 158 ; 159 ; 160 ; 165 ; 169 ; 172$; $176 ; 177$.

\section{Pisidium personatum Malm, 1855}

SINONIMIA:

Pisidium personatum Malm, 1855. Götheborgs K. Vet. Vitt. Samh. Handl. (n. t.) 3, p. 107.

Pisidium fontinale (Draparnaud): Bourguignat, 1864. Malac. de L'Arg., II, 360

Pisidium pusillum (Gmelin): Nobre, 1886. Journal de Conchyliologie, XXXIV, 121

Pisidium pulchellum Jenyns: Bofill y Haas, 1920. Treb. Mus. Cienc. Nat. Barcelona, 3, 804

\section{DESCRIPCIÓN:}

Concha: Puede confundirse con P. casertanum, de la que se diferencia por su silueta ovalada y umbos poco prominentes y bastante centrales. La escultura suele ser fina e irregular, sobre una superfice poco brillante. La charnela es similar a la de ejemplares típicos de $P$. casertanum, aunque la mayoría de las veces presenta un callo característico entre la fosa del ligamento y los dientes laterales posteriores. El callo es considerablemente más patente en la valva derecha, aunque puede verse también en la izquierda (Figura 32).

Animal: Igual que las otras especies del género.

DiMENSIONES: Longitud 3,4-4,7 mm; altura 2,9-3,2 $\mathrm{mm}$; anchura 2,2-2-7 $\mathrm{mm}$.

HÁBITAT: En todo tipo de medios dulceacuícolas. En el sedimento de lagunas, lagos de alta montaña, ríos, riachuelos, arroyos o regatos, suelos enfangados, acequias y manantiales. Muy frecuente en fuentes y abrevaderos.

DisTRIBUCIÓN: En Europa se encuentra desde Suecia y desde las islas Feroe hasta el Caspio. También en parte de África y en Madeira (Araujo, 1995). Es la segunda especie más frecuente de los Pisidios en la

Figs. 70-85.- Bivalves of Comunidad de Madrid. 70) Live specimens of Potomida littoralis, Tajo river, Valdajos (III-1985). 71) Foot of Potomida littoralis, Jarama river, Valdetorres (VII-1987). 72) Shell of Anodonta sp. on the shore of the San Juan reservoir, Alberche basin (II-1989). 73-75) Live specimens, foot and siphons of Anodonta sp., Picadas reservoir, Alberche basin (XI1988). 76-78) Anodonta sp. glochidia hanging on a filament, filament with glochidia mass and glochidia infecting a fish (Gambusia holbrooki), Picadas reservoir (XI-1988). 79-80) Anodonta sp. juveniles burying themselves in the sediment, Picadas reservoir (XI-1988). 81) Siphons of Unio cf. pictorum, Jarama river, Valdetorres (III-1987). 82) Group of empty shells of Unio cf. pictorum eaten by a water rat in a Jarama river shore, Valdetorres (III-1987). 83) Pisidium casertanum live specimens, Valsordo Fountain, Ávila (II-1989). 84-85) Pisidium nitidum showing the extended foot and siphon, Valsordo Fountain, Ávila (I-1989). 


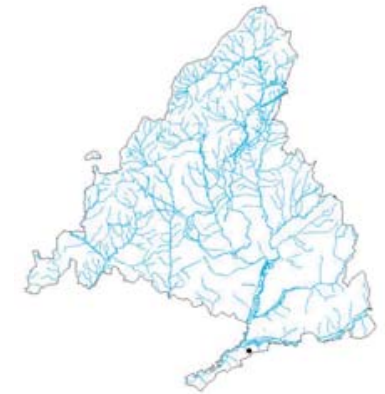

Pseudamnicola (Pseudamnicola) subproducta

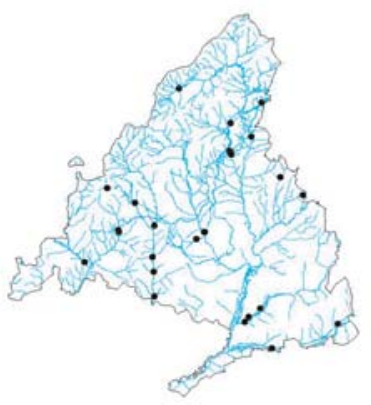

Potamopyrgus antipodarum

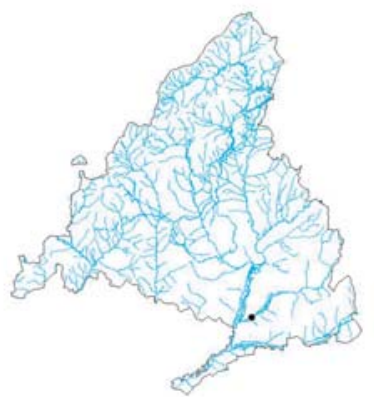

Stagnicola palustris

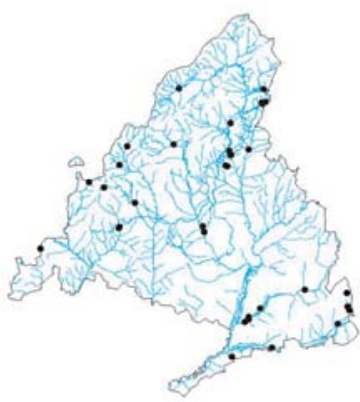

Radix balthica

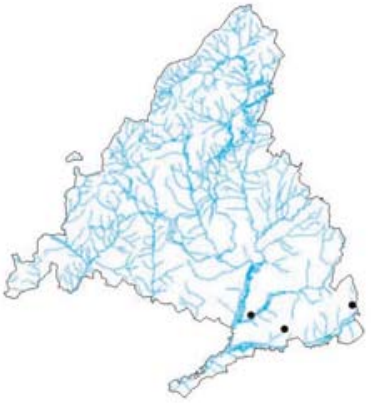

Peudamnicola (Corrosella) hinzi

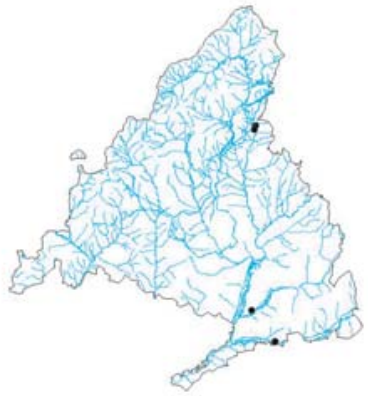

Bithynia (Bithynia) tentaculata

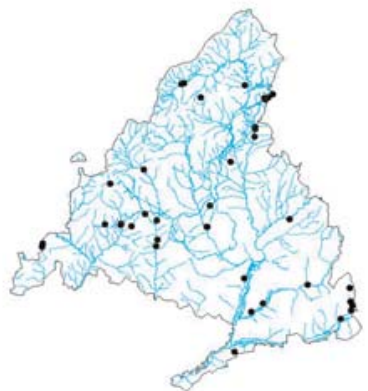

Galba truncatula

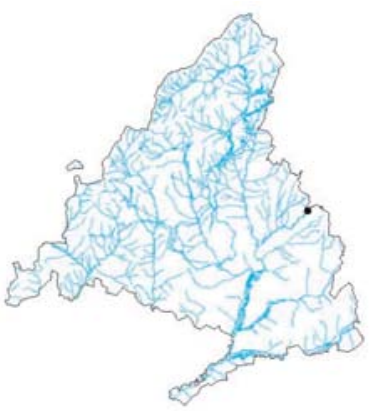

Anisus (Anisus) spirorbis

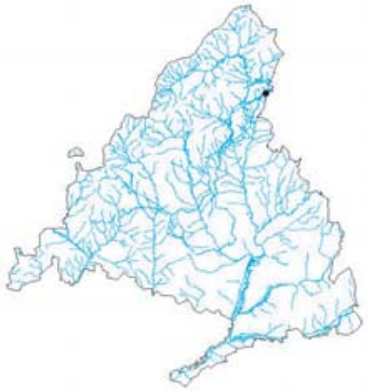

Islamia pallida

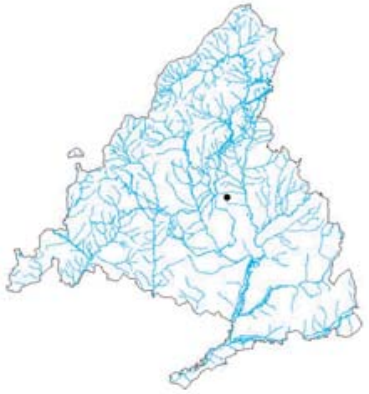

Lymnaea stagnalis

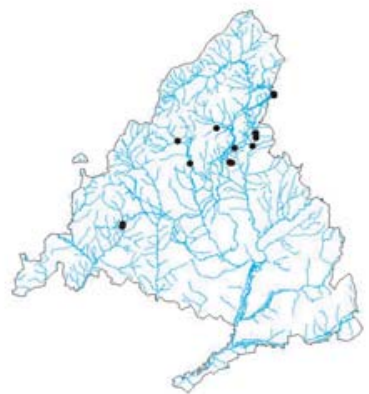

Radix auricularia



Gyraulus (Gyraulus) albus

Fig. 86.- Mapas de distribución de gasterópodos de agua dulce en la Comunidad de Madrid.

Fig. 86.- Distribution maps of freshwater gastropods in Comunidad de Madrid. 


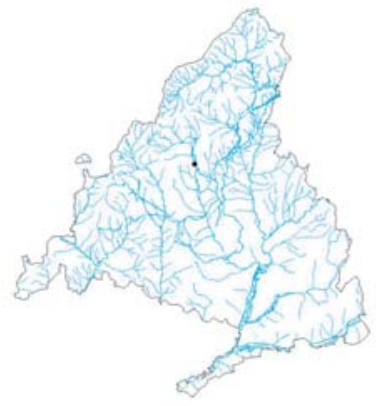

Gyraulus (Gyraulus) chinensis

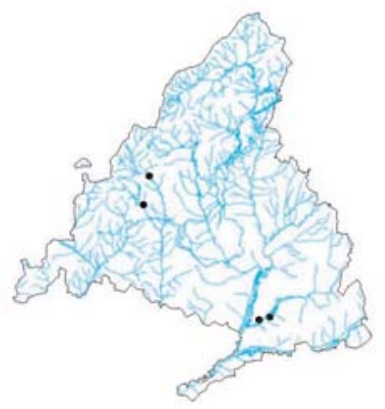

Hippeutis complanatus

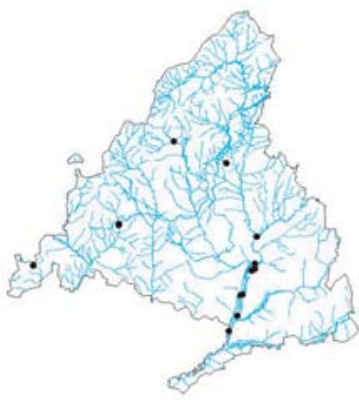

Ferrissia (Pettancylus) clessiniana

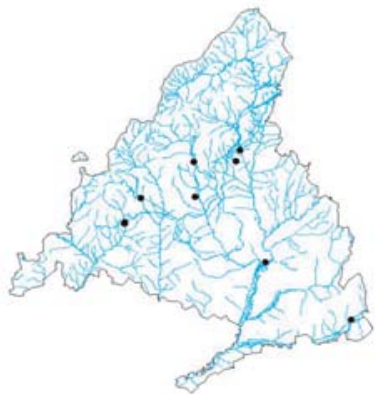

Gyraulus (Torquis) laevis

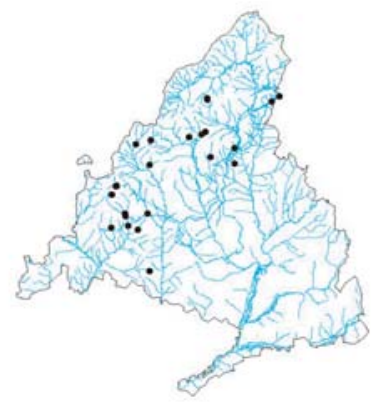

Planorbarius metidjensis

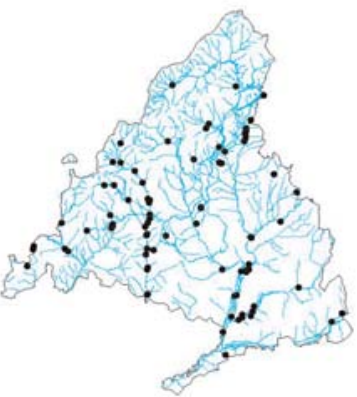

Physella (Costatella) acuta

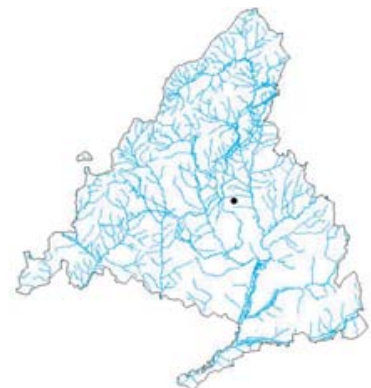

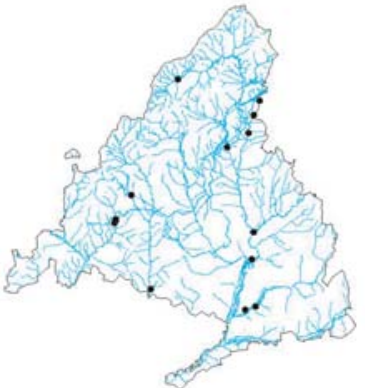

Gyraulus (Armiger) crista

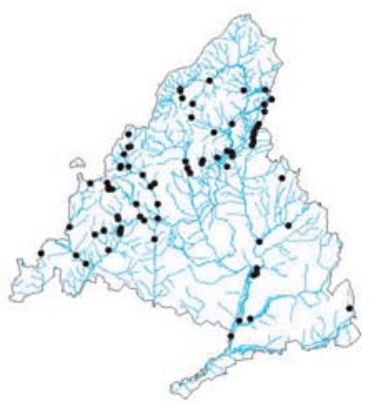

Ancylus fluviatilis

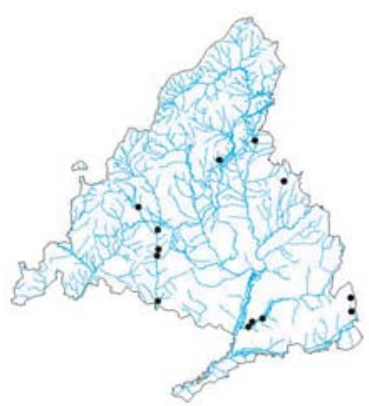

Oxyloma (Oxyloma) elegans

Oxyloma sarsii

Fig. 87.- Mapas de distribución de gasterópodos de agua dulce en la Comunidad de Madrid.

Fig. 87.- Distribution maps of freshwater gastropods in Comunidad de Madrid. 


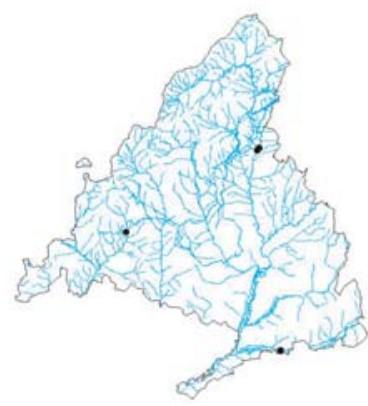

Potomida littoralis

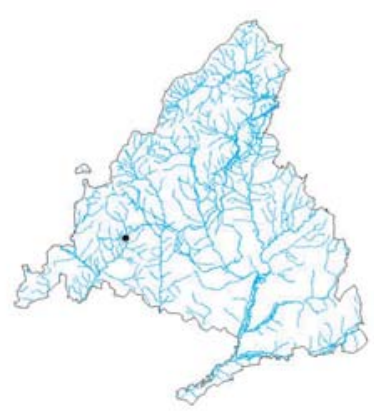

Musculium lacustre

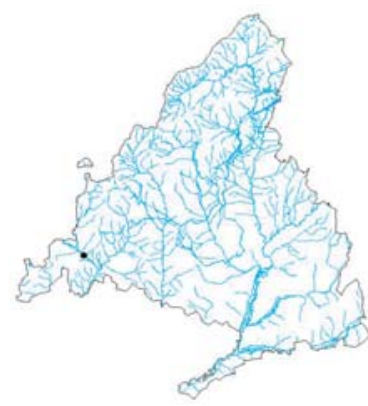

Anodonta sp.

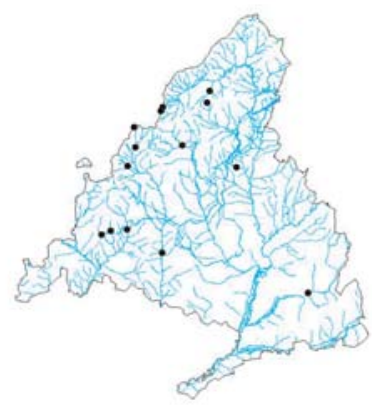

Pisidium casertanum

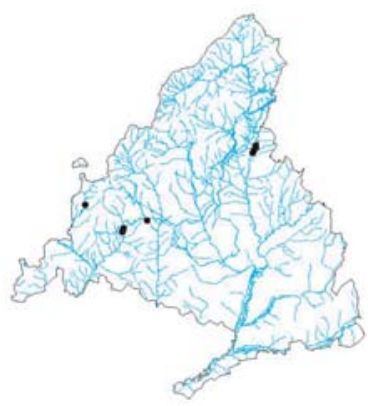

Unio cf. pictorum

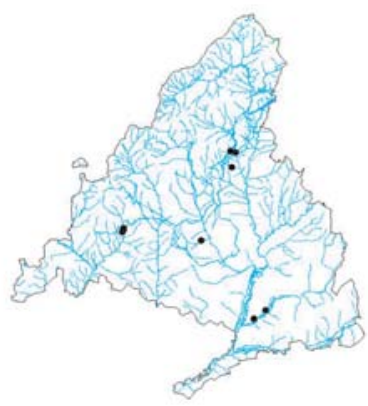

Pisidium nitidum

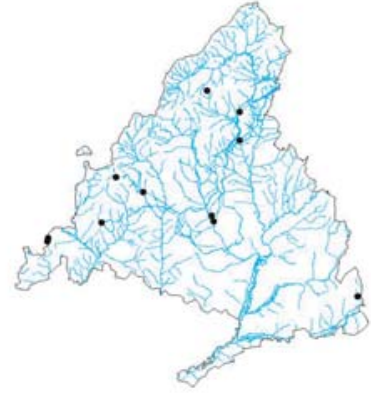

Pisidium personatum

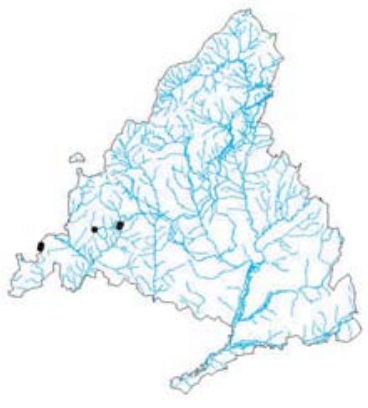

Pisidium subtruncatum

Fig. 88.- Mapas de distribución de los bivalvos en la Comunidad de Madrid.

Fig. 88. - Distribution maps of the bivalve species in Comunidad de Madrid.

Península Ibérica, distribuyéndose por todas sus cuencas hidrográficas (Araujo, 1995). La especie ha sido citada con anterioridad para la Comunidad de Madrid por Pérez Arcas (1863, como Cyclas fontinalis). Nosotros la hemos encontrado en los ríos Aulencia y Guadalix, en los arroyos Albalá, Sepulcro, de las Tórtolas, del Corralizo, y los que están situados en el Parque del Oeste y en la Junta de Energía Nuclear (Ciudad Universitaria). También fue hallada en las turberas de Canencia (Figura 88).

LOCALIDADES: 9; 130; 139; 161; 162; 163; 164; 165; 170; 174; 284.
Pisidium subtruncatum Malm, 1855

SINONIMIA:

Pisidium subtruncatum Malm, 1855. Götheborgs K. Vet. Vitt. Samh. Handl. (n. t.) 3, 92

\section{DESCRIPCIÓN:}

Concha: Característica por su silueta oblicua e inequilateral de forma que los umbos se sitúan muy retrasados; la porción anterior de la concha es proporcionalmente mayor que en otras especies de la familia, el borde superior es muy corto y el anterior superior suele ser muy inclinado. La charnela es 
fuerte y corta, con dientes laterales robustos, especialmente el anterior inferior en la valva derecha y el anterior en la izquierda. Los dientes cardinales en la valva izquierda son largos, ligeramente curvados y paralelos (Figura 33).

Animal: Igual que el resto de las especies del género, salvo que el surco pedal es más corto que en el resto de las especies del género.

DimensiOnES: Longitud 3-4,3 $\mathrm{mm}$; altura 2,6-3,8 $\mathrm{mm}$; anchura 1,7-2,6 $\mathrm{mm}$.

HÁBITAT: Habita principalmente en el sedimento de ríos y arroyos, aunque también puede ser frecuente en fuentes y manantiales. También en lagos de alta montaña.

DistriBución: Paleártica, desde Escandinavia y Feroe hasta el norte de África y el Lago Baikal al este. También en el Norte de América (Araujo, 1995). Es la tercera especie en abundancia de la Península Ibérica, habiéndose encontrado en todas sus cuencas hidrográficas a excepción de las del Guadalquivir, Segura y Pirineo Oriental (Araujo, 1995). Nosotros la hemos encontrado en el río Perales y en los arroyos de Tórtolas y del Corralizo (Figura 88).

LOCALIDADES: 94; 158; 160; 161; 162; 172; 174.

\section{Comentarios y discusión}

La Comunidad de Madrid no puede considerarse un área especialmente diversa en cuanto a su fauna autóctona de moluscos dulceacuícolas. Su composición litológica, con dominancia de granitos en el Sistema Central, margas de degradación de calizas y yesos, en el sur y sureste de la región, unidos a una climatología continental extrema, no crean las condiciones más favorables para ello, a pesar de la gran variedad de ambientes acuáticos. Ello se traduce en la predominancia de especies ubiquistas como Radix balthica, Galba truncatula, Ancylus fluviatilis y Physella acuta que son abundantes en la región, en todas, o casi todas las cuencas fluviales, y en casi todo tipo de hábitats. Entre los bivalvos, Pisidium casertanum y Pisidium personatum también están presentes en la mayoría de los habitat dulceacuícolas. Algunas especies se localizan casi exclusivamente en la vertiente sur de la sierra de Guadarrama, y particularmente en las pequeñas áreas de afloramientos calizos como es el caso de Radix auricularia y Gyraulus albus. El planórbido Planorbarius metidjensis se encuentra también en estas áreas, aunque prefiere zonas de mayor altitud con aguas corrientes, limpias y frías. Aunque más escaso, Gyraulus laevis vive igualmente en aguas limpias, pero prefiere que estén estancadas o tengan ligera corriente y es capaz de resistir períodos de sequía. Gyraulus crista es ligeramente más abundante, aunque esta especie parece presentar una distribución disyunta, con poblaciones en la cuenca del Henares. Sería conveniente intensificar los muestreos en las áreas centrales para corroborar esta hipótesis, aunque la intensa urbanización de la capital y alrededores, sugiere que aunque la especie pudiera haber estado presente en el pasado, las poblaciones podrían haber desaparecido por contaminación o pérdida de los ambientes naturales. Las demás especies autóctonas tienen una distribución más restringida, con preferencia por zonas calizas (Bithynia tentaculata, Hippeutis complanatus). Ferrisia clessiniana, con las mismas preferencias y también distribución restringida, es una especie de origen incierto (Falkner et al., 2002) ya que algunos autores la consideran alóctona aunque está presente en el registro fósil.

El género Anisus está pobremente representado en la Comunidad de Madrid. Solamente hemos encontrado una concha de $A$. vortex procedente del río Manzanares, sin localidad específica, en la colección del MNCN. Anisus spirorbis se ha encontrado vivo sólo en El Encín (río Henares). Las demás citas corresponden a conchas de la colección del MNCN.

La escasez de medios calizos en la Comunidad de Madrid se refleja en una fauna pobre en hidróbidos, ya que muchas de sus especies están asociadas a fuentes, manantiales y surgencias de aguas carbonatadas y limpias procedentes de cavidades o del medio intersticial. Se trata de medios muy sensibles y frágiles expuestos a contaminación y alteración física del hábitat por acción humana directa. Entre las especies de este grupo de gasterópodos se encuentra "Islamia" coronadoi, descrita en los alrededores de Madrid por Bourguignat (1870). Esta especie se ha buscado con intensidad en el marco de una revisión de los moluscos hidróbidos de la Península (Arconada \& Ramos, 2006), sin que se haya podido localizar. Es posible que esta especie, que se describió exclusivamente sobre caracteres de la concha, pueda haberse extinguido. Esta búsqueda, sin embargo, nos llevó al descubrimiento y descripción de una nueva especie, Islamia pallida, otro hidróbido minúsculo pero que presenta claras diferencias conquiológicas con "I." coronadoi (figuras 4 y 5) (Arconada \& Ramos, 2006). Las especies del género Pseudamnicola que, por el 
contrario pueden vivir en ambientes de menor corriente, son algo más abundantes en la región y forman poblaciones numerosas en número de efectivos. Hemos identificado dos especies de este género: $P$. (P.) subproducta y $P$. (C.) hinzi, la primera restringida a la Laguna de Ontígola y la segunda con una distribución más amplia.

Citamos aquí cuatro especies de gasterópodos presumiblemente introducidas: Potamopyrgus antipodarum, especie originaria de Nueva Zelanda que se ha introducido en Europa y América y se ha instalado formando abundantes poblaciones gracias a su estrategia reproductora por partenogénesis. En la Comunidad de Madrid presenta una amplia distribución en todo tipo de medios, siendo una plaga en ríos como el Henares. Su presencia fue ya detectada con anterioridad (Moreno et al., 1992) y debe considerarse como especie invasora. Incluso, la cita de Pseudamnicola lanceolata dada por Álvarez y Selga (1967) en la Laguna de Ontígola podría referirse a Potamopyrgus antipodarum. La primera cita de esta especie en Europa data de 1889 en Inglaterra (Smith, 1889), y según Ponder (1988), empezó a extenderse por el resto del continente a partir de 1900, por lo que bien pudiera haber llegado a la Laguna de Ontígola antes de 1967. No obstante, nosotros no la hemos detectado en esta localidad.

Gyraulus chinensis, originaria de Asia, se ha introducido accidentalmente en cultivos de arroz. La localización de ejemplares en la Comunidad de Madrid resulta sorprendente ya que se ha detectado en el río Manzanares, cerca de Colmenar Viejo, donde no existe ese cultivo. Se trata de la primera cita de la que se tiene constancia en aguas dulces no asociadas a arrozales y se ignora la causa de su introducción.

Sin duda la presencia de Lymnaea stagnalis y Oxyloma (Oxyloma) sarsii se debe a una introducción accidental en un centro de jardinería. No obstante, se incluyen en este trabajo para facilitar su identificación en caso de que pudieran extenderse en el futuro en habitat naturales de la región.

Con respecto a las náyades, se comprueba que en la Comunidad de Madrid, al igual que en el resto de la Península Ibérica, están desapareciendo de forma alarmante. Aunque quedan tramos de ríos por prospectar, nuestros datos reflejan un enrarecimiento progresivo de las especies fundamentalmente por destrucción de sus hábitat. Un ejemplo esclarecedor sería la desaparición de las poblaciones de Unio del río Jarama por la degradación de este curso fluvial a su paso por la Comunidad de Madrid.
Las áreas de mayor biodiversidad, entendidas como las que presentan un mayor número de especies en las muestras analizadas, se localizan principalmente en los tramos altos de los ríos de la vertiente sur del Guadarrama, con dos grandes áreas situadas respectivamente hacia el nordeste y sureste del Parque Regional de la Cuenca Alta del Manzanares (Figura 126). Entre las del sureste cabe destacar el área del río Perales - Quijorna, donde han aparecido 15 especies pertenecientes a todos los grupos aquí tratados con excepción de los hidróbidos. Sin embargo, en los últimos muestreos realizados el número de especies recolectadas ha disminuido sensiblemente y, aunque podría deberse a un efecto del muestreo, no descartamos que el crecimiento urbanístico del área, y consiguiente aumento de la contaminación, pueda haber tenido un impacto muy negativo sobre las especies más sensibles a la alteración del medio, como parece ser el caso de las tres especies del género Gyraulus y algunas de pequeños bivalvos. Le sigue el área del río Aulencia - Valdemorillo con 10 especies, el Arroyo Tórtolas - San Martín de Valdeiglesias con seis especies y finalmente Guadarrama - Cercedilla y Arroyo Corralizo - Colmenar de Arroyo, con cinco especies.

Hacia el nordeste, las áreas con mayor riqueza específica se localizan más próximas entre si, con predominio de las ubicadas en las franjas de calizas. La mayor diversidad corresponde al tramo Valdetorres - Talamanca del río Jarama, donde se han identificado 11 especies y río Guadalix - San Agustín con 10 especies. En la primera de ellas parece estar produciéndose un descenso en la población de moluscos dulceacuícolas, y en particular de las náyades. De hecho en los últimos muestreos sólo pudieron recolectarse conchas vacías de Unio cf. pictorum sin que se avistara ningún individuo vivo. Forman parte de este conjunto de áreas, las de los alrededores de Patones, con cinco especies de moluscos (entre las que se encuentra el hidróbido valvatiforme I. pallida) y la del Arroyo Albala, también con cinco especies.

En el extremo sur de la región destacan dos áreas separadas entre sí, la de la Laguna de San Juan - Titulcia, cuenta con 10 especies de gasterópodos y tan sólo una de bivalvo, P. nitidum, y la del Arroyo Sepulcro - Estremera en el que hemos encontrado seis especies.

El área central de la región es relativamente pobre en medios acuáticos naturales. En ella se ubica la capital y los grandes pueblos, prácticamente colindantes, y como consecuencia multitud de hábitats han desaparecido o se han alterado drásti- 

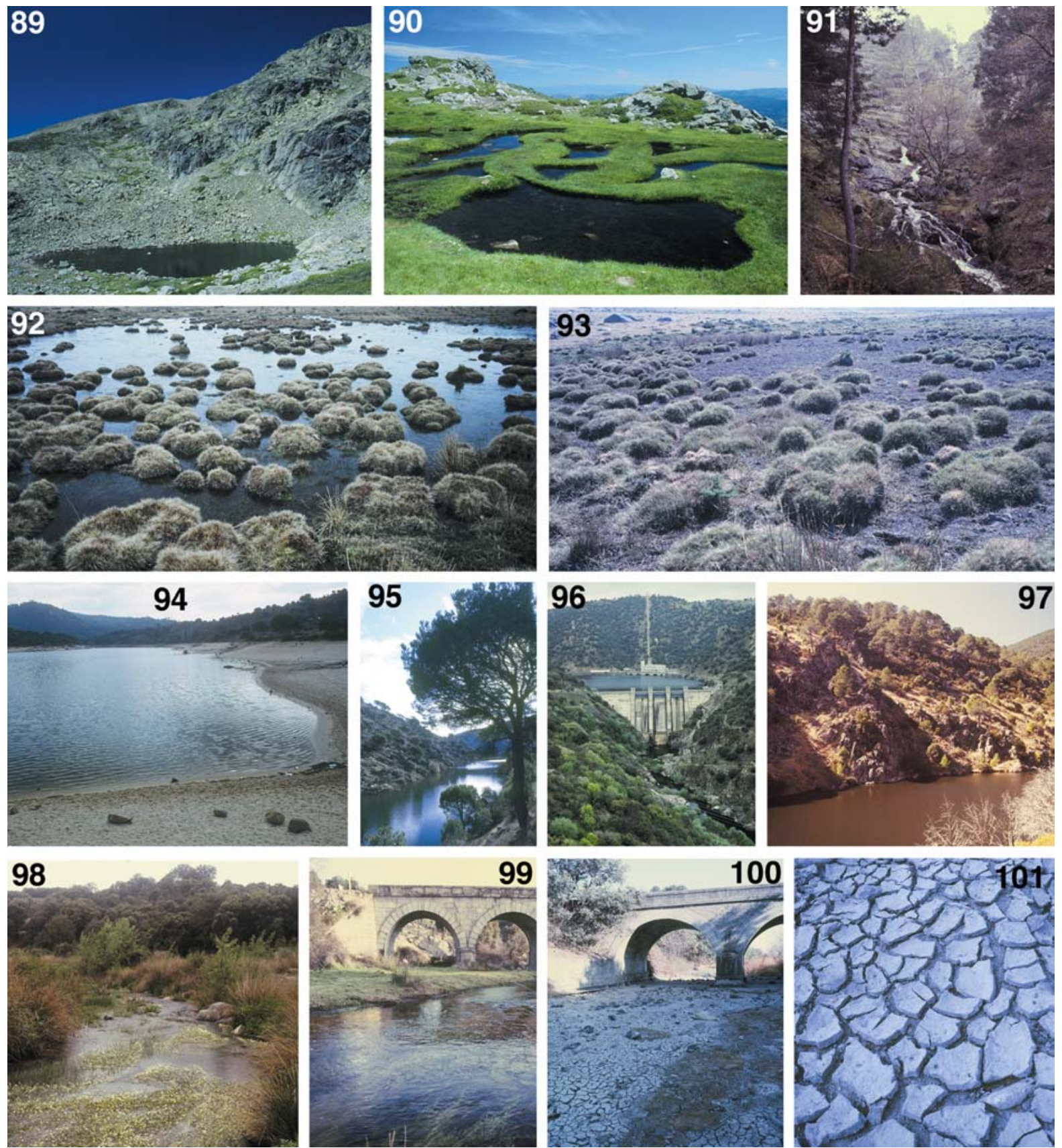

Figs. 89-101.- Hábitats dulceacuícolas de la Comunidad de Madrid: alta montaña y cuencas occidentales del Alberche, Cofio y Perales. 89) Laguna de Peñalara (II-1982). 90) Lagunillas de Peñalara (VII-1990). 91) Arroyo Sestil del Maillo, Canencia (V1984). 92-93) Turbera de Canencia, con agua (II-1985) y seca (IX-1985). 94) Embalse de San Juan, cuenca del Alberche (II-1989). 95-96) Embalse y presa de Picadas, cuenca del Alberche (I-1986). 97) Embalse del río Cofio (X-1984). 98) Río Perales por Quijorna con vegetación acuática (V-1984). 99) Río Perales por Navalagamella, con caudal normal de agua (II-1987). 100-101) Río Perales por Quijorna, seco (IX-1985).

Figs. 89-101. - Freshwater habitats of Comunidad de Madrid: high mountains and western basins of the rivers Alberche, Cofio and Perales. 89) Peñalara Lake (II-1982). 90) Peñalara Lake (VII-1990). 91) Sestil del Maillo stream, Canencia (V-1984). 92-93) Canencia Turf, full of water (II-1985) and empty (IX-1985). 94) San Juan reservoir, Alberche basin (II-1989). 95-96) reservoir and dam of Picadas, Alberche basin (I-1986). 97) Cofio river reservoir (X-1984). 98) Perales river at Quijorna with aquatic vegetation (V-1984). 99) Perales river at Navalagamella, with normal water level (II-1987). 100-101) Dry bottom of the Perales river at Quijorna (IX-1985). 
camente. Además, por debajo de la capital y de grandes pueblos los ríos reciben multitud de vertidos, muchas veces sin depurar, o sin depurar adecuadamente, lo que ha alterado de forma significativa, y a veces irreversible, los cauces, de forma que su fauna ha deaparecido. Esto es evidente, entre otros, en los tramos bajos del Guadarrama, el Jarama y el Manzanares. Tras su paso por la capital, el Manzanares está represado y estancado con fines estéticos, simulando que tiene más cauce y caudal, pero el agua apenas fluye por lo que no se puede hablar de "río" en sentido estricto de corriente de agua convenientemente oxigenada. Los tramos bajos de los ríos sufren, además, el impacto de la contaminación producida por el arrastre, por escorrentía, de los productos fitosanitarios que se utilizan en los cultivos de forma indiscriminada, así como el aporte extra de materia orgánica procedente de dichos cultivos. Esto es patente en la zona sur, principalmemte en el Henares, Tajuña y Tajo. Otro capítulo importante a considerar es el de las graveras y alteraciones de los cauces, como limpiezas, canales, etc. Las graveras de Vaciamadrid, en el tramo final del Jarama, son un buen ejemplo de esta alteración. Los canales de la cuenca del Tajo y de otros de los grandes ríos del sur también son un buen ejemplo de alteración de las cuencas, ya que modifican los caudales y el "sustrato" se vuelve artificial.

Los embalses producen un impacto de primera magnitud en los ecosistemas fluviales ya que alteran la dinámica y el caudal, la sedimentación aguas abajo, modifican la calidad del agua y otros parámetros como la temperatura. Siendo los moluscos organismos bentónicos, estas alteraciones tienen un impacto negativo importante en sus poblaciones favoreciendo el reemplazo de algunas especies autóctonas, con mayores exigencias ecológicas, por especies ubiquistas e incluso por especies invasoras, como P. antipodarum. Como consecuencia hay una tendencia hacia el empobrecimiento y la homogenización faunística entre cuencas. Los embalses, además, impiden la dispersión de las especies, incluyendo la de los peces que sirven de vector de difusión para las larvas (gloquidios) de los grandes bivalvos de agua dulce. Sin duda, esta puede ser una de las principales causas del paulatino enrarecimiento de las poblaciones de náyades en la región. En la Comunidad de Madrid hay embalses de todo tipo, desde pequeños y de montaña (como los de la zona del Escorial), a embalses inmensos. Por ejemplo, buena parte del tramo del Alberche en la Comunidad de Madrid ya no es de agua corriente sino embalsada. También la cuenca del Lozoya (que suministra la mayor parte del agua potable, tan buena y famosa, a la capital), tiene multitud de embalses que se suceden: el de la Pinilla, Riosequillo, el de Puentes Viejas, del Villar, el del Atazar. El número de grandes embalses en la Comunidad de Madrid asciende a 15 con un total de $330 \mathrm{Hm}^{3}$ de agua, incluyendo, además de los ya mencionados, el de Santillana, del Vellón, de Valmayor, del Pardo, etc.

La Red de Espacios Protegidos de la Comunidad de Madrid, entre los que se encuentran el Parque Regional de la Cuenca Alta del Manzanares, el del Curso Medio del río Guadarrama y su entorno y el Parque Natural de la Cumbre, Circo y Lagunas de Peñalara (ver Figura 126) apenas protegen una de las zonas con mayor diversidad de moluscos, la de Aulencia Valdemorillo, que está incluida en un extremo del Parque Regional de la Cuenca Alta del Manzanares. Las demás zonas de protección en el nordeste de la Región sorprenden por la pobreza relativa en especies de moluscos de agua dulce. En el sureste se encuentra el Parque Regional de los Cursos Bajos de los ríos Manzanares y Jarama, en el que todas las localidades muestreadas cuentan con menos de cinco especies, y el Refugio de la Laguna de San Juan que sí protege las 11 especies halladas en la misma. Finalmente, cabe destacar la Reserva Natural de El Regajal - Mar de Ontígola, que aunque en ella se localizan solamente cuatro especies de gasterópodos, tres de ellas ubiquistas, contiene poblaciones muy interesantes de hidróbidos del género Pseudamnicola. Ninguna de las especies de bivalvos de la familia Unionidae encontradas en nuestros muestreos se localizan en espacios protegidos ya que viven en los tramos medios y bajos de los ríos, con la excepción de Anodonta sp. que sólo la hemos encontrado en los Embalses de Picadas y San Juan. Los datos comparados de la cantidad de citas de estas especies en la bibliografía y en la colección del MNCN, con los obtenidos desde 1983 indican una clara regresión de las náyades en la Región, tanto en su distribución como en la densidad de población.

Teniendo en cuenta la riqueza específica, sugerimos que algunas áreas de mayor diversidad tanto en cuanto a número de especies como a la diversidad de géneros presentes, como las de Patones y Perales - Quijorna, serían merecedoras de alguna figura de protección.

Ninguna especie de las que se mencionan se encuentra incluida en el Catálogo Nacional de Especies Amenazadas ni en el de la Comunidad de Madrid, a pesar de estar muchas de ellas en riesgo y 

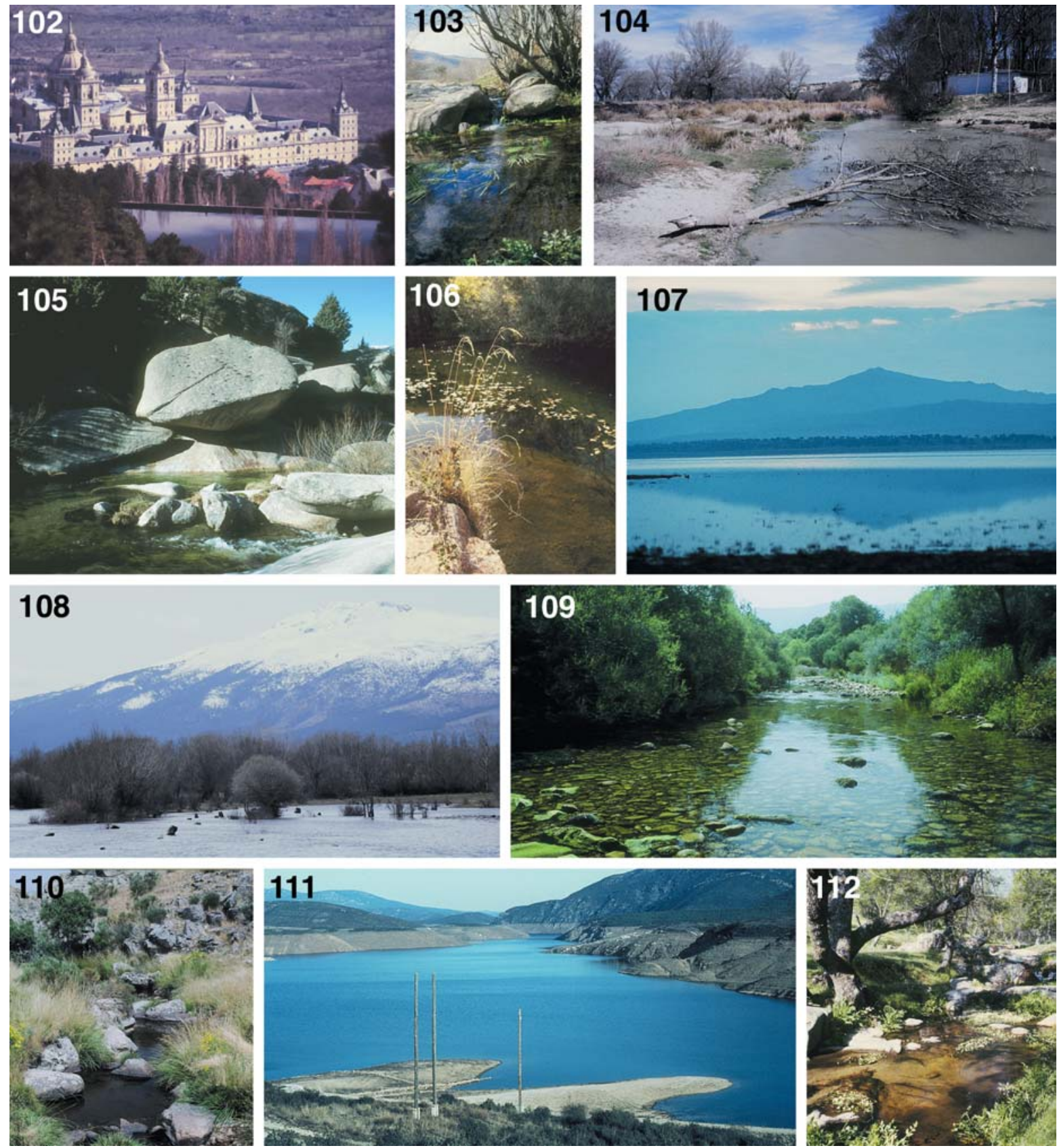

Figs. 102-112.- Hábitats dulceacuícolas de la Comunidad de Madrid: tramos medios de los ríos Guadarrama, Manzanares y Lozoya. 102) Embalse del Romeral, El Escorial (III-1987). 103) Río Aulencia, El Escorial (III-1986). 104) Río Guadarrama, Brunete (III-1989). 105) Río Manzanares por la Pedriza, Manzanares el Real (I-1991). 106) Río Manzanares, Manzanares el Real (IX-1984). 107) Embalse de Santillana, Manzanares el Real (IV-1982). 108) Embalse de la Pinilla, cuenca del Lozoya (III-1985). 109) Arroyo de la Angostura (o alto río Lozoya), Rascafría (VIII-1987). 110) Arroyo de Santa Ana, Miraflores (VIII-1987). 111) Embalse del Atazar, cuenca del río Lozoya (I-1983). 112) Arroyo Recombo, afluente de la margen derecha del Lozoya (V-1985).

Figs. 102-112. - Freshwater habitats of Comunidad de Madrid: middle parts of Guadarrama, Manzanares and Lozoya rivers. 102) Romeral Reservoir, El Escorial (III-1987). 103) Aulencia river, El Escorial (III-1986). 104) Guadarrama river, Brunete (III-1989). 105) Manzanares river at la Pedriza, Manzanares el Real (I-1991). 106) Manzanares river, Manzanares el Real (IX-1984). 107) Santillana Reservoir, Manzanares el Real (IV-1982). 108) La Pinilla reservoir, Lozoya basin (III-1985). 109) La Angostura stream (or high Lozoya), Rascafría (VIII-1987). 110) Santa Ana stream, Miraflores (VIII-1987). 111) El Atazar reservoir, Lozoya river basin (I-1983). 112) Recombo stream, Lozoya's right tributary (V-1985). 



Figs. 113-125.- Hábitats dulceacuícolas de la Comunidad de Madrid: tramos alto, medio y bajo del Jarama y cuencas del Tajuña y Tajo a su paso por la Comunidad de Madrid. 113) Río Jarama en el hayedo de Montejo (XI-1982). 114) Río Jarama en Valdetorres (VI-1986). 115) Arroyo de la Fresnera, afluente del río Guadalix, afluente del Jarama (III-1986). 116) Graveras de Vaciamadrid, cuenca baja del Jarama (I-1983). 117-118) Laguna de San Juan, Titulcia, en la cuenca del Tajuña (I-1983 y III-1984). 119) Arroyo de la Brea, cuenca del Tajo (IV-1988). 120-121) Arroyo Sepulcro, Estremera, con gran cantidad de basuras y escombros (IV-1988), y con restos de tumbas y coronas de difuntos (IV-1988). 122) Canal del Tajo y pozo, Estremera (V-1988). 123) Fuente de Colmenar Oreja, cuenca del Tajo (XI-1985). 124) Río Tajo por la Aldehuela, con represas y canales (X-1985). 125) Laguna de Ontígola, Aranjuez (IV-1993).

Figs. 113-125.- Freshwater habitats of Comunidad de Madrid: high, middle and low parts of Jarama river and Tajuña and Tajo basins. 113) Jarama river at the «hayedo de Montejo» (XI-1982). 114) Jarama river at Valdetorres (VI-1986). 115) La Fresnera stream, Guadalix river tributary, Jarama river tributary (III-1986). 116) Gravel pit of Vaciamadrid, Jarama river low basin (I-1983). 117-118) San Juan lake, Titulcia, Tajuña river basin (I-1983 y III-1984). 119) La Brea stream, Tajo river basin (IV-1988). 120121) Arroyo Sepulcro, Estremera, with some remains of graves and wreaths (IV-1988). 122) Channel and well of the Tajo river, Estremera (V-1988). 123) Colmenar de Oreja spring, Tajo basin (XI-1985). 124) Tajo river at La Aldehuela, with dams and channels (X-1985). 125) Ontígola lake, Aranjuez (IV-1993). 


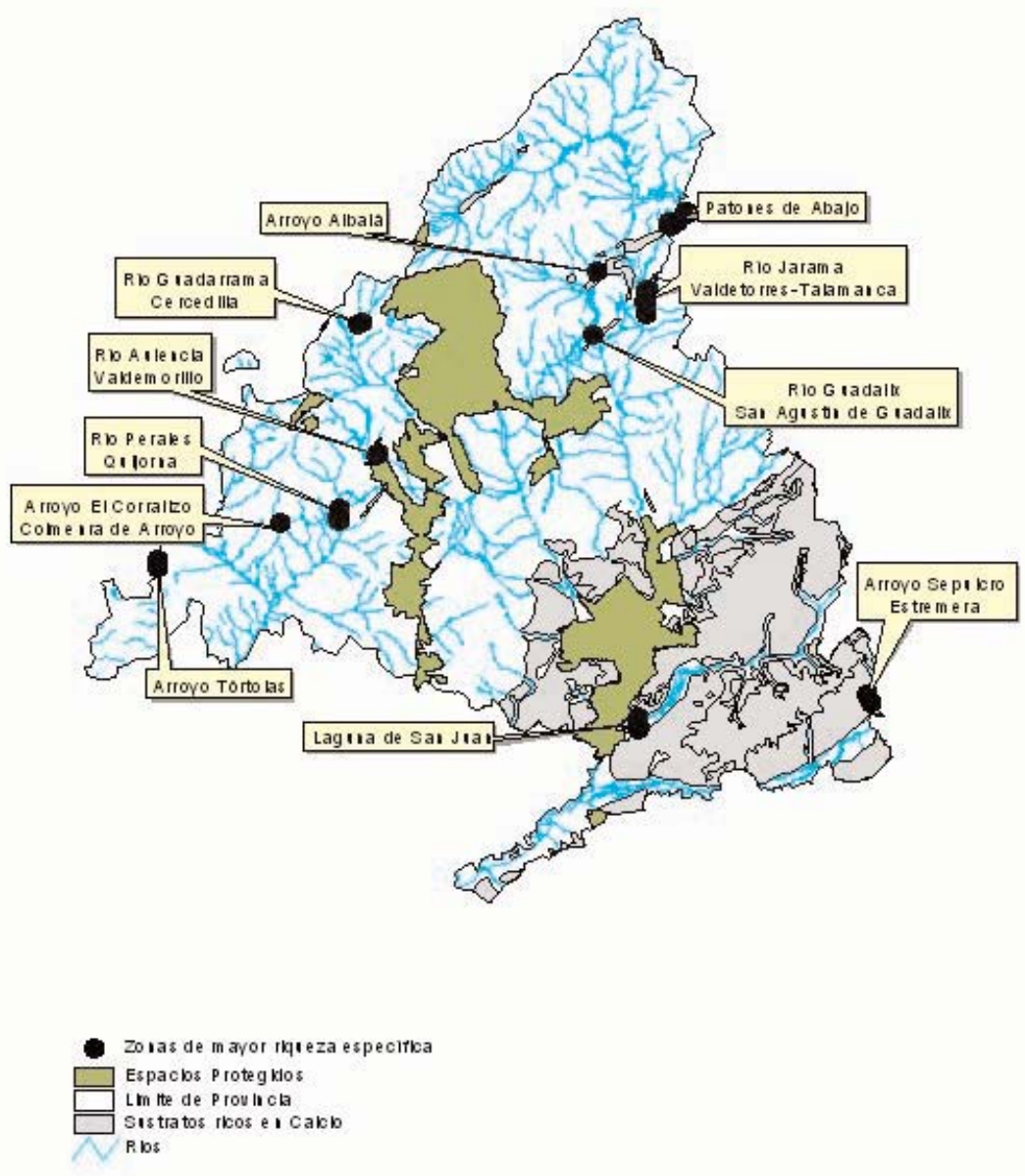

Fig. 126.- Distribución de las áreas de mayor riqueza específica de moluscos dulceacuícolas de la Comunidad de Madrid.

Fig. 126.- Distribution of highest specific richness areas for freshwater molluscs in Comunidad de Madrid.

en clara regresión. De hecho en el listado del Catálogo de Especies Amenazadas de la Comunidad de Madrid no figura todavía ninguna especie de molusco. Sin embargo, los moluscos continentales, y en particular los dulceacuícolas, constituyen uno de los grupos más amenazados, debido a las condiciones climatológicas en España (un país de clima bastante seco y árido) con sequías prolongadas y a las necesidades crecientes de consumo de agua. La sobreexplotación de los acuíferos para el cultivo y el consumo urbano, provocan que se sequen manantiales que son hábitats particularmente ricos en cuanto a su fauna de moluscos, y que además albergan una de las mayores proporciones de elementos endémicos en Europa (Arconada \& Ramos, 2003).
Los resultados de este trabajo sugieren que al menos la especie Islamia pallida y, en general, todas las especies de Uniónidos deberían incluirse en el Catálogo de la Comunidad en la categoría de "en peligro de extinción". Es necesario además llevar a cabo estudios específicos, incluyendo estudios anatómicos y moleculares, para esclarecer la taxonomía de las especies de la familia Unionidae. Los datos aún no publicados sugieren que es posible que los nombres asignados tradicionalmente a estas especies deben ser revisados, y que incluso algunas poblaciones puedan pertenecer a especies aún no descritas. También conviene llevar a cabo nuevos muestreos en algunas zonas sin prospectar o pobremente muestreadas para completar el mapa de 
distribución de las especies de moluscos en la Comunidad de Madrid. Finalmente, se hace necesario llevar a cabo estudios poblacionales de las especies sometidas a algún grado de amenaza para determinar si deben catalogarse y establecer la categoría correspondiente.

\section{AGRADECIMIENTOS}

Nuestro agradecimiento más sincero a todas las personas que nos ayudaron en los muestreos, especialmente a Nuria Martín, y nos aportaron muestras. Todos ellos se citan en el apartado Material y Métodos. A Javier Grijalbo que nos acompañó y ayudó en el muestreo en la laguna de Titulcia y alrededores, que tan bien conoce. El Centro de Investigaciones Ambientales de la Comunidad de Madrid Fernando González Bernáldez puso a nuestra disposición las muestras que tenían de la Comunidad de Madrid. Óscar Soriano, Conservador de la colección de Moluscos del MNCN nos proporcionó las facilidades necesarias para el estudio de la misma. Jorge Lobo nos ha cedido amablemente parte de la información cartográfica utilizada en este estudio y Miguel Ángel Alonso Zarazaga nos ha asesorado en la nomenclatura.

Los muestreos han sido realizados en el marco de los proyectos "Fauna Ibérica" (Refs. DGICYT, PB87-0397, PB890081, PB92-0121, PB95-0235 y CGL2004-04680-C10-01) у "Evaluación del conocimiento y del estado de conservación de la diversidad animal de Madrid" financiado por la Comunidad de Madrid (Ref. GR/AMB/0750/2004).

\section{Referencias}

Adam, W. 1960. Faune de Belgique. Mollusques. Voll, Mollusque terrestres et dulcicoles. Institut Royal des Sciences de Belgique. Bruxelles. 401 pp., 4 pls.

Álvarez, C. \& Agulló, R. M., 1981. Nota previa al estudio del "Mar de Ontígola". Boletín de la Real Sociedad Española de Historia Natural (Sección Biológica), 79: 105-113.

ÁlvAREZ, J., 1969. Über die verbritung der land und süswasserchnecken in mittelspanien in bezug auf die verschiedenen böden und gewässer. Malacologia, 9(1): 53-57.

Álvarez, J. \& Selga, D., 1967. Observaciones sobre invertebrados dulceacuícolas de los alrededores de Madrid. Boletín de la Real Sociedad Española de Historia Natural (Sección Biológica), 65: 171-197.

Anderson, R., 2003. Physella (Costatella) acuta Drapanaud in Britain and ireland. Its taxonomy, origins and relationships to other introduced Physidae. Journal of Conchology, 38(1): 7-21.

Araujo, R., 1995. Contribución a la taxonomía y biogeografía de la familia Sphaeridae (Mollusca: Bivalvia) en la Península Ibérica e Islas Baleares con especial referencia a la biología de Pisidium amnicum. Tesis doctoral, Universidad Complutense de Madrid. 393 pp.
Araujo, R., Remón, J. M., Moreno, D. \& Ramos, M. A., 1995. Relaxing techniques for freswater molluscs: trials for evaluation of different methods. Malacologia, 36(1-2): 29-41.

ArConADA, B., 2000. Contribución al conocimiento sistemático y filogenético de la familia Hydrobiidae (mollusca, Prosobreanchia) de la Península Ibérica. Tesis doctoral. Facultad de Ciencias, Universidad Autónoma de Madrid.

Arconada, B. \& Ramos, M. A., 2006. Revision of the genus Islamia Radoman, 1973 (Gastropoda, Caenogastropoda, Hydrobiidae) on the Iberian Peninsula and description of two new genera and three new species. Malacologia, 48(1-2): 77-132.

AzPeitia, F., 1933. Conchas bivalvas de agua dulce de España y Portugal. Memorias del Instituto Geológico y Minero de España. Tomos I y II. Madrid. 458 pp. y $763 \mathrm{pp}$.

BeCH, M., 1990. Fauna malacologica de Catalunya. Mol.luscs terrestres $i$ d'aigua dolça. Treballs de la Institució Catalana d'Historia Natural. Barcelona. $229 \mathrm{pp}$.

Boeters, H., 1987. Westeuropäische Moitessieriidae, 2 und Westeuropäische Hydrobiidae, 7. Moitessieriidae und Hydrobiidae in Spanien und Portugal (Gastropoda: Prosobranchia). Archiv für Molluskenkunde, 118(4/6): 181-261.

Bourguignat, M. J. R., 1870. Mollusques nouveaux, litigieux ou peu connus. Description des acéphales d'Espagne. F. Sauy. Paris. 11: 4-27; 12: 31-55.

Brown, D. S., 1980. Freshwater snails of Africa and their medical importance. Taylor \& Francis. London. $487 \mathrm{pp}$.

Brown, D., Grácio, M. A. A. \& MeIer-Brook, C., 1998.The Asian freshwater snail Gyraulus chinensis (Dunker, 1848) (Planorbidae) in West Africa and Europe. Journal of African Zoology, 112(3): 203-213.

CAlderón, A., 1894. Unionides de l'Espagne. Actas de la Real Sociedad Española de Historia Natural, 23: 31-33.

Chappuis, P. A., 1950. La récolte de la faune souterraine. Notes biospéologiques, 5:7-35.

Collier, K. J. \& Winterbourn, M. J., 1986. Processing of willow leaves in two suburban streams in Christchurch, New Zealand. New Zealand Journal of marine and freshwater research, 20: 575-582.

Drouet, H., 1893-94. Unionidae de l'Espagne. Mémoires de l'Académie de Dijon, ${ }^{\text {ème }}$ série, 4: 5-88.

Falkner, G. \& Proschwitz, T., 1998. A record of Ferrissia (Petancylus) clessiniana (Jickeli) in Sweden, with remarks on the identity and distribution of the european Ferrissia species. Journal of Conchology, 36(3): 39-40.

FALKNER, G., Ripken, E. J. \& FALKNER, M., 2002. Mollusques continentaux de France. Liste de 
Référence annotée et bibliographie. Publications scientifiques du Muséum National d'Histoire Naturelle. Paris. 350 pp.

FALNIOWSKI, A., 1980. Subgenus Radix s. str. (Gastropoda, Basommatophora) in Poland. 1. Pigmentation of the mantle and anatomy. Description of Lymnaea peregra. Zeszyty Naukowe Uniwersytetu Jagiellonskiego Prace Zoologiczne, 26: 67-108.

García de Jalón, D. \& GonzÁlez de TANAGO, M., 1982. Introducción a una zoosociología del macrobentos en los ríos de la sierra de Guadarrama. Boletín de la Estación Central de Ecología (ICONA), 11(21): 63-71.

Germain, L., 1931. Mollusques terrestres et fluviatiles. Faune de France, vol. 21/22. Lechevalier. Paris. 893 pp.

Girod, A., BiAnchi, I. \& Mariani, M., 1980. Gasteropodi, 1. (Gasteropoda: Pulmonata Prosobranchia: Neritidae, Viviparidae, Bithynidae, Valvatidae). Guide per il reconoscimento delle specie animali delle acque interne italiane, 7: 1-86.

GÓMEZ, R. M. \& VIDAL-ABARCA, M. R., 1988. Gyraulus chinensis (Dunker, 1848) en la Península Ibérica. Iberus, 8(1): 115-118.

Graells, M. P., 1846. Catálogo de los moluscos terrestres $y$ de agua dulce observados en España y descripción y notas de algunas especies nuevas o poco conocidas del mismo país. Imp. M. Martínez. Madrid y Lima. 24 pp.

Gregorides, A., 1971. Contribución al estudio sistemático y ecológico de los moluscos dulceacuícolas de las aguas corrientes del centro de España. Boletín de la Real Sociedad Española de Historia Natural (Sección Biológica), 69: 125-149.

Grossu, A. V., 1987. Description de nouvelles espèces de la Familla Succineidae (Gastropoda, Pulmonata). Travaux du Museum d'Histore Naturelle "Grigori Antipa", 29:7-18.

HAAS, F., 1917. Estudio para una monografía de las náyades de la Península Ibérica. Publicaciones de la Junta de Ciencias Naturales de Barcelona, 2: 131-190.

HAAS, F., 1929. Fauna malacológica terrestre y de agua dulce de Cataluña. Trabajos del Museo de Ciencias Naturales de Barcelona, 13: 1-491.

HAAs, F., 1969. Superfamilia Unionacea. Das Tierreich, 88: 1-663.

HubENDICK, B., 1951. Recent Lymnaeidae. Their variation, morphology, taxonomy, nomenclatura and distribution. Kungliga Svenska Vetenskapsakademiens Hand-Lingar, 3(1): 1-223.

Kerney, M. P., Cameron, R. A. D. \& Jungbluth, J. H., 1983. Die landschnecken Nord-und Mitteleuropas. Paul Parey. Berlin. 384 pp.

Larraz, M. L. \& EquisoAin, J. J., 1993. Moluscos terrestres y acuáticos de Navarra (Norte de la Península Ibérica). Universidad de Navarra. Pamplona. 326 pp.
Lobo, J. M. \& Martín-Piera, F., 2002. Searching for a predictive model for Iberian dung beetle species richness (Col., Scarabaeinae) using spatial and environmental variables. Conservation Biology, 16(1): 158-173.

LOCARD, A., 1894. Les Bythinia du système européen. Revision des espéces appurtenant à ce genre d'aprés la collection de Bourguignat. Revue Suisse de Zoologie, 2: 65-143.

LOCARD, A., 1899. Conchyliologie portugaise. Les coquilles terrestres des eaux douces et saumatres. Archives du Muséum d'histoire naturelle de Lyon, 7: 1-303.

LozeK, V., 1964. Quartärmollusken der Tschechoslowakie. Rozpravy ústredního Ústavu geolického, 31: 1-374.

Margalef, R., 1958. Materiales para el estudio de las comunidades bióticas de las aguas dulces y salobres, principalmente del NE. de España. Publicaciones del Instituto de Biología Aplicada, 28: 5-47.

Margalef, R., 1974. Ecología. Omega. Barcelona. 951 pp.

Martínez-López, F., Alonso, S. \& Pujante, A., 1988. La malacofauna de la cuenca del río Mijares (Castellón, España): distribución y aspectos ecológicos. Iberus, 8(2): 85-101.

Martínez-LóPez, F., Jiménez, J., Subias, J. \& Amela, J. F., 1986. Sobre la distribución de Potamopyrgus jenkensi (Smith, 1889) (Gastropoda: Prosobranchia) en las cuencas de los ríos Mijares, Turia y Júcar. Iberus, 6(2): 245-255.

Martinez-Ortí, A \& Robles, F., 2003. Moluscos continentales de la Comunidad Valenciana. Generalitat Valenciana Conselleria de Territoi i Habitatge. Valencia. $259 \mathrm{pp}$.

Martorell, F. \& Bofill, J., 1888. Catálogo de la Colección Conchológica que fue de D. Francisco Martorell y Peña legada por dicho señor a la ciudad de Barcelona y existente en el Museo Martorell de la propia ciudad. Tipo-Litografía de los sucesores de N. Ramírez y Ca. Barcelona. 92 pp.

MeIer-Brook, C., 1983. Taxonomic studies on Gyraulus (Gastropoda: Planorbidae). Malacologia, 23(1-2):1-113.

Moreno, D., Ramos, M. A. \& Araujo, R., 1992. Los moluscos dulceacuícolas de la provincia de Madrid. Resúmenes del IX Congreso Nacional de Malacología, Bilbao. Cuadernos de Investigaciones Biológicas, 17: 70.

NiETo, M., 1967. Los pigmentos como indicadores ecológicos en las aguas corrientes del centro de España. Tesis doctoral. Centro de Estudios Investigación y aplicaciones del agua. Barcelona. 218 pp.

Ondina, P., Hermida, J. \& Outeiro, A., 1996. Oxyloma elegans (Risso, 1826) (Gastropoda, Pulmonata) en Galicia. Iberus, 14(2): 67-70. 
PARDO, L., 1932. Datos para el studio de la fauna hidrobiológica española. Boletín de Pesca y Caza, 4(910): 6-11, 1-9.

Pérez ArCAS, L., 1863. Elementos de Zoología. 2a Edición. Imprenta G. Alhambra. Madrid. vii + 527 pp.

Pérez-Quintero, J.C., Bech, M. \& Huertas, J. L., 2004. Los moluscos de las aguas continentales de la provincia de Huelva (SO España). Iberus, 22(2): 19-31.

Ponder, W., 1988. Potamopyrgus antipodarum a molluscan coloniser of Europe and Australia. Journal of Molluscan Studies, 54: 271-285.

PRAT, N., 1978. Ecología y sistemática de los Quironómidos (Insecta: Diptera) de los embalses españoles. Tesis doctoral. Universidad de Barcelona. 359 pp.

Prat, N., 1979. Fauna marginal de los embalses españoles. Miscelánea Zoológica, 5: 149-160.

RAMOS, M.A. \& APARICIO, M. T., 1985. Gasterópodos terrestres y dulceacuícolas de las Lagunas de Ruidera (España). Iberus, 5: 113-123.

Ramos, M.A., Arconada, B., Rolán, E. \& Moreno, D., 2000. A new genus and a new species of hydrobiid snail (Mollusca: Gastropoda: Hydrobiidae) from Eastern Spain. Malacologia, 42(1-2): 75-101.

RAuT S. K., BhaumiK, S. \& DAs, S., 1995. Occurrence of the snail Physa acuta Drapanaud in Calcuta, India. Bombay Natural History Society, 92: 434.

RolÁN, E., 2001. Resistencia a la desecación de algunos moluscos de agua dulce. Noticiario de la Sociedad Española de Malacología, 35: 36-39.

SERVAIN, G., 1880. Étude sur les mollusques recueillis en Espagne et en Portugal. D. Baudin. St. Germain. 171 pp.

SiMOES, M., 1996. Nota sobre a presenta em Portugal da espécie asiática Gyraulus chinensis (Dunker, 1848) (Pulmonada: Planorbidae). García de Orta Serie Zoologica, 21(1): 43-44.

SMith, E. A., 1889. Notes on Britisk Hydrobiidae with a description of a aupposed new species. Journal of Conchology, 6: 142-145.

Soriano, O., Villena, M. \& Alonso, M. S., 2001. Catálogo de los uniónidos (Mollusca, Unionidae) de la Península Ibérica conservados en el Museo Nacional de Ciencias Naturales (CSIC). Graellsia, 57(1): 133-152.
Talavan, J. \& Talavan Serna, J., 2004. Contribución a la malacología de la Serranía de Cuenca. Spira, 1(4): 11-21.

TE, G. A., 1978. The systematics of the family Physidae (Basommatophora: Pulmonata). Ph.D. dissertation. University of Michigan. Ann Arbor.

VÉlAZ, D. \& UGARTE, J., 1933. Estudio monográfico del río Manzanares. (Biología de las aguas continentales I). Boletín del Instituto Forestal de Investigaciones y experiencias, 6(11): 1-68.

Vidal Abarca, C. \& SuÁrez, M. L., 1985. Lista faunística y bibliográfica de los moluscos (Gastrópoda \& Bivalvia) de las aguas continentales de la península Ibérica e Islas Baleares. Listas de la flora y fauna de las aguas continentales de la Península Ibérica, $\mathrm{n}^{\circ} 2$. Asociación Española de Limnología. Barcelona. 191 pp.

VidAl-Abarca, M.R., Gómez, R. M. \& SuÁREz, M. L., 1991. The planorbidae (Gastropoda: Pulmonata) from the waters of the Segura river basin: SE of Spain. Iberus, 10(1): 119-129.

Westerlund, C. A., 1885. Fauna der in der Paläartischen region (Europa, Kaukasien, Siberien, Turan, Persien, Kurdistan, Armenia, Mesopotamien, Kleinasien, Syrien, Arabien, Egypten, Tripolis, Tunesien, Algerien und Morocco) lebenden binnenconchylien. 5.- Fam. Succinidae, Auriculidae, Limnaeidae, Cyclostomidae \& Hydrocenidae. Hakan (Ohlsson's Buchdruckerei). Berlin. 135 pp.

Westerlund, C. A., 1890. Fauna der in der Paläartischen region (Europa, Kaukasien, Siberien, Turan, Persien, Kurdistan, Armenia, Mesopotamien, Kleinasien, Syrien, Arabien, Egypten, Tripolis, Tunesien, Algerien und Morocco) lebenden binnenconchylien. 7. Malacozoa Acephala. Hakan (Ohlsson's Buchdruckerei). Berlin. 319 pp.

Westerlund, C. A., 1898. Novum specilegium malacologicum. Annuaire du Musée Zoologique de l'Académie Impériale des Sciences de Saint Pétersbourg, 1898: 155-183.

ZHADIN, V. I., 1965 Mollusks of fresh and brackish waters of the U.S.S.R. Keys to the Fauna of the U.S.S.R. Zoological Institute of the Academy of Sciences of the U.S.S.R., 46, xvi +368 pp. 